\title{
Integrating workplace learning, assessment and supervision in health care education
}

Citation for published version (APA):

Embo, M. (2015). Integrating workplace learning, assessment and supervision in health care education. [Doctoral Thesis, Maastricht University]. Maastricht University. https://doi.org/10.26481/dis.20150313me

Document status and date:

Published: 01/01/2015

DOI:

10.26481/dis.20150313me

Document Version:

Publisher's PDF, also known as Version of record

\section{Please check the document version of this publication:}

- A submitted manuscript is the version of the article upon submission and before peer-review. There can be important differences between the submitted version and the official published version of record.

People interested in the research are advised to contact the author for the final version of the publication, or visit the DOI to the publisher's website.

- The final author version and the galley proof are versions of the publication after peer review.

- The final published version features the final layout of the paper including the volume, issue and page numbers.

Link to publication

\footnotetext{
General rights rights.

- You may freely distribute the URL identifying the publication in the public portal. please follow below link for the End User Agreement:

www.umlib.nl/taverne-license

Take down policy

If you believe that this document breaches copyright please contact us at:

repository@maastrichtuniversity.nl

providing details and we will investigate your claim.
}

Copyright and moral rights for the publications made accessible in the public portal are retained by the authors and/or other copyright owners and it is a condition of accessing publications that users recognise and abide by the legal requirements associated with these

- Users may download and print one copy of any publication from the public portal for the purpose of private study or research.

- You may not further distribute the material or use it for any profit-making activity or commercial gain

If the publication is distributed under the terms of Article $25 \mathrm{fa}$ of the Dutch Copyright Act, indicated by the "Taverne" license above, 


\section{Integrating workplace}

learning, assessment

and supervision

in health care education

Mieke Embo 


\section{CONTINUITY AND INTEGRATION}

The picture on the front page is made by a friend and art photographer Hendrik Boxy.

To me, the image represents a reflection of the lifelong journey of learning. Whereas the background symbolises continuity in workplace learning, the kite in the foreground, very subtly, represents integration.

The integration of learning, assessment and supervision into one model is the core of this dissertation.

However, the kite may also refer to the individual student who is about to embark upon a unique journey towards professional competence.

Each reader is free to interpret the image as he or she wishes.

ISBN 9789461594150

Copyright M Embo, Gent 2015

Cover design: Ann Van Haeken

Layout and print: Datawyse / Universitaire Pers Maastricht 


\title{
Integrating workplace learning, assessment and supervision in health care education
}

\author{
Proefschrift
}

ter verkrijging van de graad van doctor aan de Universiteit Maastricht op gezag van de Rector Magnificus, Prof. dr. L.L.G. Soete, volgens het besluit van het College van Decanen in het openbaar te verdedigen op vrijdag 13 maart 2015 om 14.00 uur door

Mieke Embo

geboren op 30 juli 1965, Gent

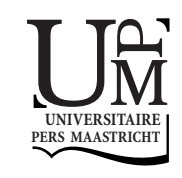


Promotoren

Prof. dr. C.P.M van der Vleuten

Prof. dr. M. Valcke, Universiteit Gent (België)

\section{Co-promotor}

Dr. E.W. Driessen

Beoordelingscommissie

Prof.dr. S. Heeneman (voorzitter)

Prof.dr. A. Derese, Universiteit Gent

Dr. W.N.K.A. van Mook

Prof.dr. F. Scheele, SLAZ Amsterdam

Prof.dr. F.W.J.M. Smeenk 
Live love learn

A wish for all

newborns

in the world 



\section{Contents}

1 Introduction 9

2 Assessment and feedback to facilitate self-directed learning in clinical 25 practice of Midwifery students.

Medical Teacher 2010; 32(7): e263-e269.

3 A framework to facilitate self-directed learning, assessment and supervision in Midwifery practice: a qualitative study of supervisors' perceptions.

Nurse Education in Practice 2014; 14(4): 441-446.

4 Scaffolding reflective learning in clinical practice: a comparison of two types of reflective activities.

Medical Teacher 2014; 36(7): 602-607.

5 Relationship between reflection ability and clinical performance: a cross-sectional and retrospective-longitudinal correlation cohort study in Midwifery.

Midwifery 2015; 31(1): 90-94.

6 Integrating learning, assessment and supervision in a competency framework for clinical workplace education.

Nurse Education Today 2014; doi:10.1016/j.nedt.2014.11.022

7 Discussion

Summary

Samenvatting

Valorisation

Dankwoord 

CHAPTER 1

Introduction

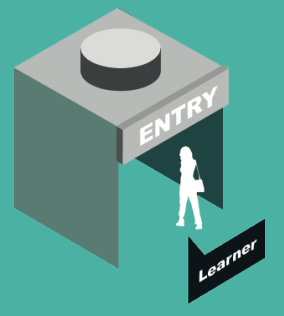





\section{BACKGROUND FOR THE PROJECT}

In the $21^{\text {st }}$ century, clinical workplaces continue to be important learning environments. ${ }^{1-4}$ In order to derive the most benefit from them, learners must take an active part in their own education by setting goals and monitoring their progress towards those goals. ${ }^{5}$ Self-directed learning skills and an ability to learn effectively from experience are critical components of workplace learning. Recent developments in learning sciences suggest that traditional models of education overlook many opportunities to support and enhance learning in clinical settings. ${ }^{6-9}$ There is a mismatch between traditional notions of workplace learning on the one hand, and modern clinical workplaces on the other, the latter building on short-term hospital attachments, short student-teacher relationships, short rotations between disciplines, and on collaborative learning in inter-professional groups rather than from a single senior professional. ${ }^{6,10,11}$ Furthermore, clinical learning environments are characterised by their heterogeneity, a high level of unpredictability, dynamics and by the dual role the learner performs: receiving professional training whilst at the same time providing medical care to real patients. ${ }^{12,13}$ Thus, clinical workplaces can be described as complex and discontinuous for learners and teachers alike. This challenges educators when it comes to conceptualising workplace learning as a continuous developmental learning process within a community of clinical practice. In other words, the challenges of the clinical workplace relate to learning, to teaching and to the assessment processes. ${ }^{3}$ The research programme presented in this doctoral thesis seeks to advance understanding of workplace learning by exploring the potential of integrating learning, assessment and supervision in a continuous developmental process, and the effects of this integration on workplace learning of midwifery students. In this introductory chapter we elucidate the concept of workplace learning by presenting the theories and models for workplace learning, assessment and supervision. We further describe the importance of integrating learning, assessment and supervision in the context of a continuous developmental workplace learning process.

\section{THEORETICAL PERSPECTIVES ON WORKPLACE LEARNING}

The concept of 'workplace learning' encapsulates three terms: 'work', 'place' and 'learning'. All three deserve attention. During its 50-year-old history, the balance between the three concepts has shifted and resulted in new ideas about workplace learning in the $21^{\text {st }}$ century. ${ }^{14}$ 'Work' is defined as 'an enabled purposive effort by an individual to initiate activity or respond to an issue or problem in a range of situations'. ${ }^{14}$ The concept of 'place' relates to transferability and generalisability of learn- 
ers. ${ }^{14}$ It is important to make a distinction between places where one learns in the individual sense, and places where the psychological examination of the learning process is effected. ${ }^{14}$ Barr uses the terms 'work-located' and 'work-related' learning to denote this bifurcation. ${ }^{15}$ The third term in the workplace learning descriptor, 'learning', can be described as an activity that involves change and development in individuals and organisations. ${ }^{4,14}$ Self-directed engagement in learning, is a continuous developmental process that requires learners to take ownership of, and decisions about how, when, where and why they engage. ${ }^{14}$ In this process, learners take the initiative, with the support and collaboration of other stakeholders involved in workplace learning and assessment. ${ }^{16,17}$ Self-direction or self-regulation is featured by the availability of choice and control by the learner. ${ }^{18-20}$ It requires a learner's intrinsic motivation to identify and manage learning needs for the purpose of lifelong improvement. ${ }^{19-21}$

Traditional perspectives on learning are still relevant in the context of state-of-the-art clinical workplace learning models. For example the work of Dewey from the early $20^{\text {th }}$ century is still influential, especially his discussion of 'experience' and 'reflection' in relation to learning. ${ }^{22-24}$ These learning process components have been incorporated in the models for professional and vocational learning by, among others, Knowles, ${ }^{25}$ Kolb, ${ }^{26}$ Schön, ${ }^{27,28}$ and Boud and colleagues. ${ }^{29}$ What these models have in common is that they all focus on individual learners, they stress cognitive aspects of performance, and they emphasise that part of learning occurs relatively independent of context. ${ }^{14,30}$ Though promising, the models present rather basic principles and guidelines; they hardly help to describe and understand the complex nature of the learning process in a workplace learning context.

During the past decades, more robust theories of workplace learning have emerged. Contemporary sociological theories suggest that effective learning in work settings is multi-faceted and draws on previously acquired formal knowledge, contextualises it and reforms it according to situations at hand. ${ }^{31}$ Situated learning can complement experiential learning theory by framing the exploration of experience within a community's norms, values and activities. ${ }^{9}$ Especially socio-cultural theories of workplace learning seem to offer useful frameworks for understanding how to facilitate a learner's continuous development in complex social clinical learning environments. These socio-cultural learning theories claim that learning and learning outcomes emerge through active participation in activities of a community and interaction with the complex and dynamic systems of the work environment. Socio-cultural learning theories therefore consider learning and expertise development to be inextricably linked with features of the context in which learning occurs. 9,14,30 
The following two socio-cultural learning theories in particular adequately reflect current perspectives on teaching and learning in clinical education: 'Communities of Practice theory' and 'Collaborative learning community theory'. 'Community of Practice theory' is highly relevant to contemporary clinical contexts because it envisions learners as members of social groups as opposed to learners as individuals, reflecting the way professionals learn and work. 'Collaborative learning community theory' goes one step further. The basis of collaborative learning is formed by a partnership in which the wisdom, knowledge and customs of the members of a local learning community are acknowledged, accessed and utilised. It requires an environment that fosters a transformative dialogue in which newness occurs. To cultivate this 'newness', the environment moreover should nurture particular educator values and attitudes. For instance, the educator should warrant: (a) a transformative nature of dialogue and collaboration; (b) trust and confidence in each member's expertise and judgement about their daily and future lives; (c) an equal amount of knowledge and experiences that each student contributes, and (d) self-reflection and readiness to have their views examined and questioned. Other key elements of this theory are collaborative relationships and generative conversations that involve dynamic and non-hierarchical two-way exchanges, sharing, criss-crossing and weaving of ideas, thoughts, opinions and feelings through which newness emerges. ${ }^{32}$ When employing these principles, one should seek to achieve educational continuity in the sense that continuous development of learners during workplace learning is guaranteed. ${ }^{33}$ In the present doctoral thesis, we build on these principles by integrating the continuity in the curriculum with continuity in learning, assessment, and supervision. ${ }^{33,34}$

\section{COMPETENCY FRAMEWORKS AND COMPETENCY-BASED EDUCATION}

Competency-based education is the basis of the pedagogical philosophy underlying many state-of-the-art curricula in health care education. In health care higher education, specific competency frameworks have been developed that differ across disciplines and countries. Some well-known frameworks are the CanMEDS 2005, ${ }^{35}$ ACGME 2003, ${ }^{36}$ or GMC 2002, ${ }^{37}$ for medical education in Canada, the USA and the UK respectively; NMC 2012 for nursing and midwifery education in the UK; ${ }^{38}$ and the international ICM 2013 Essential Competencies for Basic Midwifery Practice. ${ }^{39}$

Although the competency concept is not universally defined, most researchers in education adopt an integrated and holistic approach to competency. ${ }^{40-45}$ The integrated approach acknowledges competency as a complex combination of knowledge, attitudes, skills, and personal values. The holistic approach on the other hand, takes into 
account the cultural and social context in which competencies are assessed, and focusses on how personal attributes are used to achieve outcomes in real life scenarios. A competency of a higher order - meta-competency - has been used to describe the general ability to learn and apply competencies effectively in many different aspects of a person's activities. ${ }^{41}$ Epstein and Hundert defined this meta-competency as 'professional competence'. ${ }^{46}$ It refers to the habitual and judicious use of communication, knowledge, technical skills, clinical reasoning, emotions, values and reflection in daily practice. ${ }^{46}$ A thorough understanding of these higher order competencies might facilitate the learners' engagement in their professional competency development. ${ }^{40,43}$

In the move to competency-based education, much of the attention has shifted to the development of competencies and related learning outcomes - the competencies expected of a learner at the end of a particular phase in education or training. Therefore, competency-based education is also called outcome-based education. ${ }^{40,47,48}$ An underlying assumption is that a clear set of competencies can help students to selfdirect their own learning. ${ }^{49}$ These competencies are also important to supervisors when planning for and monitoring students' progress towards the exit outcomes. Student progress can be expressed in terms of learning outcome levels, and competency standards can be used to detail the progress towards meeting the learning outcomes. ${ }^{40,47-49}$ On the other hand, as different authors warn, inappropriate application or implementation of competency-based education can result in miscommunication, ${ }^{42}$ demotivation, a focus on suboptimal standards, an increased administrative burden, and a reduction in the educational content of clinical training programmes. ${ }^{40}$

In this doctoral research programme, we adopt the professional competency framework to guide continuous learning and the assessment of Midwifery competencies. This competency framework will also be used to help students and teachers create a continuous learning process across individual workplaces. ${ }^{33,34}$

\section{REFLECTION AND THE REFLECTIVE LEARNING CONTINUUM}

The concepts of reflection and reflective practice have been widely acknowledged as crucial for developing self-directed and lifelong learning. ${ }^{50,51}$ Reflection can be defined as a metacognitive process that occurs before, during and after situations with the purpose of developing greater understanding of both the self and the situation so that future encounters with the situation are informed from previous encounters. ${ }^{52}$ Although reflection is essential for learning from experiences, it does not come naturally to most students. ${ }^{51,53}$ Aronson therefore already suggested that formal education should 
seek to enhance the students' reflective learning competencies. ${ }^{54} \mathrm{~A}$ variety of specific activities aimed at stimulating the learners' reflections on their performance are perceived to influence their self-perceptions and efforts to improve performance. These activities include: compiling learning portfolios, ${ }^{55,56}$ designing personal learning plans, ${ }^{57}$ formulating outcome objectives, ${ }^{58}$ applying multi-source feedback, ${ }^{59,60}$ auditing one's patient records with feedback and gap analysis, ${ }^{61}$ and using questionnaire-based selfassessments of clinical performance. ${ }^{62,63}$ Although these methods help most students to make sense of their experiences, the benefits of reflection may not be fully reaped without personal support. ${ }^{59,62-64}$ A supportive mentor who provides feedback on students' reflection assignments was proven to be a pre-requisite for enhancing students' reflective competencies. ${ }^{49,64}$ It follows that supervisors need to be familiar with the different stages of reflection, evolving from descriptive writing to critical reflection, where students explore and critique assumptions and also show emotional insight. $49,50,65-67$

The term 'reflection' is often used interchangeably with 'self-assessment'. Selfassessment is a personally-generated judgement of performance effectiveness. ${ }^{68}$ Although self-assessment is regarded as an important component of workplace learning, many examples in literature raise doubts about the capacity of individuals to effectively self-assess their personal or professional strengths and/or weaknesses. ${ }^{68-71}$ Recent thinking on self-assessment suggests that we should move toward selfassessment as an externally-informed activity, enabling access to and integration of data from external sources. ${ }^{68-75}$ Informed self-assessment is a dynamic, complex process. ${ }^{63}$ Eva and Regehr emphasise the prominent place of feedback in this emerging model of informed self-assessment. They describe self-assessment as a deliberately and routinely informed process through feedback from trusted external sources. ${ }^{68}$

Therefore, the challenge in designing a workplace learning curriculum is to create reflective learning activities that facilitate continuous externally-informed selfassessment. In the curriculum used as the context of our studies - the Ghent Midwifery school - these reflective learning activities are learned, assessed and guided in an integrated manner.

\section{INTEGRATING FORMATIVE AND SUMMATIVE ASSESSMENT}

In medical education literature, feedback is stated as fundamental for effective clinical teaching and supervision of learners. ${ }^{76}$ Without feedback, good practice is not reinforced, poor performance is not corrected, and the path to improvement is not identi- 
fied. ${ }^{76}$ These consequences of either absent or inadequate feedback make clear that there is a close relationship between assessment, feedback, and continued workplace learning. ${ }^{77,78}$ For instance, the importance of supervisors' feedback on continuous workplace learning and assessment can be found in current definitions of feedback. During the past decades, the feedback definitions moved beyond the concept of feedback as mere information, toward a notion of feedback as information with an explicit purpose of improving performance. ${ }^{79-81}$ A definition that is relevant to clinical education is suggested by van de Ridder and colleagues as follows: 'specific information about the comparison between a trainee's observed performance and a standard, given with the intent to improve the trainee's performance' ${ }^{80}$ There is a large body of research on feedback, addressing its effectiveness. ${ }^{76,79,81-84}$ Despite different contexts, these studies provide ample warning that we cannot approach the use of feedback in any educational setting with the presumption that it will be effective in promoting learning and performance improvement. These studies do however suggest that feedback is 'sometimes' effective for learning. ${ }^{79}$ Although it is well known that the efficacy of feedback depends on the provision of feedback by trusted supervisors, students do not always receive high-quality supervision and feedback. ${ }^{76,81,84,85}$ Often, feedback is not based on the actual observation of performance. ${ }^{76,77}$ The provision of effective feedback does not necessarily result in a positive change in performance because feedback effectiveness also depends on feedback acceptance. Acceptance is increased if the relevance of the feedback can be demonstrated, that is, by goal setting. ${ }^{81,86}$ Competency frameworks can be used for goal setting, because they give guidance to both the feedback provider and the feedback receiver.

Feedback and assessment are closely related educational activities. ${ }^{76}$ Workplace learning has evolved from 'assessment of learning' to 'assessment for learning', with continuous feedback and the use of programmatic assessment models becoming more and more important. ${ }^{45,87-90}$ The assessment programme should be aligned with the general competency framework of the curriculum and also be tailored to the different learning contexts in the workplace. ${ }^{88}$ Programmatic assessment has led to a broader perspective on the way information from various sources is collected and collated, and on the role of human judgement. ${ }^{45,90,91}$ Assessing learners in a competency-based education context requires a radically different holistic method of assessment. ${ }^{89,91-93}$ Assessment should combine formative and summative functions to inform and guide student learning. ${ }^{89,93}$ The focus of current workplace assessment is on on-going evaluation and the provision of feedback in order to improve performance and competency development in the clinical workplace. ${ }^{30,77}$ It is clear that the emphasis is now on formative assessment. At the same time, however, patients and the society have recently been placing strong emphasis on summative assessment, because they need 
the reassurance that graduates meet the minimum standards and are made 'fit for practice'. ${ }^{78}$ For this reason, the formative and summative function of assessment should - whenever possible - be combined. ${ }^{93}$ Integrating formative and summative assessment in support of continuous development in the workplace is therefore an important topic of the research presented in this doctoral thesis.

\section{SUPERVISION AND CONTINUOUS DEVELOPMENT}

Clinical supervision has become widely recognised as an essential component of workplace learning. ${ }^{94,95}$ However, confusion exists in workplace literature about the most effective models of clinical supervision. Though different definitions of supervision are available, it is generally agreed that supervision should both ensure patient safety and promote learner development. ${ }^{94,96}$ Despite the importance of clinical supervision for continuous development, supervising a continuous developmental process in clinical workplaces can be hindered by a lack of practitioners' awareness/mastery of effective supervisory strategies and a lack of continuity in student-supervisor relationships. ${ }^{33,94,96}$ Guiding a continuous learning and assessment process requires individual supervisors in the workplace to be supported by the clinical team. This suggests the need for a cultural change. Effective communication and collaboration with clinical team members ensures they are knowledgeable about the learner's needs, promote learning opportunities, and provide effective feedback. ${ }^{81,94,97}$ Establishing such productive learning communities featuring trustful relationships and shared goals - is necessary in order to encourage supervision, to promote effective feedback, to enhance clinical performance, and to guide and assess the learner's continuous competency development. Continuity in supervision requires careful attention to the entire workplace-based curriculum, the competency framework, and the integration of learning, assessment and supervision processes in the workplace. ${ }^{33}$ Deriving the maximum of benefits from this integration and continuity is a challenge for the future of workplace learning. ${ }^{33}$

Whereas the previous sections have drawn on the theoretical and conceptual basis, the next paragraphs will describe the main argument and the research questions of the research programme presented in this thesis.

\section{MAIN ARGUMENT AND RESEARCH QUESTIONS}

Our overview of the literature of competency-based workplace learning, assessment and supervision in health care education indicates that there is a significant body of 
literature addressing the complex interplay of learning and assessment to guide performance improvement and self-directed learning in clinical practice. There is, however, a lack of evidence-based practices and insight into how to integrate learning, assessment and supervision in the workplace, and how to create a continuous developmental process for the learner within the complex and discontinuous workplaces. There is a need for alternative, yet feasible, workplace learning models, that build on competencies, and that integrate learning, assessment and supervision. Continuous development requires a programmatic approach in order to support continuous competency improvement across clinical workplaces. The research reported in this thesis aims to describe the development and evaluation of a workplace learning model that integrates learning and assessment and supports a continuous self-directed developmental process across individual workplaces.

With this rationale in mind, the following research questions will be discussed:

1. How can learning, assessment and supervision in the workplace be integrated with the aim to support a continuous developmental process?

2. What are the implications for the design of workplace learning when integrating learning, assessment and supervision into the workplace context?

3. What is the effect of integrating learning, assessment and supervision into the workplace on summative assessment?

We designed and implemented five consecutive studies to answer these questions.

Chapter 2 describes the development and evaluation of an integrated learning and assessment instrument, an instrument developed to support learning with reflection and feedback. This Midwifery Assessment and Feedback Instrument (MAFI) was adopted as the initial framework for the research in this thesis. The study addresses the three research questions. We were interested in students' perceptions of how the MAFI affects their learning, assessment and supervision. The study was expected to help understand the effect of continuous and longitudinal feedback, the effect of integrating feedback and assessment, and the role of supervision on students' self-directed learning. A qualitative study was set up, building on four focus group discussions involving second and last year Midwifery students.

Results from the study reported in chapter 2 led to the design of a qualitative study described in chapter 3 for the purpose of exploring supervisor perceptions about, and the use of, the MAFI instrument. In addition, we studied its impact on facilitating student learning processes. We conducted a qualitative study and interviewed fifteen clinical supervisors from eight different hospitals. 
The results of the studies reported in chapters 2 and 3 make it clear that students and supervisors should share the responsibility for the self-reflective learning process. The results of these studies point to the need for further in-depth exploration of reflection as an essential component of learning from experiences and self-directed competency development. The purpose of chapter 4 was to compare students' perceptions of the learning value and the perceived effect of two reflective writing activities: immediate reflection on performances (tasks during patient care) and delayed reflection on competency development (learning).

Chapter 5 subsequently deals with the relation between reflection and performance. A quantitative study investigates the relationship between reflection ability and clinical competency. For this purpose, a cross-sectional and a retrospective-longitudinal cohort study was set up, examining the assessment scores from first-, second- and third- year students. We analysed summative assessment scores of written reflections and clinical competency scores at the end of the internships.

In chapter 6, we focus on the need for a feasible and evidence-based competency framework that fits in with workplace reality. Chapters 2 to 5 present the empirical evidence for designing an Integrated Learning Assessment and Supervision Competency Framework for clinical workplace learning in health care education. This clinical workplace learning model respects - a need that we expressed in the foregoing - the holistic and integrated philosophy of competency-based education.

Finally, chapter 7, Discussion, we summarise the findings of the different studies. We moreover outline the implications of our conclusions for health care education and the opportunities for future research in workplace learning, assessment and supervision. 


\section{REFERENCES}

1. Billett S. Towards a workplace pedagogy: Guidance, participation, and engagement. Adult Educ Quart 2002;53(1):27-43.

2. Cooke M, Irby D, O'Brien B. Educating physicians: A call for reform of medical school and residency. San Francisco: Jossey Bass 2010.

3. Lester S, Costley C. Work-based learning at higher education level: value, practice and critique. Stud High Educ 2010;35(5):561-575.

4. Weber S. Sense of Workplace Learning. Vocations and Learning 2013;6(1):1-9.

5. Spencer J. Learning and teaching in the clinical environment. In: Cantillon P, Wood D (Eds.). ABC of learning and teaching in medicine. Oxford: Wiley-Blackwell 2010:25-28.

6. Bleakley A. Broadening conceptions of learning in medical education: the message from team working. Med Educ 2006;40(2):150-157.

7. Lave J, Wenger E. Situated learning. Legitimate peripheral participation. Cambridge: Cambridge University Press 1991.

8. Wenger E. Communities of practice: Learning, meaning and identity. Cambridge: Cambridge University Press 1998.

9. Mann KV. Theoretical perspectives in medical education: past experience and future possibilities. Med Educ 2011;45(1):60-68.

10. Swanwick T. Informal learning in postgraduate medical education: from cognitivism to 'culturism'. Med Educ 2005;39(8):859-865.

11. Hay A, Smithson S, Mann KV, Dornan T. Medical students' reactions to an experience-based learning model of clinical education. Perspect Med Educ 2013;1(2):58-71.

12. Dornan T. Experience Based Learning. Learning clinical medicine in workplaces. Maastricht: Universitaire Pers 2006.

13. Slowther A, Spicer J. Ethical and legal issues. In: Carter Y, Jackson N. (Eds.). Medical Education and Training: From theory to delivery. Oxford: University Press 2008:339-350.

14. Hager P. Theories of workplace learning. In: Malloch M, Cairns L, Evans K, O'Connor B (Eds.). Handbook of Workplace Learning. Los Angeles: CA Sage Publications 2011:17-32.

15. Barr H. Interprofessional issues and work based learning. In: Burton J, Jackson N (Eds.). Work based learning in primary care. Oxford: Radcliffe Medical Press 2003:73-85.

16. Knowles M. Self-Directed Learning: A Guide for Learners and Teachers. Chicago: Follet 1975.

17. Hammond M, Collins R. Self-Directed Learning: Critical practice. New York: Nichols/GP Publishing 1991.

18. Zimmerman BJ, Bonner S, Kovach R. Developing self-regulated learners: Beyond achievement to selfefficacy. Washington, DC: American Psychological Association 1996.

19. Zimmerman BJ. Attaining self-regulation: A social cognitive perspective. In: Boekaerts M, Pintrich PR, Zeidner M (Eds.). Handbook of Self-regulation. San Diego, CA: Academic Press 2000.

20. White CB. Smoothing Out Transitions: How Pedagogy Influences Medical Students' Achievement of Selfregulated Learning Goals. Adv Health Sci Educ 2007;12:279-297.

21. Dunlap JC, Grabinger S. Preparing Students for Lifelong Learning: A Review of Instructional Features and Teaching Methodologies. Performance Improvement Quarterly 2003;16(2):6-25.

22. Dewey J. Democracy and education: An introduction to the philosophy of education. New York: Free Press 1916.

23. Dewey J. How we think: A restatement of the relation of reflective thinking to the educative process. Boston DC: Heath and company 1933.

24. Dewey J. Experience and education. New York: Collier 1938.

25. Knowles M. The modern practice of adult education: From pedagogy to andragogy. Cambridge: Cambridge Book Company 1970. 
26. Kolb DA. Experiential learning. New York: Prentice Hall 1984.

27. Schön DA. Educating the Reflective Practitioner. San Francisco: Jossey-Bass 1987.

28. Schön DA. The reflective practitioner: How professionals think in action. New York: Basic Books 1983.

29. Boud D, Costley C, Walker D. Using experience for learning. Buckingham: Open University Press 1993.

30. Govaerts $\mathrm{M}$, van der Vleuten CPM. Validity in work-based assessment: expanding our horizons. Med Educ 2013;47(12):1164-1174.

31. Spouse J. Work-based learning in health care environments. Nurse Educ Pract 2001;1(1):12-18.

32. Irby BJ, Brown G, Lara-Alecio R, Jackson S. The Handbook of Educational Theories. Charlotte, North Carolina: Information Age Publishing 2013.

33. Hirsh DA, Ogur B, Thibault GE, Cox M. "Continuity" as an Organizing Principle for Clinical Education Reform. N Engl J Med 2007;356(8):858-866.

34. Ellaway R, Graves L, Berry S, Myhre D, Cummings B, Konkin J. Twelve tips for designing and running longitudinal integrated clerkships. Med Teach 2013:35;989-995.

35. Royal College of Physicians and Surgeons of Canada. CanMEDS 2005 Framework. Available from: $<$ http://www.royalcollege.cas.

36. ACGME. Accreditation Council for Graduate Medical Education. Competencies and Outcome Assessment. Available from: <http://www.acgme.org/outcome>.

37. GMC. General Medical Council. Tomorrow's Doctors. London: General Medical Council 2009. Available from: <http://www.gmc-uk.org/education/undergraduate/tomorrows_doctors_2009.asp>.

38. NMC. Nursing and Midwifery Council. Standards 2012. Available from: <http://www.nmcuk.org/Publications/Standards>.

39. ICM. International Confederation of Midwives. Essential Competencies for Basic Midwifery Practice 2013. Available from: <http://www.internationalmidwives.org/what-we-do/global-standards-competencies-and-tools.html>.

40. Leung W. Competency based medical training: review. BMJ 2002;325(7366):693-696.

41. Van Merriënboer J, Van der Klink M, Hendriks M. Competenties: van complicaties tot compromise [Competencies: from complications to compromise]. Den Haag, the Netherlands: Onderwijsraad 2002.

42. Stoof A, Martens R, Van Merriënboer R, Bastiaens T. The Boundary Approach of Competence: A Constructivist Aid for Understanding and Using the Concept of Competence. Human Resource Development Review 2002;1(3):345-365.

43. Lane IF. Professional competencies in health sciences education: from multiple intelligences to the clinic floor. Adv Health Sci Educ 2010;15(1):129-146.

44. Yanhua C, Watson R. A review of clinical competence assessment in nursing. Nurse Educ Today 2011;31(8):832-836.

45. Schuwirth LWT, van der Vleuten CPM. Programmatic assessment: From assessment of learning to assessment for learning. Med Teach 2011;33(6):478-485.

46. Epstein RM, Hundert EM. Defining and assessing professional competence. JAMA 2002;287(2):226-235.

47. Harden RM. Learning Outcomes as a tool to assess progression. Med Teach 2007;29(7):678-682.

48. Harden RM. Outcome-Based Education: the future is today. Med Teach 2007;29(7):625-629.

49. Dekker H, Schönrock-Adema J, Snoek JW, van der Molen T, Cohen-Schotanus J. Which characteristics of written feedback are perceived as stimulating students' reflective competence: an exploratory study. BMC Med Educ 2013;13:94.

50. Mann K, Gordon J, MacLeod A. Reflection and reflective practice in health professions education: A systematic review. Adv Health Sci Educ 2009;14(4):595-621.

51. Sandars J. The use of reflection in medical education: AMEE Guide No.44. Med Teach 2009;31(8):685695.

52. Ertmer PA, Newby TJ. The expert learner: Strategic, self-regulated, and reflective. Instructional Science $1996 ; 24(1): 1-24$. 
53. Driessen E, Van Tartwijk J, Donna T. The self-critical doctor: helping students become more reflective. BMJ 2008;336:827.

54. Aronson L. Twelve tips for teaching reflection at all levels of medical education. Med Teach 2011;33(3):200-205.

55. Driessen E, Van Tartwijk J, van der Vleuten C, Wass V. Portfolios in medical education: Why do they meet with mixed success? A systematic review. Med Educ 2007;41(12):1224-1233.

56. Buckley S, Coleman J, Davison I. The educational effects of portfolios on undergraduate learning: A Best Evidence Medical Education (BEME) systematic review. BEME Guide no.11. Med Teach 2009;31(4):282298.

57. Goldman S. The educational kanban: promoting effective self-directed adult learning in medical education. Acad Med 2009;84(7):927-34.

58. Ten Cate O. Entrustability of professional activities and competency-based training. Med Educ 2005;39(12):1176-1177.

59. Lockyer JM, Violato C. An examination of the appropriateness of using a common peer assessment instrument to assess physician skills across specialities. Acad Med 2004;79(10 Suppl):s5-8.

60. Sargeant J, Mann K, Sinclair D, van der Vleuten C, Metsemakers J. Understanding the influence of emotions and reflection upon multi-source feedback acceptance and use. Adv Health Sci Educ 2008;13(3):275-288.

61. Duffy FD, Lynn LA, Didura H, Hess B, Caverzagie K, Grosso L, Lipner R, Holmboe E. Self-assessment of practice performance: Development of the ABIM Practice Improvement Module (PIM). J Contin Educ Health Prof 2008;28(1):38-46.

62. Musolino GM. Fostering reflective practice: self-assessment abilities of physical therapy students and entry-level graduates. J Allied Health 2006;35(1):30-42.

63. Sargeant JM, Eva KW, Armson H, Chesluk B, Dornan T, Holmboe E, Lockyer JM, Loney E, Mann KV, van der Vleuten CPM. Features of assessment learners use to make informed self-assessments of clinical performance. Med Educ 2011;45(6):636-647.

64. Montagna L, Benaglio C, Zannini L. Reflective writing in nursing education: background, experiences and methods. Assist Inferm Ric 2010;29(3):140-152.

65. Wald HS, Borkan JM, Taylor JS, Anthony D, Reis SP. Fostering and Evaluating Reflective Capacity in Medical Education: Developing the REFLECT Rubric for Assessing Reflective Writing. Acad Med 2012;87(1):41-50.

66. Hatton N, Smith D. Reflection in teacher education: towards definition and implementation. Teach Educ 1995;11(1):33-49.

67. Epp S. The value of reflective journaling in undergraduate nursing education: A literature review. Int J Nurs Stud 2008;45(9):1379-1388.

68. Eva KW, Regehr G. Self-assessment in the health professions: A reformulation and research agenda. Acad Med 2005;80(10 Suppl):s46-54.

69. Eva KW, Regehr G. Exploring the divergence between self-assessment and self-monitoring. Adv Health Sci Educ 2011;16(3):311-329.

70. Regehr G, Eva K. Self-assessment, Self-direction, and the Self-regulating Professional. Clin Orthop Relat Res J 2006;449:34-38.

71. Eva KW, Regehr G. I'll never play professional football and other fallacies of self-assessment. J Contin Educ Health Prof 2008;28(1):14-19.

72. Boud D. Enhancing Learning through Self-Assessment. London: Kogan Page 1995:11-35.

73. Epstein R, Siegel D, Silberman J. Self-monitoring in clinical practice: A challenge for medical educators. J Contin Educ Health Prof 2008;28(1):5-13.

74. Sargeant J. Toward a common understanding of self-assessment. J Contin Educ Health Prof 2008;28(1):1-14. 
75. Sargeant J, Armson H, Chesluk B, Dornan T, Eva K, Holmboe E, Lockyer J, Loney E, Mann K, van der Vleuten $C$. The processes and dimensions of informed self-assessment: A conceptual model. Acad Med 2010;85(7):1212-1220.

76. Cantillon P, Sargeant J. Giving feedback in clinical settings. BMJ 2008;337:a1961.

77. Norcini J, Burch V. Workplace-based assessment as an educational tool: AMEE Guide No. 31. Med Teach 2007;29(9-10):855-871.

78. Norcini J, Anderson B, Bollela V, Burch V, Costa M, Duvivier R, Galbraith R, Hays R, Kent A, Perrott V, Roberts T. Criteria for good assessment: Consensus statement and recommendations from the Ottawa 2010 Conference. Med Teach 2011;33(3):206-214.

79. Watling CJ. Cognition, culture, and credibility. Deconstructing Feedback in Medical Education. Maastricht: Maastricht University 2013.

80. van de Ridder JM, Stokking KM, Mcgaghie WC, Ten Cate O. What is feedback in clinical education? Med Educ 2008;42(2):189-197.

81. Archer JC. State of the science in health professional education: Effective feedback. Med Educ 2010;44(1):101-108.

82. Kluger AN, DeNisi A. The effects of feedback interventions on performance: A historical review, a metaanalysis, and a preliminary feedback intervention theory. Psychol Bull 1996;119(2):254-284.

83. Hattie J, Timperley H. The power of feedback. Rev Educ Res 2007;77(1):81-112.

84. Saedan H, Salleh S, Balakrishnan A, Imray C, Saedon M. The role of feedback in improving the effectiveness of workplace based assessments: A systematic review. BMC Medical Education 2012;12:25.

85. Perera J, Lee N, Win K, Perera J, Wijesuriya L. Formative feedback to students: The mismatch between faculty perceptions and student expectations. Med Teach 2008; 30(4):395-399.

86. Chang A, Chou CL, Teherani A, Hauer K. Clinical skills-related learning goals of senior medical students after performance feedback. Med Educ 2011;45(9):878-885.

87. van der Vleuten CPM, Schuwirth LWT. Assessing professional competence: from methods to programmes. Med Educ 2005;39(3):309-317.

88. Driessen EW, Van Tartwijk J, Govaerts M, Teunissen P, van der Vleuten CPM. The use of programmatic assessment in the clinical workplace: A Maastricht case report. Med Teach 2012;34(3):226-231.

89. Dannefer EF. Beyond assessment of learning toward assessment for learning: Educating tomorrow's physicians. Med Teach 2013;35(7):560-563.

90. van der Vleuten CPM, Schuwirth LWT, Driessen EW, Dijkstra J, Tigelaar D, Baartman LKJ, Van Tartwijk J. A model for programmatic assessment fit for purpose. Med Teach 2012;34(3):205-214.

91. Hodges B. Assessment in the post-psychometric era: Learning to love the subjective and collective. Med Teach 2013;35(7):564-568.

92. Zibrowski EM, Sing SI, Goldszmidt MA, Watling CJ, Kenyon CF, Schulz V, Maddocks HL, Lingard L. The sum of the parts detracts from the intended whole: competencies and in-training assessments. Med Educ 2009;43(8):741-748.

93. Schuwirth L, Ash J. Assessing tomorrow's learners: In competency-based education only a radically different holistic method of assessment will work. Six things we could forget. Med Teach 2013;35(7):555-559.

94. Martin P, Copley J, Tyack Z. Twelve tips for effective clinical supervision based on a narrative literature review and expert opinion. Med Teach 2014;36(3):201-207.

95. Dornan T. Workplace learning. Perspect Med Educ 2012;1(1):15-23.

96. Kilminster S, Cottrell D, Grant J, Jolly B. AMEE Guide No.27. Effective educational and clinical supervision. Med Teach 2007;29(1):2-19.

97. Henderson A, Eaton E. Assisting nurses to facilitate student and new graduate learning in practice settings: What 'support' do nurses at the bedside need? Nurse Educ Pract 2013;13(3):197-201. 



\section{CHAPTER 2}

\section{Assessment and feedback to facilitate self-directed learning in clinical practice of midwifery students}

Mieke Embo

Erik W. Driessen

Martin Valcke

Cees P.M. van der Vleuten

Medical Teacher 2010; 32(7):e263-e269

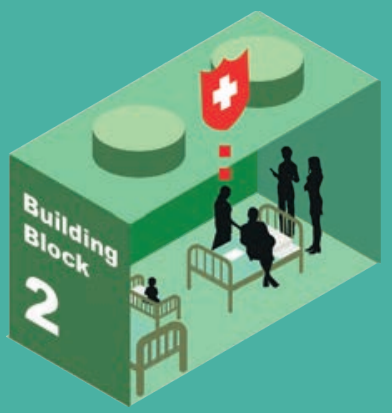




\section{ABSTRACT}

Background: Clinical workplaces are hectic and dynamic learning environments, which require students to take charge of their own learning. Competency development during clinical internships is a continuous process that is facilitated and guided by feedback. Limited feedback, lack of supervision and problematic assessment of clinical competencies make the development of learning instruments to support self-directed learning necessary.

Aims: To explore students' perceptions about a newly introduced integrated feedback and assessment instrument to support self-directed learning in clinical practice. Students collected feedback from clinical supervisors and wrote it on a competencybased format. This feedback was used for self-assessment, which had to be completed before the final assessment.

Methods: Four focus group discussions were conducted with second and last year Midwifery students. Focus groups were audiotaped, transcribed verbatim and analysed in a thematic way using ATLAS.ti for qualitative data analysis.

Results: The analysis of the transcripts suggested that integrating feedback and assessment supports participation and active involvement in learning by collecting, writing, asking, reading and rereading feedback. Under the condition of training and dedicated time, these learning activities stimulate reflection and facilitate the development of strategies for improvement. The integration supports self-assessment and formative assessment but the value for summative assessment is contested. The quality of feedback and empowerment by motivated supervisors are essential to maximise the learning effects.

Conclusions: The Integrated Midwifery Assessment and Feedback Instrument is a valuable tool for supporting formative learning and assessment in clinical practice, but its effect on students' self-directed learning depends on the feedback and support from supervisors. 


\section{INTRODUCTION}

Clinical internships are an essential phase of health professions education during which students develop their competencies in authentic clinical environments. ${ }^{1,2}$ According to modern theories of workplace learning, competency development is a continuous process that is facilitated and guided by feedback., This article describes a learning instrument designed to support students in taking charge of their own learning in the workplace.

The clinical workplace is a hectic and dynamic learning environment, characterized by high workload and conflicting demands of service and training. ${ }^{5-7}$ This reality requires students to develop new competencies including self-directed learning techniques. ${ }^{8}$

Hammond and Collins (1991) describe self-directed learning as 'a process in which learners take the initiative, with the support and collaboration of others. For increasing self- and social awareness; critically analysing and reflecting on their situations; diagnosing their learning needs with specific reference to competencies they have helped identify; formulating socially and personally relevant learning goals; identifying human and material resources for learning, choosing and implementing appropriate learning strategies; and reflecting on and evaluating their learning' ${ }^{9}$

Although, support and collaboration are prerequisites for effective workplace learning, many studies have reported that supervision can be problematic. Frequently mentioned areas of difficulty are the continuity and frequency of supervision, ${ }^{10,11}$ and the provision of feedback and support of self-directed learning. Students see direct observation and constructive feedback as key features of effective clinical learning. ${ }^{12}$ Feedback can facilitate reflection and self-assessment ${ }^{6}$ but, unfortunately, students do not always receive adequate feedback. ${ }^{13}$ Teachers may either neglect to give feedback altogether or the feedback fails to make trainees aware of their strengths and weaknesses in a manner that is conducive to learning. As a result, students are unable to evaluate whether they are achieving their learning goals, developing new goals or making plans to pursue those goals. ${ }^{14}$ Moreover, inadequate feedback does not tell students where they are relative to where they ought to be and where they should go.

Written feedback can be read, reread, archived and exchanged, and thus be a source of information to support self-reflection and authentic assessment. Although research has shown that assessment is a powerful driving force for learning, ${ }^{15,16}$ assessment of clinical competencies remains problematic. Many assessment methods cover only a limited range of competencies and often competencies are not assessed in the context 
in which they are learned. ${ }^{17}$ Next to this, assessment criteria are often ill defined, and there is a lack of standardized methods for focussed assessment, and not enough opportunity for reflection, specific feedback and regular monitoring. ${ }^{18}$

In order to address some of the above-mentioned problems, we developed an instrument that integrates feedback and assessment and is aimed at supporting self-directed learning in the clinical workplace. We conducted a qualitative focus group study to explore students' perceptions of the instrument.

Our main research questions were:

1. What is the effect of continuous and longitudinal written feedback on students' self-directed learning in clinical practice?

2. What is the effect of the integration of feedback and assessment in self-directed learning in clinical practice?

3. What is the role of supervision in self-directed learning based on the integration of feedback and assessment?

\section{METHODS}

\section{Context}

This study was carried out at the Midwifery Department of University College Arteveldehogeschool Ghent, Belgium. The three-year programme in Midwifery that is offered by the school consists of a modular, competency-based curriculum based on a framework of 24 medical and generic competencies, related to six professional roles. In order to support the development of students' competencies, the Midwifery department has integrated into the curriculum a programme aimed at enhancing self-directed learning skills. From the first week of this programme, students receive information about the different parts of the programme: the acquisition and assessment of the competencies, the giving and receiving of feedback on the competencies and how to reflect on the competencies.

The Midwifery students have internships in different settings as the maternity ward, delivery ward, gynaecology, neonatology and first-line perinatal care. During the internships, students are guided and supported by a clinical supervisor in the workplace and a teacher from the Midwifery department. Teachers are all midwives with clinical experience. The teacher pays a weekly visit to students in the workplace. Both the clinical supervisor and the teacher take up the educational (supervision of the learning 
process) and the clinical role (provision of patient care with the student). Normally, teachers are more focussed on the overall learning process and clinical supervisors emphasise the observation during patient care.

As students received limited feedback, we started in 2006 with the development of the Midwifery Assessment and Feedback Instrument (MAFI) in order to support the learning and assessment of the competencies based on principles of self-directed learning. According to the definition of Hammond and Collins of self-directed learning, students were made responsible for their own learning. They had to take the initiative to ask for feedback and to reflect on competencies. By comparing the written feedback with learning outcomes, they were stimulated to diagnose their learning needs and to evaluate their learning (figure 1).

In MAFI, the 24 competencies and the 6 roles of the Midwifery programme are presented within a framework. In relation to each internship, the relevant competencies in this framework are emphasised. MAFI is a paper and pencil method presenting a format for the feedback unit and the assessment unit. In the feedback unit, there is space for written feedback and written reflections about the selected competencies. Oral feedback can be written by the student, the clinical supervisor, the teacher and any staff member who observes and works with this particular student. It is the students' responsibility to ensure that sufficient feedback on their progress in all the competencies has been collected at the end of the internship period. Written feedback from students is authenticated by the supervisor by his/her signature. The assessment unit contains a checklist of the selected competencies that students must master during the internship. Each competency results in a specification of a set of learning outcomes for the internship. In the checklist, different levels in competency mastery are reflected with a colour code that are next applied in relation to each curriculum year the internship has been set up (green: year 1, red: year 2, blue: year 3). This helps students to indicate whether the learning outcomes for that specific year have been accomplished (Pass) or unaccomplished (Fail). In order to help students make this judgement, the learning outcomes are defined and expressed in concrete terms. The checklist is used by students for self-monitoring and self-assessment. At an assessment meeting halfway the internship, students and their clinical supervisor and teacher compare the information in the feedback unit with the information in the assessment unit. This assessment is formative, and aimed at improving the student's performance. Although, it is not always possible to realize, a final assessment meeting at the end of the internship with the student, the clinical supervisor and the teacher is recommended to arrive at a pass/fail decision. At the end, the student's performance is graded by a school committee, which judges the student's overall internship performance. Students were in- 
formed about the concept and the use of MAFI, and they were trained in writing feedback.

\begin{tabular}{|c|c|c|c|c|c|c|c|c|c|c|c|}
\hline \multicolumn{2}{|c|}{$\begin{array}{l}\text { FRAMEWORK PROGRAMME } \\
\text { ROLES and COMPETENCIES }\end{array}$} & \multirow{2}{*}{\multicolumn{3}{|c|}{ WRITTEN FEEDBACK UNIT }} & \multirow{2}{*}{\multicolumn{7}{|c|}{\begin{tabular}{|l|} 
ASSESSMENT UNIT \\
Checklist with LEARNING OUTCOMES (LO) \\
Pass or Fail \\
For the different LEVELS (YEARS)
\end{tabular}}} \\
\hline ROLE & COMPETENCIES & & & & & & & & & & \\
\hline \multirow{7}{*}{ 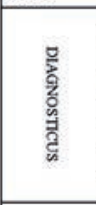 } & $\mathrm{cl}$ & \multicolumn{3}{|c|}{ COMPETENCY 3} & \multicolumn{7}{|l|}{ COMPETENCY 3} \\
\hline & $\mathrm{C2}$ & \multirow{5}{*}{\begin{tabular}{|l|} 
DATE \\
DMSY \\
\end{tabular}} & \multirow{2}{*}{\begin{tabular}{|l|} 
FEEDBACK \\
Feedback on performances \\
\end{tabular}} & \multirow{4}{*}{\begin{tabular}{|l|} 
NAME \\
Student \\
Mentor \\
Teanther \\
Doutor \\
\end{tabular}} & & \multicolumn{2}{|c|}{ YEAR 1} & \multicolumn{2}{|c|}{ YEAR 2} & \multicolumn{2}{|c|}{ YEAR 3} \\
\hline & $\mathrm{C3}$ & & & & & PASS & FAll & PASS & FAll & PASS & FAll. \\
\hline & $\frac{\mathrm{CA}}{\mathrm{cs}}$ & & & & LO1 & & & & & & \\
\hline & cs & & & & $\mathrm{LO2}$ & & & & & & \\
\hline & \begin{tabular}{|l|}
$\mathrm{C} 6$ \\
$\mathrm{C} 7$
\end{tabular} & & & & 103 & & & & & & \\
\hline & \begin{tabular}{|l|}
$\mathrm{C7}$ \\
$\mathrm{C} 8$
\end{tabular} & \multirow{2}{*}{\multicolumn{3}{|c|}{ The same system is used for all the competencies }} & \multirow{2}{*}{\multicolumn{7}{|c|}{ The same system is used for all the competencies }} \\
\hline \multirow{8}{*}{ 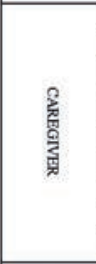 } & \begin{tabular}{|c|}
$c 8$ \\
$c 9$
\end{tabular} & & & & & & & & & & \\
\hline & c9 & \multirow{3}{*}{\multicolumn{3}{|c|}{ Example competency 18}} & & & & & & & \\
\hline & $\mathrm{C10}$ & & & & first second third year s & tudent & & & & & \\
\hline & C11 & & & & 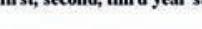 & & & & & & \\
\hline & $\mathrm{Cl2}$ & \multirow{3}{*}{\multicolumn{3}{|c|}{$\begin{array}{l}\text { COMPETENCY } 18 \\
\text { Give health advice and information }\end{array}$}} & & & & & & & \\
\hline & $\mathrm{Cl3}$ & & & & \multicolumn{7}{|c|}{$\begin{array}{l}\text { COMPETENCY } 18 \\
\text { Give health advice and information }\end{array}$} \\
\hline & C14 & & & & & YEAR & $R 1$ & YEA & $\mathrm{R} 2$ & YEA & AR 3. \\
\hline & \begin{tabular}{|l|}
$\mathrm{Cl5}$ \\
$\mathrm{Cl6}$
\end{tabular} & DATE & FEEDBACK & NAME & & PASS & FAIl & PASS & FAIL & PASS & FAll. \\
\hline \multirow{3}{*}{ 这 } & \begin{tabular}{|l|}
$\mathrm{C} 17$ \\
\end{tabular} & \multirow[t]{2}{*}{ Day 3} & \multirow[t]{2}{*}{$\begin{array}{l}\text { You didn't write fredback on } \\
\text { this competency. }\end{array}$} & \multirow[t]{2}{*}{ Teacher } & \multirow{2}{*}{\begin{tabular}{|l|} 
LO1 - Answering ade- \\
quate on questions from \\
patient and farnily
\end{tabular}} & \multirow[t]{2}{*}{$\mathrm{x}$} & \multirow{2}{*}{\multicolumn{2}{|c|}{$\mathrm{x}$}} & & \multirow[t]{2}{*}{$x$} & \\
\hline & $\mathrm{Cl} 8$ _ & & & & & & & & & & \\
\hline & $\begin{array}{l}\text { Give bealutiogivec } \\
\text { and information }\end{array}$ & \multirow[t]{3}{*}{ Day 4} & \multirow{3}{*}{$\begin{array}{l}\text { You are very enthousiastic to } \\
\text { give information but try to take } \\
\text { into account the situation. The } \\
\text { mother was soo tired to receive } \\
\text { such detailed information. }\end{array}$} & \multirow[t]{3}{*}{ Mentor } & \multirow{3}{*}{\begin{tabular}{|l|} 
LO2 - Giving adjusted \\
informaton: correct, \\
small amount, understan- \\
dable language
\end{tabular}} & & & \multirow[t]{3}{*}{$x$} & & $x$ & \\
\hline $\begin{array}{l}\text { RE- } \\
\text { SEARCHER }\end{array}$ & C19 & & & & & & & & & & \\
\hline MANAGER & $\mathrm{c} 20$ & & & & & & & & & & \\
\hline & $\mathrm{C} 21^{21}$ & Day 20 & Student gave good advice about & Mentor- & LO3 - Controling if the & & & & & $x$ & \\
\hline $\begin{array}{l}\text { PRO- } \\
\text { FESSIONAL. }\end{array}$ & \begin{tabular}{|l}
$\mathrm{C} 22$ \\
$\mathrm{C} 23$
\end{tabular} & & $\begin{array}{l}\text { breastfeeding and also about } \\
\text { other care issues. She controled }\end{array}$ & & $\begin{array}{l}\text { advice and inormation is } \\
\text { understood and }\end{array}$ & & & & & & \\
\hline & $\mathrm{C24}$ & & & & & & & & & & \\
\hline
\end{tabular}

Figure 1. Format of the learning and assessment instrument

\section{Data collection}

A total of four focus groups were conducted: two with second year students $(n=23)$ and other two with third year students $(n=10)$. The focus groups comprised a representative sample of Midwifery students with different clerkship experiences on maternity and delivery wards. All the second and last year Midwifery students $(n=108)$ from the University College Arteveldehogeschool Ghent, using MAFI during those clerkships, were invited by letter to participate in one focus-group session on two selected dates. Participation was voluntary and all participating students signed consent forms prior to the sessions.

The focus group method was chosen because it is an appropriate method to elicit a wide range of ideas and opinions on a well-defined topic. 


\section{Procedure}

The study was conducted in the summer of 2008. The focus groups lasted 60-90 min, and were facilitated by a member of the research team (Erik Driessen) and a researcher of the Midwifery department who was not involved in the training of the students. This was done to ensure that participants felt free to express their views on MAFI without any hierarchical pressure. At the start, the moderators assured the students that full confidentiality was guaranteed.

Discussions were audiotaped and field notes were written immediately following each session. Audiotapes were transcribed ad verbatim by Mieke Embo.

The topics addressed by the focus groups were the value of the integrated feedback and assessment instrument for students' learning during internships and the specific value of the feedback unit and the assessment unit, respectively. Other topics were the value of MAFI for supervision and the role of the supervisors in facilitating the use of MAFI.

\section{Analysis}

The focus group interviews were analysed using the program ATLAS.ti. Analysis was carried out at two levels using accepted qualitative procedures. ${ }^{19}$ Content analysis was performed by two researchers (Mieke Embo, Leen Lauwers), who independently coded the data in line with the research questions and categorized the students' views. They compared their findings and resolved any differences by discussion until consensus of themes and sub-themes was attained. Another researcher reanalysed all the data, using a constant comparative method to establish connections and relationships, and to identify central themes in relation to the research questions. In order to ensure the trustworthiness of the analytic process, we conducted member checking by submitting the results of the analysis and the transcripts to two members of each focus group. Based on their comments more attention was paid to the impact of time issues and to negative feedback.

\section{RESULTS}

We present the results for the central themes that were identified in relation to the research questions. 


\section{Feedback and self-directed learning}

Although, students said that they would appreciate continuous and longitudinal written feedback from supervisors, more than $90 \%$ of the feedback from supervisors during the practice period was written by the students themselves. This written feedback was authenticated with a signature from the supervisor who provided the feedback. The teachers wrote feedback, but they came to the workplace only once or twice and the clinical supervisors wrote almost no feedback. According to the students, the clinical supervisors did not write feedback due to lack of time, lack of competence (in respect of what, where and how to write feedback), lack of motivation and reluctance to give feedback, in relation to interpersonal competencies in particular.

All students thought that the writing of feedback in MAFI stimulated reflection. One participant said:

'It takes a lot of time but I do find that because I have to write it down, I have to think about what went well and what did not go well and why'.

Although the supervisors rarely provided written feedback, they did give verbal feedback. Students were motivated to ask for it because it was instructed that every competence on MAFI needed evidence before entering assessment. Students reported that verbal feedback from supervisors facilitated their reflective writing about competencies. Conversely, reflective writing was hampered when there was little feedback, an imbalance of positive and negative feedback or feedback on a limited range of competencies only. Students experienced that feedback did often focus on their weaknesses and that this type of feedback rarely provided guidance for improvement. Some students said that verbal feedback that was predominantly or exclusively negative undermined their confidence, which in turn had a negative impact on their reflective writing. Importantly, all the students reported that the feedback did not cover the full scope of the competencies on MAFI, with teachers and clinical supervisors tending to limit their feedback to medical-technical competencies to the neglect of general competencies.

Students said they had to be motivated to produce daily written feedback. Motivation appeared to depend on different factors. While third year students were more internally motivated by individual growth and personal development, the majority of the second year students were motivated by external factors as there were assessment and supervision. 
'The information can help you to avoid making the same mistakes again or to improve during your next internship' (third year).

'The paperwork is a real burden of the internship. The only benefit is for the assessors, so they can read if you have done it right' (second year).

Due of the continuous and longitudinal training of writing feedback, students made progress in their writing. Although writing feedback was difficult, third year students had developed strategies that made it easier. They wrote feedback immediately after working with, or without, a clinical supervisor, asking the clinical supervisor to supplement or correct student's written feedback. Second year students strongly depended on external input for feedback. They were afraid to ask for more feedback than they received, especially on generic competencies. They were afraid of receiving negative feedback, which could undermine their self-confidence. However, at the same time they were aware that it was their responsibility to ask for feedback.

The amount of needed time for writing feedback was related to the way the MAFI was structured. Most students were positive about the effects of reflective writing but preferred a less structured and detailed instrument so that writing would take less time and could be discussed with the clinical supervisor.

Continuous and longitudinal written feedback enabled students, teachers and supervisors to read and reread the feedback given during the learning period. Students and teachers did read the feedback but clinical supervisors did so very rarely. There was a general agreement among the students that rereading feedback was valuable because it reminded them of advice and helped them to develop strategies for improvement.

'I read feedback in the evening or in the morning or just before practical work so that it is fresh in my mind and then it helps me to learn. There are always things that you remember, but others that you forget'.

However, students also said that they did not reread unexpected negative feedback, because it undermined their self-confidence. Teachers were motivated to read the feedback because they hardly ever observed students, and therefore needed the information for the final assessment. The clinical supervisors hardly paid any attention to the continuous collected written feedback. Students reported that clinical supervisors did not have enough time to do so and failed to recognize that substantial benefits might be gained from observing students' performance. 


\section{Assessment and self-directed learning}

All the students were motivated to use the assessment checklist and thought the checklist was valuable because it provided a concrete and easy-to-use overview of their learning outcomes. The amount of detail was not considered a barrier. Quite the opposite, students reported that the details made the checklist useful as a 'quick scan' of their learning progress.

The third year students said the written feedback was relevant in view of selfassessment. Students replied to the question whether the instrument would have the same effect without the written feedback as followed:

'The checklist is the conclusion, but it doesn't tell you how well you are doing. If you write feedback you have more information'.

'The feedback unit is very broad and with the checklist, you see immediately where you have to work on'.

Being stimulated to take responsibility for their own learning by reflecting on learning outcomes and competencies appeared to be of crucial importance to students. Interestingly, they mentioned different activities, as described in the definition by Hammond and Collins: monitoring competencies (a), setting goals (b), diagnosing gaps and learning needs (c) and asking for learning opportunities (d). ${ }^{9}$ These activities are illustrated by the following quotes.

'...because you put yourself under a magnifying glass. You assess yourself. Yes that is insightful. You can learn a lot from your own actions, such as the initiatives you take. When you have to reflect on this, you can grow by looking back; you pause and then decide what you take forward and what you leave behind' (a-b).

'I do look at my checklist, for example when I am in the middle of an assignment, and then I tick what I have done and what I still have to do ... and also, at the start of the placement, which outcomes I am going to achieve ...' (a-c).

'It's also my responsibility to remind the midwives of the type of learning opportunities I want to have' (d).

The integration of feedback and assessment was perceived as valuable for formative learning and assessment, but its value for summative assessment and grading was contested. Despite the efforts of the designers of MAFI to separate teaching and 
assessment, as is recommended in the literature, students appeared to attach much importance to the involvement of clinical supervisors in their assessment. Although during their day-to-day activities the students were mostly supervised by them, their final assessment was often determined in a discussion between the student and the teacher. Students felt uncomfortable that their clinical supervisors did not always contribute to the final assessment. Third year students argued in support of a final assessment meeting in which the student, the clinical supervisor and the teacher were present. They contended that in this way the written feedback could be controlled and optimized and that such a dialogue allowed comparisons between the judgements of the student, the clinical supervisor and the teacher. As one student said:

'I thought it was very useful because you have to think for yourself: What have I achieved? But you also get confirmation from your clinical supervisor and the teacher that 'Yes, I agree you did that' or you may think 'Yes I achieved that goal', but the clinical supervisor says 'some further work remains to be done'. The fact that someone says that is very important'.

\section{Supervision and self-directed learning}

MAFI is a learning instrument based on providing feedback, assessment and support. Students described the role of the clinical supervisors and some conditions they thought would support self-directed learning with MAFI. They focussed on the clinical supervisors, who to them were most important with regard to the effect of MAFI.

'Empowering students to engage in self-directed learning with MAFI' and 'providing feedback that could be written in MAFI' are phrases that summarize what students expect from their clinical supervisors. Actions of the clinical supervisors that empowered students to regulate their learning were considered to boost students' confidence in self-directed learning activities as there are asking, writing and reading feedback, diagnosing learning needs with the checklist and asking for learning opportunities, reflecting on new performances and competency development,... . A good 'studentclinical supervisor relationship' was prerequisite for building self-confidence. For second year students, the quality of the student-supervisor relationship was related to 'a positive feeling about working together' and for third year students it was related to their feeling of being empowered to self-direct their learning process. As one third year student puts it: 
'I think that it's essential for the clinical supervisor to be concerned and involved. If that is the case, the supervisor will take an interest in your overall learning process and give you the opportunity to improve in a good and comforting way'.

The student-supervisor relationship evoked strong emotions from the students. A positive impact on self-confidence was related to a sense of success, responsibility and encouragement. Negative effects on self-confidence led to stress, depression, feelings of inferiority, fear and a sense of unfairness. Students felt that they received more feedback from supervisors who were motivated to guide them. While some students talked about clinical supervisors who 'loved to teach', others referred to clinical supervisors who were clearly unwilling to undertake the teaching role.

Students' acceptance of feedback was also linked to the quality of the studentsupervisor relationship. Within a good relationship the continuous and longitudinal collected written feedback was used formatively and focused on the development of competencies by comparing the feedback with the checklist. As we saw earlier, second year students mostly focussed on assessment and third year students on the progress they made in the development of competencies. If the student-supervisor relationship was sub-optimal, third year students too focussed mainly on summative assessment. This was particularly relevant if the feedback was negative.

Supervising the self-directed learning of students in the workplace with MAFI requires specific competencies. The students said they often encountered a lack of teaching competencies in their clinical supervisors. They suggested staff development activities to improve supervisors' and teachers' competencies in relation to: how to supervise students, how to give and write feedback, how to support the development of competencies and how to determine, which competencies should be trained and assessed.

According to the students, staff development activities should tackle the use of ' $\mathrm{MAFI}$ ', because the instrument was underused and most clinical supervisors did not know how to use it properly.

'They don't understand the relevance of the two units. They see it more as a list of activities than as a feedback instrument'. 


\section{DISCUSSION}

We explored students' perceptions of the effects of an integrated instrument for feedback and assessment during internships in Midwifery practice. Students generally agreed that the integration of feedback and assessment supported self-directed learning, provided they received feedback from motivated and competent clinical supervisors. They also appreciated that MAFI made it possible to have an active role in their own development. The instruction they were given to collect written feedback about all the competencies by writing feedback, asking for feedback and reading and rereading feedback was experienced as time consuming and easier said than done. But, it was also considered to promote self-reflection, self-monitoring and the creation of personal action plans by asking 'what went well, what should be improved and how'. ${ }^{20}$ The assessment unit of MAFI was seen as a 'quick scan' of learning outcomes, which could be compared with evidence from the feedback unit and thus enabled monitoring and formative assessment of competencies. The assessment unit was considered to support self-assessment. However, the students doubted the value of the integration of feedback and assessment for summative assessment and regretted that the possibilities for supervisors to support their self-directed learning were generally underused.

The students reported that continuous and longitudinal feedback on self-directed learning enhanced their motivation to take the initiative in writing feedback on all the competencies. We saw a shift in motivation concerning the written feedback between the second and the third year. Where second year students were mainly externally motivated (by assessment and supervisors), third year students were more internally motivated to use feedback to diagnose learning needs and develop plans for improvement. Growing confidence in the learning process and development of competencies might optimize the effect of MAFI. In line with results reported in the literature, the students identified effective feedback as a key factor in self-directed learning. ${ }^{21,22}$ The role of the supervisor was more important than the role of the instrument itself and students stated that clinical supervisors and teachers should increase their efforts to provide effective feedback. While the use of clinical performance ratings is not undisputed in the literature, ${ }^{23}$ all the students in this study appreciated the overview of the competencies and learning outcomes that was offered by MAFI. ${ }^{24,25}$ This overview was seen as a quick scan for students. Feedback can be a part of assessment and other studies have shown that this motivates students to take responsibility to monitor their own learning, reflect on competency growth and look for learning opportunities. ${ }^{20,22}$ In this study, the students constantly compared their own performance with standards in the checklist and this enabled them to identify areas that required further work. The MAFI was valuable for formative learning and assessment but was not perceived as 
contributive to the quality of the summative assessment. Students were convinced that a final assessment conversation between the student, the clinical supervisor and the teacher was essential and might contribute to the quality of assessment. We need to more strictly adhere to plan to do this final assessment conversation and we foresee it has the intended effect in further research.

The effect of MAFI on students' self-directed learning and self-confidence in their own learning process depended on the support from motivated, empathic and competent supervisors. First of all, the supervisors were responsible for providing effective feedback, which could be written by students. As described in the literature, it was generally difficult for the students to collect feedback, on general competencies in particular. ${ }^{21}$ Furthermore, although a balance between positive and negative feedback is generally recommended, ${ }^{26}$ the students indicated that they suffered when they received negative feedback regularly, saying it undermined their self-confidence with a negative impact on reflective writing. In the literature we found different opinions on this topic. On the one hand, teachers are reported to be very hesitant to provide negative feedback, ${ }^{7}$ but on the other hand there are reports that the overall prevalence of belittlement and humiliation is surprisingly high in the clinical setting. ${ }^{27}$ Second, students expected practical and emotional support from their clinical supervisors. The effect of a supporting relationship on learning was often linked with a positive feeling about 'working together', but this was more important for second than for third year students. When the student-supervisor relationship was suboptimal, third year students too were more occupied with summative assessment than with learning.

Time or rather time constraints for working with the MAFI were mentioned in different ways during this study. Use of MAFI by supervisors was affected by lack of time. Clinical supervisors did not have sufficient time to give feedback and hardly wrote feedback, although students very much appreciated it when they did so. Students suggested that the feedback unit might be changed to become less detailed in order to make the clinical supervisors more motivated to write. There was also a positive time issue: when MAFI is used students and supervisors are compelled to devote more time to the learning process and to supervision. This issue is actually being dealt with in a follow up study investigating the perceptions of supervisors of the value of MAFI on the support of self-directed learning in clinical practice.

Several limitations of this study need to be considered. The most important limitation was the self-reported nature about the effects of MAFI on the learning of the students. Another limitation emphasises that the participating students were volunteers, which may have biased students' responses. Furthermore, the participating group represented 
only a small percentage of the entire student cohorts. Because of the small sample and specific context of Midwifery education in Belgium, the generalizability of the results may be limited.

\section{CONCLUSION}

The results of this study suggest that the integration of feedback and assessment in a clearly defined learning and assessment instrument is a potentially valuable method to promote self-directed learning and formative assessment during internships. However, the students contested the instrument's value for summative assessment, at least in this current form, and the instrument appeared to be undervalued and underused by supervisors. Feedback and motivated, competent supervisor(s) are essential for successful effect of MAFI on self-directed learning in practice. Those intending to use an integrated instrument, such as MAFI should pay attention to the training of students, clinical supervisors and teachers in the use of the instrument and provide dedicated time for reflective writing and dialogue. Provided it is used as intended, an instrument for the integration of feedback and assessment in an authentic clinical setting can provide opportunities for supporting self-directed learning in the workplace. 


\section{REFERENCES}

1. Daelmans HEM, Overmeer RM, van der Hem-Stokroos HH, Scherpbier AJJA, Stehouwer CDA, van der Vleuten CPM. In-training assessment: Qualitative study of effects on supervision and feedback in an undergraduate clinical rotation. Med Educ 2006;40(1):51-58.

2. van Hell EA, Kuks JBM, Schönrock-Adema J, van Lohuizen MT, Cohen-Schotanus J. Transition to clinical training: Influence of pre-clinical knowledge and skills, and consequences for clinical performance. Med Educ 2008;42(8):830-837.

3. Fox RD, Bennett NL. Education and debate. Continuing medical education: Learning and Change: implications for continuing medical education. BMJ 1998;316(7129):466-468.

4. Andersen RS, Hansen RP, Søndergaard J, Bro F. Learning based on patient case reviews: an interview study. BMC Med Educ 2008;8:43.

5. Irby D, Bowen JL. Time-efficient strategies for learning and performance. Clin Teach 2004;1(1):23-28.

6. White CB. Smoothing Out Transitions: How Pedagogy Influences Medical Students' Achievement of Selfregulated Learning Goals. Adv Health Sci Educ 2007;12(3):279-297.

7. Ramani S, Leinster S. AMEE Guide no.34: Teaching in the clinical environment. Med Teach 2008;30(4):347-364.

8. Walton MM, Elliott SE. Improving safety and quality: How can education help? Med J Aust 2006;184(10 Suppl):s60-64.

9. Hammond M, Collins R. Self-Directed Learning: Critical Practice. New York: Nichols/GP Publishing 1991.

10. Schweinfurth JM. Lifelong learning in otolaryngology: Self-directed learning. Otolaryngol Clin North Am 2007;40(6):1323-1330.

11. Seifan A, Kheck N, Shemer J. Perspective: The case for subspecialty clinical learning in early medical education - moving from case-based to patient-based learning. Acad Med 2008;83(5):438-443.

12. van der Hem-Stokroos HH, Daelmans HEM, van der Vleuten CPM, Haarman HJTM, Scherpbier AJJA. A qualitative study of constructive clinical learning experiences. Med Teach 2003;25(2):120-126.

13. Branch WT, Paranjape A. Feedback and Reflection: Teaching methods for clinical settings. Acad Med 2002;77(12):1185-1188.

14. Ende J. Feedback in clinical medical education. J Am Med Assoc 1983;250(6):777-781.

15. Swanson DB, Norman GR, Linn RL. Performance-based assessment: Lessons from the health professions. Educ Res 1995;25(5):5-11

16. Norcini J, McKinley D. Assessment methods in medical education. Teach Teacher Educ 2007;23(3):239250.

17. McKinley RK, Strand J, Ward L, Gray T, Alun-Jones T, Miller H. Cheklists for assessment and certification of clinical procedural skills omit essential competencies: A systematic review. Med Educ 2008;42(4):338349.

18. Borel-Rinkes IHM, Gouma DJ, Hamming JF. Surgical training in the Netherlands. World J Surg 2008;32(10):2172-2177.

19. Miles B, Hubermann A. Qualitative Data Analysis. Thousand Oaks, CA, Sage publications 1994.

20. Bienstock LJ, Katz NT, Cox SM, Hueppchen N, Erickson S, Puscheck EE. To the point: Medical education, reviews - Providing feedback. Am J Obstet Gynaec 2007;196(6):508-13.

21. Heron G. Using Students' Written Feedback on 'Race' Issues to Enhance Self-regulated Learning. Br J Soc Work 2008;38(2):376-394.

22. Koh LC. Refocusing formative feedback to enhance learning in pre-registration nurse education. Nurse Educ Pract 2008;8(4):223-230.

23. Govaerts MJB, van der Vleuten CPM, Schuwirth LWT, Muijtjens AMM. Broadening Perspectives on Clinical Performance Assessment: Rethinking the Nature of In-training Assessment. Adv Health Sci Educ 2007;12(2):239-260. 
24. Harden R. Outcome-Based Education: The future is today. Med Teach 2007;29(7),625-629.

25. van der Vleuten C, Schuwirth L. Assessing professional competence: from methods to programmes. Med Educ 2005;39(3):309-317.

26. Salerno MD, Jackson J, O'Malley P. Interactive Faculty Development Seminars improve the quality of written feedback in Ambulatory Teaching. J. Gen Intern Med 2003;18(10):831-834.

27. Mattick K, Knight L. The importance of vocational and social aspects of approaches to learning for medical students. Adv Health Sci Educ 2009;14(5):629-644. 



\section{CHAPTER 3}

\section{A framework to facilitate self-directed learning, assessment and supervision}

in midwifery practice:

A qualitative study of supervisors' perceptions

Mieke Embo

Erik W. Driessen

Martin Valcke

Cees P.M. van der Vleuten

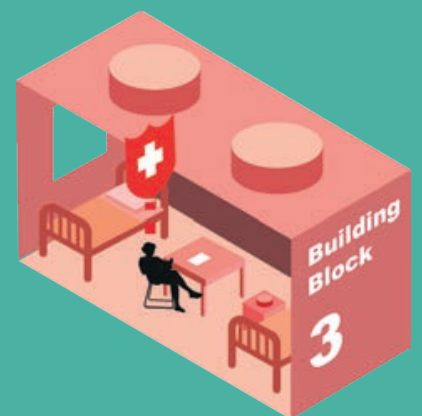




\section{ABSTRACT}

Background: Self-directed learning is an educational concept that has received increasing attention. The recent workplace literature, however, reports problems with the facilitation of self-directed learning in clinical practice. We developed the Midwifery Assessment and Feedback Instrument (MAFI) as a framework to facilitate self-directed learning. In the present study, we sought clinical supervisors' perceptions of the usefulness of MAFI.

Methods: Interviews with fifteen clinical supervisors were audio taped, transcribed verbatim and analysed thematically using ATLAS.ti software for qualitative data analysis.

Results: Four themes emerged from the analysis. (1) The competency-based educational structure promotes the setting of realistic learning outcomes and a focus on competency development, (2) instructing students to write reflections facilitates studentcentred supervision, (3) creating a feedback culture is necessary to achieve continuity in supervision and (4) integrating feedback and assessment might facilitate competency development under the condition that evidence is discussed during assessment meetings. Supervisors stressed the need for direct observation, and instruction how to facilitate a self-directed learning process.

Conclusion: The MAFI appears to be a useful framework to promote self-directed learning in clinical practice. The effect can be advanced by creating a feedback and assessment culture where learners and supervisors share the responsibility for developing self-directed learning. 


\section{BACKGROUND}

Increasingly complex and diverse health organisations of the $21^{\text {st }}$ century require nursing and midwifery students to take charge of their own learning. ${ }^{1,2}$ Based on adult learning theories, Knowles $(1975)^{3}$ clearly defines self-directed learning as: a process in which individuals take the initiative, with or without the help of others, in diagnosing learning needs, formulating learning goals, identifying human and material resources for learning, choosing and implementing appropriate learning strategies, and evaluating learning outcomes. ${ }^{4,5}$ To stimulate the development of self-directed learning, clinical education is turning to constructivist perspectives drawing on humanistic and social learning theories. ${ }^{6}$ Central notions are learner-centred education, self-motivated learning and self-actualization, whilst teachers are expected to facilitate students' selfdirected learning. ${ }^{7}$ Lave and Wenger $(1991)^{8}$ perceived socio-cultural learning as participation in a community of practice and as dialogue. Clinical internships are important communities of practice for nursing and midwifery students and clinical supervisors play a fundamental role in facilitating student self-directed learning. ${ }^{9}$ In the unstructured reality of day-to-day clinical practice, however, this approach poses a considerable challenge. The clinical workplace literature presents several barriers to self-directed learning and its supervision which can be clustered according: (1) lack of educational structure, ${ }^{10,11}$ (2) limited learner involvement and student-centred supervision, ${ }^{7,12}$ (3) discontinuity of supervision and feedback, and (4) separation of formative and summative assessment. ${ }^{13,14,15}$ To enable clinical supervisors and students to overcome these barriers, we designed the Midwifery Assessment and Feedback instrument (MAFI, figure 1) aimed at achieving four goals: improving educational structure, promoting an active role of students and supervisors in facilitating individual learning processes, promoting continuity of supervision, and integrating formative and summative assessment. As such, facilitating self-directed learning occurs and is encouraged in the presence of a facilitative learning instrument, MAFI, with guidelines and is not therefore a fully independent student activity.

(1) To structure clinical education, the MAFI is based on a competency framework, ${ }^{10}$ comprising the midwifery competencies students are expected to have attained at the end of the three-year Midwifery programme. In relation to each internship, the relevant competencies are emphasised (figure 1, column 1). MAFI is a paper and pencil method, integrating a written feedback unit (figure 1, column 2) and an assessment unit (figure 1, column 3) with the same competency-structure. The purpose of this integrated, competency-based framework is to standardize expected outcomes, match behaviour to the standards ${ }^{16}$ and facilitate the impact of feedback to empower students to take control of their own learning. ${ }^{17}$ 
(2) Active involvement of students and the role of supervisors as facilitators of students' self-directed learning processes are supported by the MAFI portfolio. According to the

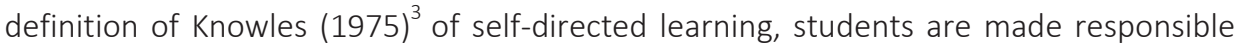
for their own learning by the instruction to take the initiative to ask for feedback and to reflect on competencies. ${ }^{18,19}$ In the feedback unit, there is space for written feedback and reflections about the selected competencies. Oral feedback can be written by the student, the clinical supervisor and by any staff member who observes the student. Written information from students is authenticated by the supervisor by his/her signature. Since self-assessment has been shown to have limitations, effective feedback is an important complementary condition for self-directed learning. ${ }^{15,20,21}$ Therefore, learners should be trained in seeking and receiving feedback, ${ }^{22}$ whilst supervisors need training and sufficient time for providing useful feedback.

(3) To promote continuity of supervision, students are instructed to write reflections and seek feedback on a daily basis to collect information that can be used to monitor their ongoing development. ${ }^{19,23}$ It is the students' responsibility to ensure that sufficient feedback on their progress in all the competencies has been collected at the end of the internship period. Documenting students' longitudinal development enables students and supervisors to monitor students' self-directed learning activities and remedy weaknesses in competency development. ${ }^{24}$

(4) To promote self-directed learning, the MAFI portfolio integrates formative and summative assessment in clinical learning. ${ }^{7}$ Therefore, the MAFI is designed with a feedback and an assessment unit. In response to criticism directed at both the poor linkage of clinical assessment to students' actual performance and the lack of direct observation of students, ${ }^{11}$ the MAFI checklist is designed to support formative assessment by linking feedback and reflections collected in the feedback unit to concrete and observable learning outcomes in the checklist, which can be discussed during assessment meetings at the midpoint and end of the internship. As such, the checklist also helps to ground summative assessment in indicators of observed student performance. $^{25,26}$

Having exploring students' perceptions of the MAFI in an earlier study, we conducted the present study to explore the relevance of the four goals of the MAFI to facilitate self-directed learning in the clinical workplace from the perspective of the supervisors. The students perceived the MAFI as a potentially valuable tool, but noted that it was undervalued and underused by their supervisors. ${ }^{27}$ The present study builds on this observation by exploring the opinions of the supervisors. We used a qualitative study 
design involving semi-structured interviews with supervisors. Our research questions were:

- What are the perceived effects of the MAFI on facilitating midwifery students' selfdirected learning and their supervision in clinical practice?

- What are the perceived conditions that determine achievement of the expected effects of the MAFI?
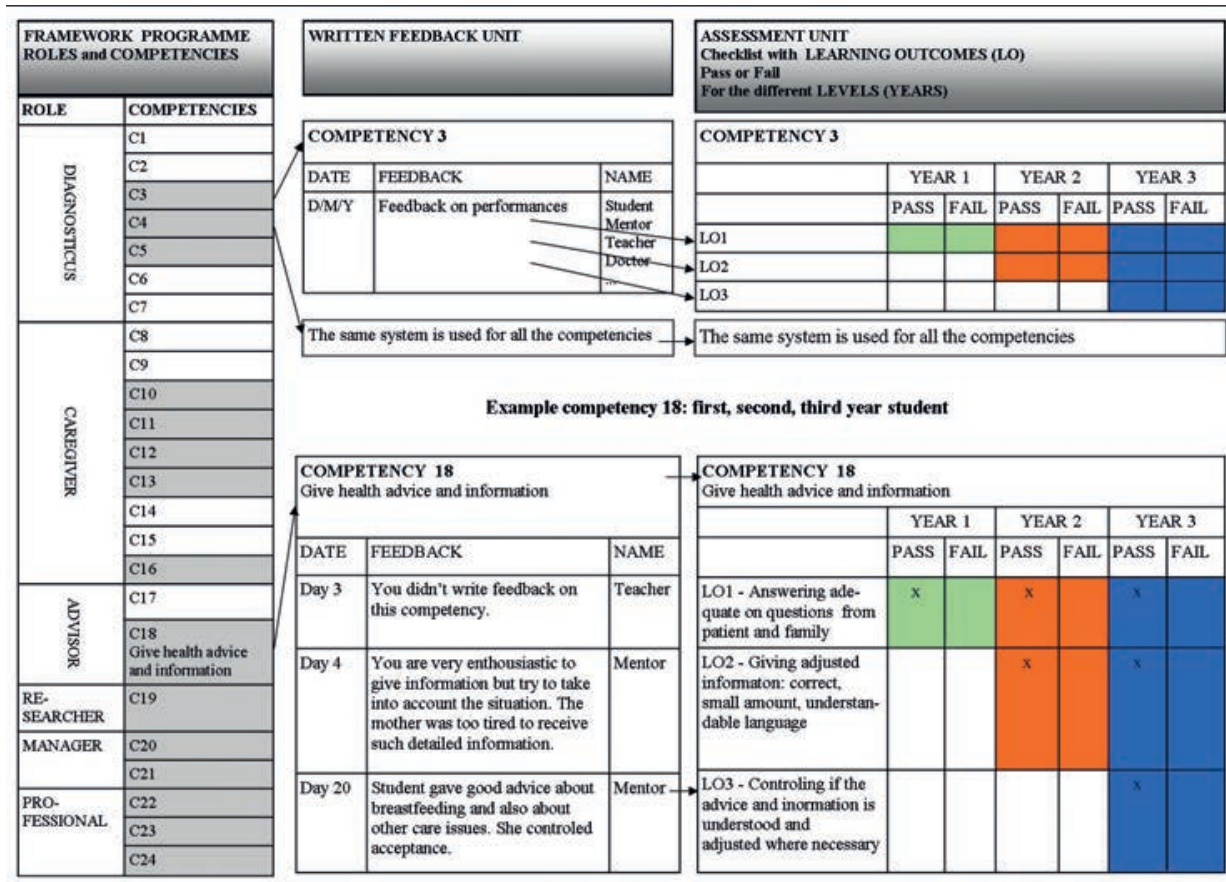

Example competency 18: first, second, third year student

\begin{tabular}{|c|c|c|c|c|c|c|c|c|c|}
\hline \multirow{2}{*}{\multicolumn{3}{|c|}{$\begin{array}{l}\text { COMPETENCY } 18 \\
\text { Give health advice and information }\end{array}$}} & \multicolumn{7}{|c|}{$\begin{array}{l}\text { COMPETENCY } 18 \\
\text { Give health advice and information }\end{array}$} \\
\hline & & & & \multicolumn{2}{|c|}{ YEAR 1} & \multicolumn{2}{|c|}{ YEAR 2} & \multicolumn{2}{|c|}{ YEAR 3} \\
\hline DATE & FEEDBACK & NAME & & PASS & FAIl & PASS & FAII & PASS & FAll. \\
\hline Day 3 & $\begin{array}{l}\text { You didn't write feedback on } \\
\text { this competency. }\end{array}$ & Teacher & $\begin{array}{l}\text { LO1 - Answering ade- } \\
\text { quate on questions from } \\
\text { patient and family }\end{array}$ & $\mathrm{x}$ & & $x$ & & $x$ & \\
\hline Day 4 & $\begin{array}{l}\text { You are very enthousiastic to } \\
\text { give information but try to take } \\
\text { into account the situation. The } \\
\text { mother was too tired to receive } \\
\text { such detailed information. }\end{array}$ & Mentor & $\begin{array}{l}\mathrm{LO} 2 \text { - Giving adjusted } \\
\text { informaton: correct, } \\
\text { small amount, understan- } \\
\text { dable language }\end{array}$ & & & $x$ & & $x$ & \\
\hline Day 20 & $\begin{array}{l}\text { Student gave good advice about } \\
\text { breastfeeding and also about } \\
\text { other care issues. She controled } \\
\text { acceptance. }\end{array}$ & Mentor- & $\begin{array}{l}\text { LO3 - Controling if the } \\
\text { advice and inomation is } \\
\text { understood and } \\
\text { adjusted where necessary }\end{array}$ & & & & & $x$ & \\
\hline
\end{tabular}

Figure 1. Format of the learning and assessment instrument.

\section{METHODS}

\section{Context}

In 2007, the Midwifery Department of University College Arteveldehogeschool Ghent, Belgium implemented a three-year competency-based curriculum. The competences were derived from the competency frameworks of (1) the International Confederation of Midwives, (2) the European directives, (3) the Belgian professional profile and (4) the Flemish educational profile of midwives. The competency framework received a special Quality label from the accreditation body NVAO (Nederlands Vlaams Accreditatie 
Orgaan). NVAO was established by the Dutch and Flemish governments as an independent accreditation organisation tasked with providing an expert and objective assessment of the quality of higher education in the Netherlands and Flanders. The competency outcomes are relevant to all midwives. In order to support the competency-based orientation, the MAFI was introduced to help students and supervisors attain the four MAFI goals during the clinical internships. Annual training in the use of the MAFI is offered to all clinical supervisors.

\section{Participants}

From the 25 hospitals that offer clinical internships for midwifery students, eight maternity and delivery wards were randomly selected for inclusion in the study. Every hospital has an average of 4 students per training period. The first author (ME) contacted the heads of the wards by telephone to introduce the research project and to ask for participation in the study. Using purposeful sampling, ${ }^{28}$ we selected two supervisors of each ward to take part in an individual face-to-face interview. The heads gave the references to the first author in a second telephone call. In the period July-August 2009, the selected supervisors were contacted by telephone by the first author (ME). They additionally received an email with an information letter and an informed consent form. All participating supervisors signed the consent form prior to the interview. Clinical supervisors from one hospital were unable to participate due to planning problems, and one supervisor was unable to participate due to unforeseen workload. Fifteen supervisors were interviewed and this group appeared to demonstrate saturation as no new information was coded in the last two interviews. The sample comprised two men and thirteen women and participants' clinical experience ranged from four months to 32 years (14.5 years average). This reflects the typical gender distribution and experience of clinical supervisors. In addition to their role as a supervisor, two interviewees had a management role and two interviewees were coordinators of workplace learning. All had a midwifery degree, except for one supervisor who had a nursing degree. Ten supervisors supervised students in the delivery and the maternity ward, three supervised only in the delivery ward and two only in the antenatal/postnatal ward.

\section{Study design}

We conducted a qualitative study with semi-structured interviews. The interviews consisted of open-ended questions to obtain rich information from the participants about their experiences and perceptions regarding the MAFI. ${ }^{29}$ The interviews were conducted, recorded and transcribed by the principal investigator (ME). The study was 
conducted in full accordance with the 1975 Declaration of Helsinki and the revised version of 1983 and in full accordance with national ethical guidelines.

\section{Analysis}

The transcripts were analysed using the program ATLAS.ti software (version 6.1.6). Content analysis was performed by the first author and a research assistant who independently coded the data from all the interviews in line with the research questions and categorized the supervisors' views. They compared their findings and resolved any differences by discussion until consensus of codes was attained. Single passages of text could generate different codes and similar codes were combined. The codes were then categorised into themes which were discussed by two researchers. The accepted coding and themes were then structured according to the four goals of the MAFI framework. As we wanted to explore how individual supervisors experienced the effect of MAFI on the development of self-directed learning and it's supervision, we built a matrix based on the qualitative analysis methods described by Miles and Huberman (1994). ${ }^{28}$ We defined the rows and columns of the matrix as follows: (1) Each supervisor had two columns, one for the perceived effect of MAFI and one for the determining conditions, (2) the rows were defined according the four MAFI goals. This matrix permitted careful comparisons, detection of differences, noting of patterns and permit simple quantification that was appropriate to answer the research questions. The first author (ME) was involved in all aspects of the fieldwork: recruitment of participants, data collection, transcription and data analysis. This ensured consistency of the research procedure and interview style as well as accuracy of transcription. To ensure accuracy of analysis and compliance with ethical guidelines, the results of the analysis were reported back to four interviewees. ${ }^{30}$ This did not necessitate changes in the results.

\section{RESULTS}

We present key findings in table 1 and describe the results for each of the four MAFI goals.

\section{Educational structure}

The majority of respondents (12/15 R) agreed that the competency-based educational structure promoted a focus on realistic outcomes. They characterized this structure as 'complete', 'thorough' and 'reflecting concrete examples'. Furthermore, they said that the competency list in the MAFI stimulated them to consider a more complete list of 
competencies when giving feedback: 'I don't think it is a bad thing that they know one should pay attention to diversity, to professional behaviour. If those competencies weren't mentioned they might easily be overlooked.' They particularly appreciated it that each competency had to be considered in the feedback unit and in the assessment unit, although they also mentioned negative perceptions. All supervisors perceived MAFI as a time-consuming learning instrument for students and supervisors and three supervisors (R1, R2, R9) mentioned that supervision with MAFI was not realistic because there was not always time during the clinical working day to write and read reflections and feedback. The time issue was often linked with the structure of MAFI. Slightly more than half of the supervisors (9/15 R) also mentioned the complexity of the competency framework and some of them (3/15 R) emphasised the difficulty identifying both competency components in students' stories and relationships between competencies and situations. Although supervisors noticed that students were familiar with the MAFI $(10 / 15 \mathrm{R})$, three supervisors remarked that supervisors' lack of familiarity with the competency framework could result in avoidance behaviour. There was general agreement among the respondents $(11 / 15 \mathrm{R})$ that supervisors and all the staff members observing students, should be trained to be able to use the MAFI to its full potential.

\section{Active involvement in learning and student-centred supervision}

All the supervisors agreed that students who used the MAFI were more likely to ask for feedback and to write it down. Consequently, students were more actively involved in their clinical learning. However, some of them also stressed that, in busy workplaces, it takes more than eager students to ensure effective feedback and they suggested that students should first write down reflective notes before asking for feedback for different reasons. First, this MAFI requirement stimulated active involvement and selfreflection: 'But when they have to write it down first, they start to think about it. They reflect on their abilities and opportunities for improvement'. Second, they perceived that reflective students stimulated them to give more feedback. Finally, the majority of supervisors (9/15 R) perceived that reading students' reflective notes before giving or writing feedback facilitated individual supervision as it helped supervisors to see students' individual learning paths through the eyes of the students: 'Before, we were given a form that we filled in ourselves. That was easier for us. Well, when I say easier, it took more time, but it was easier because you only had to consider your own point of view. Now, the learners are in control, and you have to put yourself in their place and assess their behaviour critically, from their perspective'. All supervisors agreed that MAFI without supervisors, observing students, reading reflections and providing feedback, would not necessary stimulate a self-directed learning process. The majority of supervisors mentioned key conditions for the development of active involvement 
facilitated by learner-centred supervision. Conditions which were not always fulfilled such as: (1) a good balance between reading reflections and observation of student performance for validation and to counterbalance overly positive students (14/15 R); (2) learners actively approaching supervisors to ask for feedback (10/15 R) and (3) supervisors overcoming their reluctance to write negative feedback, especially on students' behavior (13/15 R).

\section{Continuity of supervision}

According to all but one supervisor, the most useful features of the MAFI were the written reflections and feedback at all stages of the clinical internship. Being able to fall back on written notes to remind them of previous events helped supervisors to monitor whether students actually used feedback for learning. It was also considered important that the MAFI facilitated reflection and feedback even when the supervisor was not on duty or did not observe the student. Although the general agreement that the continuous collected written information was potentially valuable to document competency development, one third of the supervisors (5/15 R) worried about the writing activity of their colleagues that might hamper the facilitating effect of MAFI. They perceived that some colleagues never wrote feedback, wrote too positive feedback or put a signature for validation without reading students' reflections. As key-condition for continuity of supervision supervisors mentioned a feedback culture that stimulates students and supervisors to submit and review written reflections, and which is characterized by a consistent behaviour of different supervisors to guarantee evidence in the written information. One supervisor was very sensitive for a kind of 'learners' manipulating feedback behaviour' as quoted: 'What I also noticed, if you take your time to write feedback, and you write negative feedback, then students will not be so inclined to give their documents to you because they are afraid for the impact on summative assessment. They will look for positive feedback writers'. 
Table 1: The MAFI-framework, results.

\begin{tabular}{|c|c|c|c|c|}
\hline GOAL & FEATURES & LEARNING EFFECT & PROBLEMS & CONDITIONS \\
\hline $\begin{array}{l}\text { Educational } \\
\text { structure }\end{array}$ & $\begin{array}{l}\text { Competences are the } \\
\text { learning outcomes }\end{array}$ & $\begin{array}{l}\text { Promotes: } \\
\text { - the setting of } \\
\text { realistic outcomes } \\
\text { - a focus on } \\
\text { competency } \\
\text { development }\end{array}$ & $\begin{array}{l}\text { Competences are: } \\
\text { - complex } \\
\text { - too time } \\
\text { consuming }\end{array}$ & $\begin{array}{l}\text { Time } \\
\text { Training } \\
\text { Limited number of } \\
\text { competences }\end{array}$ \\
\hline $\begin{array}{l}\text { Learning and } \\
\text { guidance process }\end{array}$ & $\begin{array}{l}\text { 1. Learners write } \\
\text { reflections after } \\
\text { performances under } \\
\text { a competence - } \\
\text { structure } \\
\text { 2. Learners ask } \\
\text { feedback } \\
\text { 3. Supervisors read } \\
\text { reflections } \\
\text { 4. Supervisors give } \\
\text { and write feedback }\end{array}$ & $\begin{array}{l}\text { Promotes: } \\
\text { - active involvement } \\
\text { in learning } \\
\text { - student-centered } \\
\text { supervision } \\
\text { - a 2-way feedback } \\
\text { process }\end{array}$ & $\begin{array}{l}\text { Lack of: } \\
\text { - observation } \\
\text { - reading time } \\
\text { - negative feedback, } \\
\text { especially on } \\
\text { professional } \\
\text { behaviour }\end{array}$ & $\begin{array}{l}\text { Observation to } \\
\text { validate reflections } \\
\text { Active students } \\
\text { Motivation to write } \\
\text { negative feedback }\end{array}$ \\
\hline $\begin{array}{l}\text { Documenting } \\
\text { competency } \\
\text { development }\end{array}$ & $\begin{array}{l}\text { Collected evidence is } \\
\text { available for learners } \\
\text { and supervisors at all } \\
\text { stages of the } \\
\text { internship }\end{array}$ & $\begin{array}{l}\text { Facilitates: } \\
\text { - the continuous } \\
\text { self-directed } \\
\text { learning process } \\
\text { - supervision (f.e. } \\
\text { how does the } \\
\text { learner use } \\
\text { feedback?) }\end{array}$ & $\begin{array}{l}\text { Bias in information: } \\
\text { - learners are } \\
\text { selecting positive } \\
\text { feedback writers } \\
\text { - inconsistent } \\
\text { feedback between } \\
\text { supervisors }\end{array}$ & $\begin{array}{l}\text { Effective feedback } \\
\text { culture }\end{array}$ \\
\hline $\begin{array}{l}\text { Integrating learning } \\
\text { and assessment }\end{array}$ & $\begin{array}{l}\text { Written feedback } \\
\text { can be judged } \\
\text { against the concrete } \\
\text { criteria of the } \\
\text { checklist }\end{array}$ & $\begin{array}{l}\text { Facilitates: } \\
\text { - formative } \\
\text { assessment } \\
\text { - summative } \\
\text { assessment }\end{array}$ & $\begin{array}{l}\text { Lack of: } \\
\text { - supervisors' } \\
\text { involvement in } \\
\text { summative } \\
\text { assessment } \\
\text { - assessment } \\
\text { dialogues }\end{array}$ & $\begin{array}{l}\text { Explicit roles in } \\
\text { learning and } \\
\text { assessment } \\
\text { Systematically } \\
\text { planned assessment } \\
\text { meetings }\end{array}$ \\
\hline
\end{tabular}

\section{Integrating learning and assessment}

There was general agreement among the supervisors that integrating learning and assessment could potentially support the development of self-directed learning, but they also indicated that, in practice, the assessment unit was underused. In fact, two supervisors didn't use the checklist regularly and five supervisors never looked at the checklist because they were not aware of their role in assessment nor were they trained in facilitating self-directed learning. Those who did use the assessment unit (7/15 R), particularly appreciated the competency-based assessment criteria, because the 
checklist highlighted students' strengths and weaknesses, which helped students and supervisors to identify learning opportunities, diagnose learning needs, formulate goals and develop a concrete plan of action for the upcoming period. The integration of learning and assessment also facilitated summative assessment because written feedback could be judged against the concrete criteria of the checklist: 'you have a tool that clearly shows: you started here, and now, in the final part of your third year, you are still at the same level'. Importantly, the majority of supervisors (12/15 R) emphasised that the MAFI should be regarded as a framework providing evidence that must be discussed during assessment meetings with students and their supervisors, taking up the responsibility for the self-directed learning and assessment process. One supervisor noticed that supervisors' motivation to write feedback will enhance when they are involved in the final assessment discussion. For the moment, assessment meetings at the end of the internship were rare because they were not planned systematically. Consequently, students and supervisors couldn't meet each other due to different time tables or high workload (11/15 R).

\section{DISCUSSION}

This study explored clinical supervisors' experiences with and perceptions of the impact of the MAFI and conditions for its effective use as a framework to facilitate students' self-directed learning and their supervision in clinical practice.

Supervisors' appreciation of the concrete descriptions of learning outcomes, is in line with studies supporting assessment of observable behaviours, ${ }^{31}$ and with studies stressing the value of a shared terminology to discuss competencies. ${ }^{10,32}$ The educational structure in MAFI facilitates diagnosing learning needs, by relating competencies to professional standards in the checklist. ${ }^{10}$ Supervisors' appreciation of the full range of MAFI competencies is consistent with research that stresses the need to cater for competencies that traditionally tend to remain out of focus. ${ }^{10,33}$ Thus, as learning outcomes are preset and specific, the MAFI-framework ensures that the midwives are fit for purpose. ${ }^{7}$

Second, the fact that supervisors reported that both students and supervisors took control of the learning and assessment process suggests that the MAFI can counteract a tendency, reported in the literature, for current feedback models to be teacher driven and one-way processes. ${ }^{12}$ MAFI stimulates self-regulated learning as students will take more initiative in activities that promote their learning, such as reflection and asking for 
feedback. When supervision starts with learner's reflection, a two-way process will follow.

Third, the fact that supervisors agreed that the MAFI promoted continuity of supervision is consistent with Archer's view that feedback should be set up along a continuum within a culture of feedback. ${ }^{12}$ This continuity emphasises the formative process of selfdirected learning and gives insight how learners use feedback to improve their future learning.

Supporting formative and summative assessment was the final MAFI goal. As we found in literature, the relationship between assessment and feedback remains complex and the function of assessment must be differentiated between formative and summative assessment. Formative assessment is specifically intended to provide feedback on performance to improve. ${ }^{14,15}$ Although supervisors' role in this formative process is well known, the results in this study indicate that supervisors' role in summative assessment deserves more attention. Supervisors felt not responsible for summative assessment and their reluctance to give fail judgments is in line with earlier research. ${ }^{34}$

Despite its potential and the supervisors' generally positive experiences, they also reported difficulties with the MAFI structured framework and mentioned a number of conditions that had to be met if the MAFI was to be effective in facilitating self-directed learning and it's supervision.

Although the perceived value of a competency-based educational structure, all the supervisors agreed that facilitating self-directed learning with MAFI was time consuming and complex. Some supervisors perceived that unravelling care giving situations into competencies could hinder the feedback process and the motivation to use MAFI due to lack of time, lack of training or the number of competencies. Further research on this topic is clearly needed.

Supervisors' remarks about conditions that should be met to realize the second MAFI goal, stimulating learners' active involvement and student centred supervision, were in line with earlier research advocating that effective feedback should be based on direct observation of student-patient interactions and not on hearsay. ${ }^{35,36}$ Direct observation means also participation in practical work and dialogue about the work. As argued by Wenger (1998), ${ }^{37}$ it is in the interaction between participation and dialogue that learners will master their performance in practice. ${ }^{38}$ Furthermore, direct observation can balance inaccuracies, so often observed in self-assessment. ${ }^{20}$ In contrast to studies reporting that students rarely ask for feedback, ${ }^{39}$ the supervisors indicated that, since 
the implementation of the MAFI, students have been asking for feedback more frequently.

In order to meet the third learning effect, promoting continuity in supervision, we propose that a formal role of 'feedback provider' should be defined for staff members, supervisors and teachers, accompanied by training. This is consistent with suggestions from the literature that clinical supervisors and teachers need to understand the importance of reflection as a valuable way of helping students make sense of their practice, and master facilitating competencies to promote self-directed learning. ${ }^{4,19,23}$ Clinical workplaces are challenged to create a feedback culture where learners are stimulated to submit reflections and health care workers are motivated to present a consistent behaviour in giving effective feedback, including negative feedback on behaviours. $^{14,23}$

Finally, the results suggest that an integrated learning and assessment instrument requires an integrated supervisory model with supervisors, feeling responsible for the formative process of developing ways of thinking in order to enhance and shape future practice (Schön, 1998), ${ }^{40}$ but also for summative assessment of competencies at the end of the internship. Engaging clinical supervisors in the final summative assessment discussions might enhance their motivation to facilitate formative learning and assessment with continuous effective feedback. This presents a promising avenue for further research in the domain of self-directed learning in competence-based education of all health care professionals involved in workplace learning during internships.

A limitation of the present study is the limited sample size and the setting of the study in one midwifery department in Belgium, which inevitably limits the generalizability of the results. Nevertheless, the participants expressed a variety of opinions. Not all of them appreciated the framework to the same extent and their educational and clinical expertise differed quite considerably.

\section{CONCLUSION}

The results of this study suggest that an integrated assessment and feedback framework can be a potentially powerful tool for facilitating self-directed learning and supervision in clinical practice. But, although the competency-based education structure of the MAFI is potentially able to facilitate students' development and active involvement in their learning as well as continuity of supervision, most supervisors appeared to under use the assessment unit, and the supervisors identified different 
conditions that would have to be met to achieve the expected effects. This appears to imply that those intending to implement an integrated learning and assessment framework should also dedicate considerable effort to create a positive assessment and feedback culture which is crucial for equipping students with the necessary skills for self-directed learning in the clinical workplace. 


\section{REFERENCES}

1. Sharples K, Moseley L. Learning to learn in practice: An evaluation of 35-day practice orientation programme. Nurse Educ Pract 2009;10(2),57-63.

2. Moss C, Grealish L, Lake S. Valuing the gap: A dialectic between theory and practice in graduate nursing education from a constructive educational approach. Nurse Educ Today 2010;30(4):327-332.

3. Knowles M. Self-Directed Learning: A Guide for Learners and Teachers. Chicago: Follet 1975.

4. Levett-Jones T. Self-directed learning: Implications and limitations for undergraduate nursing education. Nurse Educ Today 2005;25(5):363-368.

5. Yuan H, Williams B, Fang J, Pang D. Chinese baccalaureate nursing students' readiness for self-directed learning. Nurse Educ Today 2011;32(4):427-431.

6. Mann K. Theoretical perspectives in medical education: past experience and future possibilities. Med Educ 2011;45(1):60-68.

7. Timmins F. Take time to facilitate self-directed learning. Nurse Educ Pract 2008;8:302-305.

8. Lave J, Wenger E. Situated Learning: Legitimate Peripheral Participation. Cambridge: Cambridge University Press 1991.

9. Gignac-Caille O. Student and faculty perceptions of effective clinical instructors in ADN programs. J Nurs Educ 2001;40(8),347-353.

10. Harden R. Outcome-Based Education: The future is today. Med Teach 2007;29(7):625-629.

11. Zibrowski EM, Singh SI, Goldszmidt MA, Watling CJ, Kenyon CF, Schulz V, Maddocks HL, Lingard L. The sum of the parts detracts from the intended whole: competencies and in-training assessments. Med Educ 2009;43(8):741-748.

12. Archer J. State of the science in health professional education: Effective feedback. Med Educ 2010;44(1):101-108.

13. Norcini J, McKinley D. Assessment methods in medical education. Teach Teacher Educ 2007;23(3):239250.

14. Parboteeah S, Anwar M. Thematic analysis of written assignment feedback: Implications for nurse education. Nurse Educ Today 2009(7);29:753-757.

15. Sweet L, Glover P, PcPhee T. The midwifery miniCEX - A valuable clinical assessment tool for midwifery education. Nurse Educ Pract 2013;13(2):147-153.

16. Carver C, Scheier M. Attention and Self-regulation: a Control Theory Approach to Human Behaviour. New York: Springer 1981.

17. Gibbs G, Simpson C. Conditions under which assessment supports students' learning. Learning and teaching in Higher Education 2004;1:1-31.

18. Nicol D, Macfarlane-Dick D. Formative assessment and self-regulated learning: A model and seven principles of good feedback practice. Stud High Educ 2006;31(2):199-218.

19. Bulman C, Lathlean J, Gobbi M. The concept of reflection in nursing: Qualitative findings on student and teacher perspectives. Nurse Educ Today 2012;32(5):e8-13.

20. Davis D, Mazmanian P, Fordis M, Van Harris H., Thorpe K, Perrier L. Accuracy of physician selfassessment compared with observed measures of competence: a systematic review. JAMA 2006;296(9):1094-1102.

21. Eva K, Regehr G. I'll never play football and other fallacies of self-assessment. J Cont Educ Health Prof 2008;28(1):14-19.

22. Dannefer E, Henson L. The portfolio approach to competency-based assessment at the Cleveland Clinic Lerner College of Medicine. Acad Med 2007;82(5):493-502.

23. Coward $M$. Does the use of reflective models restrict critical thinking and therefore learning in nurse education? What have we done? Nurse Educ Today 2011;31(8):883-886. 
24. Wilkinson T, Challis M, Hobma S, Newble D, Parboosingh J, Sibbald R, Wakeford R. The use of portfolios for assessment of the competence and performance of doctors in practice. Med Educ 2002;36(10):918924.

25. Norcini J, Burch V. Workplace-based assessment as an educational tool: AMEE Guide no.31. Med Teach 2007;29(9):855-871.

26. Palmer E, Devitt P. Limitations of student-driven formative assessment in a clinical clerkship. A randomized controlled trial. BMC Medical Education 2008;8:29-35.

27. Embo M, Driessen E, Valcke M, van der Vleuten C. Assessment and feedback to facilitate self-directed learning in clinical practice of Midwifery students. Med Teach 2010;32(7):e263-269.

28. Miles B, Hubermann A. Qualitative Data Analysis. Thousand Oaks, CA: Sage publications, 1994.

29. Rice P, Ezzy D. Qualitative Research Methods. Victoria, Australia: Oxford University Press 2000.

30. Guba E, Lincoln Y. Fourth generation evaluation. Newbury Park, CA: Sage publications 1989.

31. Hauer K, Holmboe E, Kogan J. Twelve tips for implementing tools for direct observation of medical trainees' clinical skills during patient encounters. Med Teach 2011;33(1):27-33.

32. Pangaro L. Investing in descriptive evaluation: a vision for the future of assessment. Med Teach 2000;22(5):478-481.

33. Smith S, Goldman R, Dollase R, Scott Taylor J. Assessing medical students for non-traditional competencies. Med Teach 2007;29(7):711-716.

34. Dudek N, Marks M, Regehr G. Failure to fail: the perspectives of clinical supervisors. Acad Med 2005;80(10 Suppl):s84-87.

35. Branch W, Paranjape A. Feedback and Reflection: Teaching methods for clinical settings. Acad Med 2002;77(12):1185-1188.

36. Kilminster S, Cottrell D, Grant J, Jolly B. AMEE Guide No. 27: Effective educational and clinical supervision. Med Teach 2007;29(1),2-19.

37. Wenger E. Communities of Practice. Learning, Meaning, and Identity. Learning in Doing: Social, Cognitive and Computational Perspectives. Cambridge: University Press 1998.

38. Solvoll B. Heggen K. Teaching and learning care - Exploring nursing students' clinical practice. Nurse Educ Today 2010;30(1):73-77.

39. van der Hem-Stokroos H, Daelmans H, van der Vleuten C, Haarman H, Scherpbier A. A qualitative study of constructive clinical learning experiences. Med Teach 2003;25(2),120-126.

40. Schön DA. Educating the Reflective Practitioner. California: Jossey-Bass Inc 1998. 


\section{CHAPTER 4}

\section{Scaffolding reflective learning in clinical practice: \\ A comparison of two types of reflective activities}

Mieke Embo

Erik W. Driessen

Martin Valcke

Cees P.M. van der Vleuten

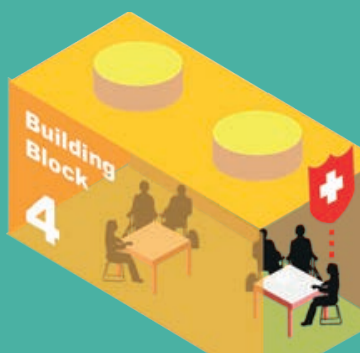

Medical Teacher 2014;36(7):602-607. 


\section{ABSTRACT}

Background: The development of reflective learning skills is a continuous process that needs scaffolding. It can be described as a continuum, with the focus of reflection differing in granularity from recent, concrete activities to global competency development.

Aim: To explore learners' perceptions regarding the effects of two reflective writing activities designed to stimulate reflection at different degrees of granularity during clinical training.

Methods: Totally 142 respondents (students and recent graduates) completed a questionnaire. Quantitative and qualitative data were triangulated.

Results: Immediate reflection-on-action was perceived to be more valuable than delayed reflection-on-competency-development because it facilitated day-to-day improvement. Delayed reflection was perceived to facilitate overall self-assessment, self-confidence and continuous improvement, but this perception was mainly found among graduates. Detailed reflection immediately after a challenging learning experience and broad reflection on progress appeared to serve different learning goals and consequently require different arrangements regarding feedback and timing.

Conclusions: Granularity of focus has consequences for scaffolding reflective learning, with immediate reflection on concrete events and reflection on long-term progress requiring different approaches. Learners appeared to prefer immediate reflection-onaction. 


\section{INTRODUCTION}

The development of reflective learning has been described as essential for experiential learning in clinical practice. ${ }^{1}$ Definitions of reflection generally relate to review, interpretation and understanding of experiences to guide present and future behaviour. ${ }^{2-6}$ Education programmes use various activities to promote reflection but little is known about their learning effects. ${ }^{7}$

Reflective writing has been described as an effective activity to promote reflective learning ${ }^{4,8}$ but it does not always lead to critical reflection and methods used, such as journals and portfolios, have met with mixed student responses. ${ }^{3,6,9}$ Nevertheless, there seems to be general agreement about the elements that are most influential in developing reflection. Activities involving documentation of reflective activities will only foster in-depth reflection if they are: (1) related to relevant experiences; (2) clear and meaningful for learning; (3) flexible to address individual learning needs; (4) guided by well-informed tutors who promote reflective learning; (5) scaffolded by feedback based on reading of the written reflections; (6) assessed using qualitative criteria; (7) discussed with tutors and peers; (8) implemented in a safe learning environment and (9) supported by the availability of adequate time for reflection and feedback. ${ }^{2,3,10-12}$

Reflective skills are essential for the development of professionals who are competent, self-aware and have the ability to self-monitor and self-assess their performance and engage in continuing learning throughout their professional careers. ${ }^{5}$ Reflective learning in the workplace is a continuous process aimed at guiding present and future behaviour $^{4}$ and varying in granularity of focus from a recent concrete activity to global performance over a longer period of time. Models of reflective learning differ depending on the granularity of focus that is aimed for. According to Schön, there is a difference between 'reflection-in-action' and 'reflection-on-action'. ${ }^{13}$ Sagasser et al. $(2012)^{14}$ found that learning in practice occurred in a short and a long loop, both involving selfmonitoring. Their analysis revealed that trainees reflected during and after activities, which suggests that their self-monitoring may reflect Schön's 'reflection-in-action' (short loop) and 'reflection-on-action' (long loop). This concept of self-monitoring diverged from Eva and Regehr (2011) ${ }^{15}$ who defined reflection-in-action as a process of self-monitoring performance in the moment and reflection-on-action as a more integrative process of self-assessment, drawing on all relevant experience to date, respectively. Van Kammen developed a model for discussing reflection viewing reflection as interaction between reflection on concrete actions and reflection on competencies, the latter being defined as a more abstract thinking process than the former. ${ }^{16}$ In response to these two types of reflection, education programmes have introduced a 
variety of reflective learning activities. ${ }^{3,17}$ In general, strategies focusing on concrete actions are described as a substantially more accurate mechanisms for ensuring safe and effective performance, because reflection on a day-to-day basis and the corresponding feedback facilitate students' awareness of where they have gone wrong and how they can improve. ${ }^{8,15,16}$ Although reflection-on-competency-development is a more abstract and complex process than reflection-on-action, Eva and Regehr consider reflection on progress essential for continuous professional development. ${ }^{15,18}$

We conducted a study to explore students' perceptions of the effectiveness of these two reflective processes for their learning. For this purpose, we collected and analysed perceptions of learners who had experienced two reflective activities during clinical training: moment-by-moment reflection on concrete recent actions and delayed reflection on overall competency development during longer periods of three to six weeks. Our main research question was: 'in the perception of students, what are the learning effects of reflective writing aimed at 1 : improving actions in the moment (reflection-on-action) and 2: competency development over a longer period of time (reflection-on-competency-development), and which approach do students value the most?

\section{METHOD}

\section{Context}

The study was conducted among students of the undergraduate programme of the midwifery department of University College Arteveldehogeschool Ghent (Belgium). The three-year programme in Midwifery that is offered by the school consists of a modular, competency-based curriculum based on a framework on 24 medical and generic competencies, related to six professional roles. From the end of the first year students engage in workplace-based learning during clinical internships. During the internships, students are guided and supported by a clinical supervisor in the workplace and a teacher from the Midwifery department. Both the clinical supervisor and the teacher take up the educational (supervision of the learning process) and the clinical role (provision of patient care with the student). Normally, teachers are more focused on the overall learning process and clinical supervisors emphasise the observation during patient care. Students are stimulated to reflect on concrete activities and global competency development by a combination of reflective writing on actions immediately after their occurrence and reflective writing on longitudinal competency development. For immediate reflection on actions, students are instructed to write daily reflections on 
their performance in the workplace. They are also encouraged to ask for an immediate feedback on these actions ${ }^{19}$ and required to submit their written reflections to their supervisor or teacher and ask for their feedback. For reflection on competency development students are asked at the end of each internship to produce written reflections on their competency development during the internship and to use these reflections to set learning goals for the next internship. This type of reflection starts at the end of the first, six-week, internship at the end of year 1, and continues at three-week intervals during years 2 and 3 , resulting in five and seven written reflections on competency development in years 2 and 3, respectively. The clinical supervisor and the teacher from the Midwifery department are instructed and trained to give students verbal and written feedback on activities they have performed and on their reflections on these activities. Assessment of reflection is based on pre-set criteria, measuring learners' authenticity and level of reflective thinking. The written reflections on competency development are read only by the teachers from the department, who provide verbal and written feedback on the development of students' learning processes and on students' reflections on it. The reflections on action are assessed summatively by a school committee using ratings on a scale from 0 to 20 . The teachers rate students' reflections on competency development using the same scale. This score accounts for $5 \%$ of the final score.

\section{Design}

We administered a short paper-based questionnaire to elicit perceptions of the effects and value of the two types of reflection. Respondents were asked to rate the overall value of the two activities on a 10-point scale (1=very low; 10=very high). Perceptions of the learning effects of both types of reflection were elicited by asking for each type of reflection the following open-ended questions: (1) describe what you learn from reflective writing; (2) describe elements inhibiting and stimulating learning. A pilot test of the questionnaire among third-year students resulted in one minor change in lay-out and showed that the questions were easy to understand and elicited pertinent data.

\section{Data collection}

Both types of reflective writing were introduced in the curriculum in 2007. Invitations to participate in the study were sent to all present and former students who had experienced these activities: all current undergraduate students and midwives one year after graduation. Between May and September 2011, the questionnaire was completed by 146 respondents (overall response rate: 53\%; first-year students 32/76, second-year students 57/77, third-year students 36/62, graduates 21/58). Students in years 2 and 3 
completed the questionnaire in the classroom in the presence of a teacher who was not involved in the research project. First-year students received the questionnaire from the teacher during the first week of their internship and were asked to complete and return it in a closed envelope at the end of the internship. The graduates received the questionnaire by post. A reminder was sent by e-mail.

\section{Data analysis}

The scores were entered into SPSS for Windows, Release 20.0 (IBM SPSS Statistics, NY). Paired sample $t$-tests were performed to compare the perceived value of the learning effects of the two different types of reflection: reflection-on-action and reflection-oncompetency-development. Effect sizes were calculated for the differences between the two means. Effect sizes are an increasingly important 'scale-free' index used to quantify the degree of practical significance of study results. ${ }^{20}$

The answers to the open-ended questions were analysed qualitatively to identify patterns and themes. All the answers were typed up and analysed using ATLAS.ti 6.0 software (Scientific Software Development $\mathrm{GmbH}, 2006)$. The first author and a research assistant performed qualitative content analysis. ${ }^{21}$ The answers were read through several times to gain an overall idea of the content. Texts relating to learning effectiveness and texts on inhibiting and stimulating conditions were analysed separately for the two types of reflective activities. Units of meaning, i.e. words, sentences and paragraphs expressing the same meaning, were identified, condensed, abstracted and coded. Based on commonalities, the codes were sorted into categories, and based on the researchers' interpretations of the underlying meaning of the categories, themes were developed. The latter process involved moving back and forth between full text, codes and categories.

\section{Ethical considerations}

The Ethical Review Board of the Dutch Association for Medical Education (NVMO) approved the study. Prior to the study, all participants received information about the study and signed an informed consent form. They were assured of confidentiality and anonymity when the findings were used for discussions or published in any form. The students were free to withdraw from the study at any time. Data were used for educational research purposes only. Participation was voluntary and participants received no compensation. 


\section{RESULTS}

We first present the quantitative results followed by the qualitative results. Table 1 displays the mean scores (on a 10-point scale) on the perceived learning value of the two types of reflective activities. The score for immediate reflective writing on actions was generally higher compared to the score for reflective writing on competency development at the end of an internship. Second year students, in particular, gave very low scores on the learning value of reflection-on-competency-development. It was not until after graduation that respondents, retrospectively, valued delayed reflection more positively, although the mean score was moderate $(6.42 / 10$, SD 1.66). A paired t-test showed that the differences between the two reflective writing activities were statistically significant for all respondents except for graduates. The differences decreased from year 2 onwards. Effect sizes were large for all student groups (year 1: 0.98; year 2: 1.48; year 3: 1.10), but low for the graduates (0.26).

\section{Reflection-on-action}

The main reason the respondents gave for their preference for immediate reflectionon-action was that it made them pause, look back on concrete actions and record information about their learning, which provided insight into their strengths, weaknesses and learning needs. This reflective writing activity enabled them to take immediate remedial steps to improve their performance in the next action: 'The daily reflections help both in noticing mistakes and difficulties and in making adjustments at an early stage so that you reach the competency level faster' (UG1-R28). Students particularly appreciated that immediate reflection on clinical experiences stimulated their learning during internships: 'Because I was made to reflect on a daily basis, I made a lot more progress during my six-week internship' (UG1-R23).

Another effect of immediate reflection-on-action mentioned by respondents was that it challenged them to ask for feedback, which, in turn, stimulated supervisors to give verbal feedback on observed performances. Nevertheless, one-third of respondents perceived a lack of feedback, especially written feedback on their written reflections. Respondents perceived different barriers preventing supervisors from giving feedback: lack of time, lack of motivation and the competency-based structure of the feedback form. The latter is illustrated by the following quote: 'Competencies are positive to note progress. However, sometimes it would be easier to write reflections of the day on a blank sheet. This would also make it easier for midwives who are unfamiliar with the competencies to write feedback' (UG1-R10). Senior students and graduates reported this phenomenon more often than junior students. 
Table 1: Perceived learning value of reflection-on-actions versus reflection-on-competency-development

\begin{tabular}{|c|c|c|c|c|c|c|c|c|c|}
\hline & \multirow[b]{2}{*}{$\mathrm{n}$} & \multicolumn{2}{|c|}{$\begin{array}{l}\text { Reflection-on- } \\
\text { action }\end{array}$} & \multicolumn{2}{|c|}{$\begin{array}{l}\text { Reflection-on- } \\
\text { competency-development }\end{array}$} & \multicolumn{3}{|c|}{ Paired sample $t$-test } & \multirow[t]{2}{*}{ Effect Size } \\
\hline & & Mean & SD & Mean & SD & $t$ & df1 & sig & \\
\hline year 1 & 32 & 7.28 & 1.08 & 5.70 & 1.99 & 4.31 & 31 & 0.000 & 0.98 \\
\hline year 2 & 57 & 6.85 & 1.20 & 4.57 & 1.81 & 8.06 & 56 & 0.000 & 1.48 \\
\hline year 3 & 36 & 6.88 & 1.23 & 5.20 & 1.76 & 5.57 & 35 & 0.000 & 1.10 \\
\hline grad. & 21 & 6.88 & 1.77 & 6.42 & 1.66 & 0.74 & 20 & 0.466 & 0.26 \\
\hline
\end{tabular}

$\mathrm{N}=$ number of respondents; Mean: on a score from 1 to 10 ; SD=standard deviation; $t=$ paired samples $t$-test; $\mathrm{df}=$ degrees of freedom; sig=significant at $\mathrm{p}<0.0001$; Effect size= Effect size estimate for the differences between two means.

Although most respondents emphasised the value of daily reflective writing, some respondents indicated that they thought daily reflection was excessive, especially considering that experiences worth reflecting on did not occur every day. Respondents also reported that reflecting honestly upon weaknesses that were revealed during challenging experiences was essential for learning, but caused tension between 'writing fair reflections' and 'fear of summative assessment': 'Because this is part of your assessment, you tend to write about experiences that you believe will give a positive assessment. You don't really learn from this. A lot depends on the strength of the relationship you have with your supervisor. When you make a big mistake, you are afraid to reflect on it for fear it will disadvantage you during the final assessment of the placement. Nevertheless, these are the very learning experiences on which you should reflect' (Grad-R12).

\section{Reflection-on-competency-development}

Students gave different reasons for their lower appreciation of reflection-oncompetency-development at the end of internships.

Respondents frequently mentioned their overriding preoccupation with immediate performance during the present internship and that reflecting on competency development had no direct effect on their day-to-day performance. First- and second-year students, in particular, felt that the daily reflections facilitated their awareness of competency development during the internship. Consequently, reflection on competency development at the end of an internship seemed a mere repetition of the daily reflections and students felt that they wrote reflections on competency development mainly for the benefit of their supervisor, the assessment and their portfolio. 
Another frequently reported reason for not valuing reflections on competency development was the perceived time investment, which appeared to be associated with the frequency of reflection, the writing activity, summative assessment and the competency structure of reflective writing assignments. The majority of respondents felt that writing reflections every three weeks took up too much of their supervisors' and their own time. Time constraints and little progress often caused respondents to resort to 'copying previous reflections' or 'just putting something down to get it over with'. One in five respondents suggested that the learning effect might be enhanced by reducing the frequency of reflective writing, e.g. to once or twice a year. As with reflection-onaction, respondents reported a lack of feedback on their progress. To deal with this, it was suggested to replace written reflections with a reflective dialogue, which might facilitate learners' reflections and supervisors' feedback on competency development. As one of the respondents put it: 'This seems to me to result in less work to write for the student, less time to read for the supervisor and a more fair reflection with feedback' (Grad-R2). Additionally, a reflective dialogue might reduce the perceived imbalance between time investment and weight in summative assessment: 'The reflection report takes about one day to complete and it is only $5 \%$ of the points' (UG2-R4). Finally, respondents reported that the structure of the writing assignment required them to reflect on all the competencies, whereas not all competencies were relevant to or addressed during all the internships.

Competency-related reflection was valued mostly by graduates, who retrospectively saw the merits of this type of reflective activity. Graduates recognised more often that, during undergraduate training, reflective writing on competency development was useful because it facilitated longitudinal learning across internships: 'I learnt to deal with a longer period of training and feedback. I made a global analysis of my own actions and that often had a positive effect on my next internship' (Grad-R15).

\section{DISCUSSION}

We collected and analysed quantitative and qualitative data on the perceptions of students and recent graduates of an undergraduate midwifery programme regarding the learning effects of activities to stimulate reflection-on-action and reflection-oncompetency-development.

Students were required to engage in both types of reflective activities, and the results revealed a marked preference for reflection-on-action. Respondents valued the immediate applicability of this type of reflection to improve their learning and perfor- 
mance in the workplace, whereas they did not experience a similar direct effect from reflection on overall competency development. These results are consistent with the work of Eva and Regehr (2011), ${ }^{15}$ who reported an apparent divergence between poor overall self-assessment and effective self-monitoring. This divergence may be similar to respondents' different perceptions of the two types of reflection that we found in the present study.

In the introduction we listed the most influential enabling elements for the development of reflective learning. New in this study are the perceptions of learners that reflective writing activities aimed at different learning goals may require different learning conditions, relating to timing and content of reflection and to feedback. We will discuss these conditions consecutively.

As is so often the case in clinical education, time or rather the lack of it was an important reason given by respondents to explain why they did not perceive reflection on competency development to be very useful. The strict scheduling of both types of reflection during internships - immediate reflection on actions (daily) and reflection on competency development (every three weeks) - made reflection highly labour intensive for both students and supervisors. The short time interval between reflections on competency development may also have prevented students from appreciating the different purposes of the two types of reflection. Respondents suggested that a stronger distinction might be made between detailed reflection immediately after challenging learning experiences and global reflection after effective progress, which could be achieved by increasing the intervals at which the latter type of reflection was required. Increasing the intervals will reduce the amount of reflection required. This amount of reflection may have led to some quite superficial and ritualised reflections. As discussed by Boud and Walker (1998), ${ }^{22}$ consideration of the context in which reflective action is engaged is a challenge in using reflection.

The second difference in learning conditions relates to feedback. An interesting effect of daily reflection on action was that it encouraged students to ask for feedback and supervisors to provide feedback on observed actions. Nevertheless, respondents consistently indicated that they would like to receive more written feedback. This applied for both types of reflection but there appears to be a difference between the two types of reflection with regard to content and delivery of feedback. In this respect the results of the present study appear to be consistent with research indicating that different reflective processes may require different feedback: specific feedback on performance versus general feedback on the learning process. ${ }^{23}$ The distinction between specific and general feedback refers to feedback content, but the respondents 
in this study distinguished also between different ways of delivering feedback. For feedback on progress, they preferred a progress dialogue over written feedback. Trainees in the long self-regulation loop also valued progress meetings, because these enabled them to discuss their progress and learning plans. ${ }^{14}$

First-year students were most positive about how structuring reflection-on-action facilitated reflective learning. As students got more experienced, however, they preferred a less structured format over the fixed structure they had to use. These results confirm evidence that flexibility is essential to address individual learning needs and foster in-depth reflective learning. ${ }^{12,24}$ We suggest further research exploring the effect of the feedback form's structure on the type, and perhaps quality of feedback provided.

The limited sample size, the response rate of $53 \%$, the short questionnaire and the setting of the study in one Midwifery department in Belgium inevitably limits the generalizability of the results. The response rate was moderate and we cannot exclude that respondents might be more orientated to one reflection approach. Also the results may be specific for an educational setting where both types of reflection are used simultaneously. This means we have to be careful in generalising the findings to learning environments where only one type of reflection is used.

\section{CONCLUSION}

Developing reflective learning in clinical practice is a continuous process, and this study gives some insight into effects of the granularity of the focus of reflection on learner's perceptions of its usefulness. Immediate detailed reflection on actions was appreciated the most. Most learners were primarily focused on direct improvement of specific actions, which was most effectively supported by reflection-on-action, especially as it stimulated them to ask for feedback. Reflecting on more global long-term competency development was less appreciated, because it had no clear and direct effect on improvement of day-to-day performance. The results suggest that since the two types of activities to support reflective learning address different learning goals they probably also require different underlying educational arrangements, specifically in respect of the length of the reflective learning cycle and the provision of feedback. 


\section{REFERENCES}

1. Driessen E, Overeem K, Tartwijk van E. Learning from practice: Mentoring, feedback, and portfolios. In: Dornan T, Mann K, Scherpbier A, Spencer J (Eds.). Medical Education, Theory and Practice. Churchill Livingstone: Elsevier 2010:211-227.

2. Mann K, Gordon J, MacLeod A. Reflection and reflective practice in health professions education: A systematic review. Adv Health Sci Educ 2009;14(4):595-621.

3. Wald HS, Davis SW, Reis SP, Monroe AD, Borkan JM. Reflecting on reflections: Enhancement of medical education curriculum with structured field notes and guided feedback. Acad Med 2009;84(7): 830-837.

4. Wald HS, Reis SP. Beyond the Margins: Reflective writing and development of reflective capacity in medical education. J Gen Intern Med 2010;25(7):746-9.

5. Mann KV. Theoretical Perspectives in medical education: Past experience and future possibilities. Med Educ 2011;45(1):60-68.

6. Vivekananda-Schmidt P, Marshall M, Stark P, Mckendree J, Sandars J, Smithson S. Lessons from medical students' perceptions of learning reflective skills: A multi-institutional study. Med Teach 2011;33(10):846-850.

7. Sargeant JM, Eva KW, Armson H, Chesluk B, Dornan T, Holmboe E, Lockyer JM, Loney E, Mann KV, van der Vleuten CPM. Features of assessment learners use to make informed self-assessments of clinical performance. Med Educ 2011;45(6):636-647.

8. Parboteeah S, Anwar M. Thematic analysis of written assignment feedback: Implications for nurse education. Nurse Educ Today 2009;29(7):753-757.

9. Driessen E, van Tartwijk J, Overeem K, Vermunt JD, van der Vleuten CPM. Conditions for successful reflective use of portfolios in undergraduate medical education. Med Educ 2005;39(12):1230-1235.

10. Driessen E. Portfolio critics: Do they have a point? Med Teach 2009;31(4):279-281.

11. Li ST, Favreau MA, West DC. Pediatric resident and faculty attitudes toward self-assessment and selfdirected learning: A cross-sectional study. BMC Med Educ 2009;9:16.

12. van der Vleuten CPM, Schuwirth LWT, Driessen EW, Dijkstra J, Tigelaar D, Baartman LKJ, Van Tartwijk J. A model for programmatic assessment fit for purpose. Med Teach 2012;34(3):205-214.

13. Schön D. Educating the Reflective Practitioner. San Francisco, CA: Jossey-Bass 1987.

14. Sagasser MH, Kramer AWM, van der Vleuten CPM. How do postgraduate GP trainees regulate their learning and what helps and hinders them? A qualitative study. BMC Med Educ 2012;12: 67.

15. Eva KW, Regehr G. Exploring the divergence between self-assessment and self-monitoring. Adv Health Sci Educ 2011;16(3):311-329.

16. Van Tartwijk J, Driessen E, Hoeberigs B, Kösters J, Ritzen M, Stokking K, van der Vleuten CPM. Werken met een elektronisch portfolio [Using an electronic portfolio]. Groningen/ Houten, The Netherlands: Wolters-Noordhoff 2003:53-56.

17. Li ST, Paterniti DA, Co JP, West DC. Successful self-directed lifelong learning in medicine: A conceptual model derived from qualitative analysis of a national survey of pediatric residents. Acad Med 2010;85(7):1229-1236.

18. Eva KW, Regehr G. Self-assessment in the health professions: A reformulation and research agenda. Acad Med 2005;80(10 Suppl):s46-54.

19. Embo MPC, Driessen EW, Valcke M, van der Vleuten CPM. Assessment and feedback to facilitate selfdirected learning in clinical practice of Midwifery students. Med Teach 2010;32(7):e263-269.

20. Hojat M, Xu G. A Visitor's Guide to Effect Sizes. Adv Health Sci Educ 2004;9(3):241-249.

21. Graneheim UH, Lundman B. Qualitative content analysis in nursing research: Concepts, procedures and measures to achieve trustworthiness. Nurse Educ Today 2004;24(2):105-112.

22. Boud D, Walker D. Promoting reflection in professional courses: The challenge of context. Stud Higher Educ 1998;23(2):191-206. 
23. Hirsch M, Gabriel S. Feedback strategies: Critique and evaluation of oral and written assignments. J Accounting Educ 1995;13(3):259-279.

24. Driessen E, van Tartwijk J, van der Vleuten CPM, Wass VJ. Portfolios in medical education: Why do they meet with mixed success? A systematic review. Med Educ 2007;41(12):1224-1233. 



\section{CHAPTER 5}

Relationship between reflection ability and clinical performance:

A cross-sectional and retrospective-longitudinal correlation cohort study in Midwifery

Mieke Embo

Erik W. Driessen

Martin Valcke

Cees P.M. van der Vleuten

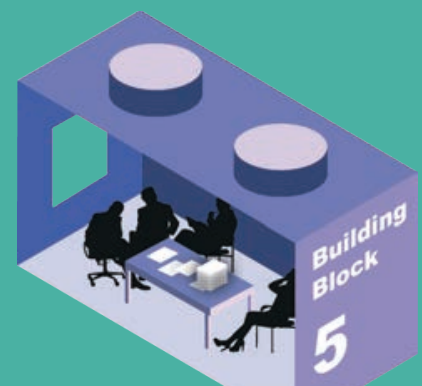




\section{ABSTRACT}

Background: Increasingly, reflection is highlighted as integral to core practice competencies but empirical research into the relationship between reflection and performance in the clinical workplace is scarce.

Aim: This study investigated the relationship between reflection ability and clinical performance.

Methods: We designed a cross-sectional and a retrospective-longitudinal cohort study. Data from first, second and third year midwifery students were collected to study the variables 'clinical performance' and 'reflection ability'. Data were analysed with SPSS for Windows, Release 20.0. Descriptive statistics, Pearson's Product Moment Correlation Coefficients $(r)$ and $r^{2}$ values were computed to investigate associations between the research variables.

Results: The results showed a moderate observed correlation between reflection ability and clinical performance scores. When adopting a cross-sectional perspective, all correlation values were significant $(p<0.01)$ and above 0.4 , with the exception of the third year correlations. Assuming perfect reliability in the measurement, the adjusted correlations, for year 2 and year 3 indicated a high association between reflection ability and clinical performance $(>0.6)$. The results based on the retrospective-longitudinal data set explained a moderate proportion of the variance after correction for attenuation. Finally, the results indicate that 'reflection ability' scores of earlier years are significant related with 'clinical performance' scores of subsequent years. These results suggest that 1 ) reflection ability is linked to clinical performance; 2) that written reflections are an important, but not the sole way to assess professional competence and that 3 ) reflection is a contributor to clinical performance improvement.

Conclusions: The data showed a moderate but significant relationship between 'reflection ability' and 'clinical performance' scores in clinical practice of midwifery students. Reflection therefore seems an important component of professional competence. 


\section{INTRODUCTION}

The midwifery professional (i.e. the fully qualified midwife) is an individual who has met the International Confederation of Midwives (ICM) Definition of a Midwife, ${ }^{1}$ and who has been educated and who has demonstrated competency in performance of the ICM Essential Competencies for Basic Midwifery Practice. ${ }^{2}$ Reflection is increasingly highlighted as an integral part of professional competence. ${ }^{3,4}$ It is generally assumed that reflective practice, that is, the willingness of students to think critically and to engage themselves in reflection upon their professional activities, contributes to the performance improvement. ${ }^{5-8}$ The notion of reflection as a contributor to performance improvement has its roots in the work of John Dewey. Dewey's philosophy (1938) ${ }^{9}$ proposes a theory that puts personal experiences at the centre of education. Sound educational experiences guarantee continuity and interaction between the learner and what is learned. The challenge for experience-based education is to provide learners with quality experiences that result in growth. A key element of experience-based learning is that learners are invited to analyse their experiences by reflecting, evaluating and reconstructing them. Building on earlier experiences, this analysis helps drawing meaning from new experiences. These explicit deliberations upon experiences may lead to further action. ${ }^{10,11}$ Interest in the theme of reflection with the goal of improving clinical performance has seen an exponential growth. However, hardly any empirical research has been conducted into the relationship between reflection and performance. ${ }^{3,12,13}$

The relationship between reflection and performance is part of the definition of professional competence: 'the habitual and judicious use of communication, knowledge, technical skills, clinical reasoning, emotions, values, and reflection in daily practice for the benefit of the individual and the community being served. ${ }^{14}$ Within this definition, reflection is identified as a core skill for professional development. ${ }^{3,15}$ Reflection is intended to deepen understanding and to explore the broader context of experience. ${ }^{12,16}$ Although a recent study by Lew and Schmidt $(2011)^{13}$ found that the self-reflection resulted in limited improvement in academic performance, there is evidence that reflection can help learners in understanding and assimilating new concepts, contextualising learning and enabling performance improvement. ${ }^{12,17-21}$

As reflection does not develop automatically, health care educators look for educational strategies promoting the development of the reflective capacity as early as possible in the training process. In this context, reflective writing has been described as an effective mechanism promoting self-reflection within medical education. ${ }^{3,22,23}$ However, research about reflective writing in medical education has remained largely anecdotal or was 
based on student self-reporting. ${ }^{24}$ A review concluded that reflection research is still at an early stage and that exploratory research approaches are appropriate to develop deeper understanding of reflective learning and how this is related to performance improvement. $^{20}$

The purpose of the present study was to investigate the relationship between reflection ability and clinical performance. The research question, then, was: Is there a relationship between reflection ability and clinical performance? We used clinical performance scores as the best proxy of professional competence. This is in line with While $(1994)^{25}$ who makes an important distinction between the concepts of 'competence' and 'performance' in nursing and midwifery. She concluded that as competence is concerned with perceived skills, it cannot be directly measured, whereas performance as actual situated behaviour is open to measurement and reflects what midwives and nurses actually do in clinical practice. ${ }^{26}$ We analysed clinical performance data both cross-sectionally and longitudinally to study the relationship with reflective ability.

\section{METHOD}

\section{Context}

The Midwifery department of the University College Arteveldehogeschool Ghent (Belgium) offers a three-year undergraduate competency-based programme (corresponding 180 credit points). According to the European Directives, clinical placement is an essential phase of the midwifery programme during which students develop their competencies in authentic clinical environments. Students attend clinical placements in each of the three years of the programme (corresponding 70 credits) and in different settings (table 1). Clinical placement is based on an integrated reflective learning and assessment strategy. ${ }^{27}$ In order to promote reflective learning, students are instructed to reflect on their competency development at the end of each clinical placement. These written reflection assignments are scored from 1 to 20 by a clinical teacher according to preset assessment criteria. Clinical teachers are practitioners that observe learners in the workplace setting and take a responsibility in their assessment. The criteria assess the effectiveness of the reflection cycle on clinical performances and on competency development. An important criterion is whether the students' reflections are authentic. Therefore, the clinical teacher and the clinical supervisors who observed the student assess these reflections. These scores are used in this study as the 'reflection ability' data set. Assessment of clinical performances is based on a competencybased rating scale. Each competency consists of a set of context-specific assessment 
criteria. In the rating scale, different levels in competency mastery are expected for year 1 , year 2 and year 3 . The clinical supervisor and the clinical teacher for each clinical placement assess the student's performance with the help of the rating scale. The school assessment committee aggregates pass/fail judgements on individual competency level into a final judgement on midwifery competence (score from 1 to 20). These scores are used in this study as the 'clinical performance' data set. The school assessment committee consists of all clinical teachers involved in the programme. Learners are informed about the score assigned by the school assessment committee and there is an opportunity to ask for feedback from clinical teachers. In this way, they can be seen as learning aids, providing feedback and guidance for further workplace learning.

Table 1. Clinical placements

\begin{tabular}{|c|c|c|c|c|}
\hline $\begin{array}{l}\text { Undergraduate } \\
\text { year }\end{array}$ & $\begin{array}{l}\text { Clinical placements } \\
\text { (= setting) }\end{array}$ & $\begin{array}{l}\text { European Credit Transfer } \\
\text { System (ECTS }=\text { credits) }\end{array}$ & Weeks & $\begin{array}{l}\text { Effective working } \\
\text { hours on the ward }\end{array}$ \\
\hline 1 & Maternity ward & 10 & 6 & 226 \\
\hline \multirow[t]{4}{*}{2} & Maternity ward & 5 & 3 & 113 \\
\hline & Delivery ward & 10 & 6 & 226 \\
\hline & Gynaecology ward & 5 & 3 & 113 \\
\hline & Neonatal low care & 5 & 3 & 113 \\
\hline \multirow[t]{5}{*}{3} & Maternity ward & 5 & 3 & 113 \\
\hline & Delivery ward & 15 & 9 & 339 \\
\hline & $\begin{array}{l}\text { Perinatal care in the first } \\
\text { echelon }\end{array}$ & 5 & 3 & 113 \\
\hline & Neonatal high care & 5 & 3 & 113 \\
\hline & Minor: choice & 5 & 3 & 113 \\
\hline TOTAL & & 70 ECTS & 42 weeks & 1582 hours \\
\hline
\end{tabular}

* The undergraduate midwifery bachelor programme consists of 180 ECTS (= 60 ECTS for each undergraduate year)

\section{Data collection}

Data from first, second and third year students were collected to study the variables 'clinical performance' and 'reflection ability'. We designed a cross-sectional and a retrospective-longitudinal cohort study to answer the research question. This combined design was important due to the high dropout rate in the first year. In Belgium, with the exception of medicine and dentistry, no entry requirements are set other than the diploma of secondary education to start most higher education programmes. Conse- 
quently between $25 \%$ and $45 \%$ of starting students leave during the first year of the programme. In the cross-sectional design, all the students who did a clinical placement in the first year, were included, even those who later left the programme. This is different from the retrospective-longitudinal design in which only data are included of graduates that completed the three consecutive years.

Thus, data were collected in two ways: (1) the cross-sectional data were collected in September 2013 from all first $(n=69)$, second $(n=50)$ and third $(n=50)$ year students who completed their clinical placements in the academic year 2012-2013; (2) the retrospective-longitudinal data were collected from a sample of 95 students who graduated in September $2012(n=43)$ and September $2013(n=52)$ and incorporated also the data of their involvement in the study programme in the earlier two years (starting in September 2009).

\section{Data analysis}

Data were analysed with SPSS for Windows, Release 20.0. Descriptive statistics, Pearson's Product Moment Correlation Coefficients $(r)$ and $r^{2}$ values were computed to investigate associations between the research variables: 'clinical performance' scores and 'reflection ability' scores. A significance level of $p<0.05$ was used, and $r$ values of 0 to 0.2 were generally considered weak, 0.3 to 0.6 moderate, and 0.7 to 1 strong. ${ }^{28}$ Reliability coefficients were estimated (Cronbach's alpha) based on the repeated assessment across clinical placements. On the basis of the observed correlations and reliabilities, true correlations were estimated by correcting for attenuation. ${ }^{29}$

\section{Ethical considerations}

The Ethical Review Board from the Dutch Association of Medical Education approved this study (NERB dossier number 272).

\section{RESULTS}

This section starts with an overview of the descriptive results. Table 2 represents summary statistics for 'clinical performance' and 'reflection ability' scores for both the cross-sectional and the retrospective-longitudinal data. 
Table 2 Summary statistics for reflection ability and clinical performance scores

\begin{tabular}{|c|c|c|c|c|c|}
\hline & $\begin{array}{l}\text { Students } \\
\text { (n) }\end{array}$ & $\begin{array}{l}\text { Minimum } \\
\text { score }\end{array}$ & $\begin{array}{l}\text { Maximum } \\
\text { score }\end{array}$ & $\begin{array}{l}\text { Mean }{ }^{*} \\
\text { score }\end{array}$ & $\begin{array}{l}\text { SD } \\
\text { score }\end{array}$ \\
\hline \multicolumn{6}{|l|}{ Cross-sectional data } \\
\hline Year 1 Reflection ability & 69 & 7 & 18 & 14.60 & 2.08 \\
\hline Year 1 Clinical Performance & 69 & 7 & 17 & 12.69 & 2.18 \\
\hline Year 2 Reflection ability & 50 & 12 & 18 & 14.85 & 1.36 \\
\hline Year 2 Clinical Performance & 50 & 8.50 & 15 & 12.55 & 1.56 \\
\hline Year 3 Reflection ability & 50 & 12.20 & 16.80 & 15.27 & 1.06 \\
\hline Year 3 Clinical Performance & 50 & 10.80 & 16.60 & 14.18 & 1.20 \\
\hline \multicolumn{6}{|c|}{ Retrospective-longitudinal data } \\
\hline Year 1 Reflection ability & 95 & 5 & 20 & 15.15 & 2.40 \\
\hline Year 1 Clinical Performance & 95 & 5 & 17 & 12.94 & 2.17 \\
\hline Year 2 Reflection ability & 95 & 10 & 18 & 14.81 & 1.58 \\
\hline Year 2 Clinical Performance & 95 & 10.50 & 16 & 13.16 & 1.16 \\
\hline Year 3 Reflection ability & 95 & 9.40 & 18 & 15.10 & 1.40 \\
\hline Year 3 Clinical Performance & 95 & 9.60 & 16.80 & 13.96 & 1.36 \\
\hline
\end{tabular}

$\mathrm{SD}$, standard deviation

Scores ranged from 1 to 20

* The mean scores for second- and third-year students reflect the mean of four (year 2) to five (year 3) different clinical placements during the year.

Table 3 outlines the correlation analysis scores $(r)$ when studying the association between midwifery student 'clinical performance' and their 'reflection ability' scores. The value of $r$ indicates the strength of the correlation. Next to the strength of the correlation also the significance value should be considered. ${ }^{28}$ Looking at the observed correlation scores, we find positive correlations between 'clinical performance' and 'reflection ability' scores for all study years and in both data sets. All correlations are significant at the 0.01 level (one tailed), except the third year correlation in the crosssectional data set. The lower correlation score for third year students was not found in the retrospective-longitudinal data set. The observed correlation scores indicate that there is a moderate association between 'clinical performance' and 'reflection ability' scores. Correlation scores allow us to estimate the proportion of variation within our data that is explained by the relationship between both variables. The remaining variation might be due to extraneous variables, both situational and participant. The proportion of explained variation is given by $r^{2}$. Note that the proportion of variation explained does not have to be large to be important. ${ }^{28}$ From the cross-sectional results, we can conclude that 31\% (year 1), 30\% (year 2) and 9\% (year 3) of the variation in the performance data can be attributed to reflection or vice versa. From the retrospective 
data set, we conclude that 18\% (year 1), 16\% (year 2) and 20\% (year 3) respectively of the proportion in the variance of performance can be linked to reflection. Looking at the values after correction for attenuation, we found high correlations for second and third year students in both perspectives. The proportion in the variance of 'clinical performance' that can be linked to 'reflection ability' shifted in the retrospectivelongitudinal data set from low to moderate values: 47\% (year 2) and 56\% (year 3).

Table 3. Correlations between reflection ability and clinical performance

\begin{tabular}{|c|c|c|c|c|c|c|c|}
\hline & \multirow{2}{*}{$\begin{array}{c}\text { Students } \\
\text { (n) }\end{array}$} & \multicolumn{2}{|c|}{ Observed } & \multicolumn{2}{|c|}{ Reliability } & \multicolumn{2}{|l|}{ True } \\
\hline & & $r$ & $r^{2}$ & Refl. & Perf. & $r$ & $r^{2}$ \\
\hline \multicolumn{8}{|l|}{ Cross-sectional perspective } \\
\hline Reflection year 1 - Performance year 1 & 69 & $0.56 * *$ & 0.31 & & & & \\
\hline Reflection year 2- Performance year 2 & 50 & $0.55^{* *}$ & 0.30 & 0.13 & 0.60 & 1.00 & 1.00 \\
\hline Reflection year 3 - Performance year 3 & 50 & $0.30 *$ & 0.09 & 0.15 & 0.61 & 1.00 & 1.00 \\
\hline \multicolumn{8}{|l|}{ Retrospective longitudinal perspective } \\
\hline Reflection year 1 - Performance year 1 & 95 & $0.42 * *$ & 0.18 & & & & \\
\hline Reflection year 2 - Performance year 2 & 95 & $0.40 * *$ & 0.16 & 0.55 & 0.47 & 0.69 & 0.47 \\
\hline Reflection year 3 - Performance year 3 & 95 & $0.45^{* *}$ & 0.20 & 0.49 & 0.72 & 0.75 & 0.56 \\
\hline
\end{tabular}

Reflection, Reflection ability, Refl.; Performance, Clinical performance, Perf.

Observed values: $r$, Pearson's product-moment correlation coefficient; $r^{2}$, explained proportion in variance. True values: $r$, de-attenuated correlation coefficient; $r^{2}$, explained proportion in variance after de-attenuation. Adjusted correlation is not possible for year 1 as students have only undertaken one clinical placement. Reliability: Cronbach's alpha

* Correlation is significant at the 0.05 level (one-tailed)

** Correlation is significant at the 0.01 level (one-tailed)

Table 4 Correlations between reflection ability scores and clinical performance scores in consecutive years

\begin{tabular}{|c|c|c|c|c|c|c|c|}
\hline & \multirow{2}{*}{$\begin{array}{c}\text { Students } \\
\text { (n) }\end{array}$} & \multicolumn{2}{|c|}{ Observed } & \multicolumn{2}{|c|}{ Reliability } & \multicolumn{2}{|l|}{ True } \\
\hline & & $r$ & $r^{2}$ & Refl. & Perf. & $r$ & $r^{2}$ \\
\hline \multicolumn{8}{|l|}{ Retrospective longitudinal data } \\
\hline Reflection year 1 - Performance year 1 & 95 & $0.42 * *$ & 0.17 & & & & \\
\hline Reflection year 1 - Performance year 2 & 95 & $0.27^{* *}$ & 0.07 & & & & \\
\hline Reflection year 1 - Performance year 3 & 95 & $0.27^{* *}$ & 0.07 & & & & \\
\hline Reflection year 2 - Performance year 2 & 95 & $0.40 * *$ & 0.16 & 0.55 & 0.47 & 0.69 & 0.47 \\
\hline Reflection year 2 - Performance year 3 & 95 & $0.25^{* *}$ & 0.06 & 0.55 & 0.72 & 0.39 & 0.15 \\
\hline Reflection year 3 - Performance year 3 & 95 & $0.45^{* *}$ & 0.20 & 0.49 & 0.72 & 0.75 & 0.56 \\
\hline
\end{tabular}

**. Correlation is significant at the 0.01 level (one-tailed) 
Table 4 presents the correlations within the retrospective-longitudinal data in order to correct the data for a halo-effect within study years. The table shows how 'reflection ability' scores of earlier years are still significant related with 'clinical performance' scores in subsequent years.

\section{DISCUSSION}

The goal of the present study was to assess the relationship between clinical performance and reflection ability in clinical practice. We explored the relationship in Midwifery students in different study programme years. We used both a cross-sectional and a retrospective-longitudinal design to study the correlations between clinical performance and reflection ability data.

Our findings demonstrated a moderate observed correlation between reflection ability and clinical performance scores, indicating that specific levels of clinical performance are associated with reflection ability. When adopting a cross-sectional perspective, all correlation values were significant $(p<0.01)$ and above 0.4 , with the exception of the third year correlations. Assuming perfect reliability in the measurement, the adjusted correlations for year 2 and year 3 indicated a high association between reflection ability and clinical performance $(>0.6)$. The analysis results, based on the retrospectivelongitudinal data set, explained a moderate proportion in variance after correction for attenuation. The differences in $r^{2}$-values were larger in the cross-sectional design but these values may be biased owing to the fact that the data also include information from students that failed. The findings from this study suggest that reflection ability is linked to clinical performance in the workplace. These moderate but significant correlation values confirm that reflection is an essential characteristic of professional competence. ${ }^{3,14}$ These findings are important because reflection and performance were measured in the clinical learning environment. They confirm results of existing correlation research between reflection ability and performance in other learning environments. ${ }^{13,19}$ The results also reiterate the importance of considering written reflections as an important way to assess professional competence. However, reflection is of course not the sole component of professional competence and reflection should be combined with other measures to assess other aspects of performance in the workplace. $^{30,31}$

Moreover the results of this study indicate that 'reflection ability' scores of earlier years are significant related to 'clinical performance' scores of subsequent years. This finding supports the evidence that reflection improves students' learning. ${ }^{8,12,13,17-21}$ The results 
suggest that students' abilities to reflect on how and what they have learned during patient care has a measurable effect and leads to improvements in clinical performance. The results also underpin the recommendation in the literature to stimulate students' reflective ability from the early study years. ${ }^{32}$

The current study has several limitations. An important limitation is that the same individuals carried out the judgement on reflective ability and on clinical performance, so they are not completely independent of each other. This may have inflated the correlational analysis. We only studied the relationship between reflection ability and clinical performance in the context of one University College programme about midwifery. Given the marked variability in clinical health care education and clinical practice, the findings may not be transferrable to other programmes. A second limitation is the number of participants. According to Brace et al. (2012), ${ }^{28}$ to be acceptable for correlation analysis, one should normally have a sample of 100 participants.

\section{CONCLUSION}

In conclusion, looking to the adjusted correlations in a cross-sectional and retrospective-longitudinal cohort study, we found significant correlations between 'reflection ability' and 'clinical performance' scores in clinical practice in all the undergraduate midwifery years. Reflection therefore seems an important component of professional competence. Further studies might focus on the impact of reflection on performance in midwifery students with different levels of reflection ability and clinical performance. Intervention studies could also build on a differentiated perspective of involving students in reflective writing in view of their clinical performance. 


\section{REFERENCES}

1. International Confederation of Midwives, 2011. Definition of the Midwife. Available from: $<$ www.internationalmidwives.org>.

2. International Confederation of Midwives, 2013. Essential Competencies for Basic Midwifery Practice. Available from: <www.internationalmidwives.org>.

3. Wald HS, Reis SP. Beyond the Margins: Reflective writing and development of reflective capacity in medical education. J Gen Intern Med 2010;25(7):746-749.

4. Fullerton JT, Thompson JB, Severino RS. The International Confederation of Midwives essential competencies for basic midwifery practice. An update study: 2009-2010. Midwifery 2011;27(4):399-408.

5. Epstein RM. Mindful practice. JAMA 1999;282:833-839.

6. Maudsley G, Strivens J. Promoting professional knowledge, experiential learning and critical thinking for medical students. Med Educ 2000;34(7):535-44.

7. Guest CB, Regehr G, Tiberius RG. The lifelong challenge of expertise. Med Educ 2001;35(1):78-81.

8. Mamede S, Schmidt H. The structure of reflective practice in medicine. Med Educ 2004;38(12):13021308.

9. Dewey J. Experience and Education. New York: Simon and Schuster 1938.

10. Kolb DA. Experiential learning: Experience as the Source of Learning and Development. New Jersey: Prentice Hall 1984.

11. Boud D, Keogh R, Walker D. Reflection: Turning Experience into Learning. London: Kogan Page 2000.

12. Mann K. Theoretical perspectives in medical education: Past experience and future possibilities. Med Educ 2011;45(1):60-68.

13. Lew MD, Schmidt HG. Self-reflection and academic performance: Is there a relationship? Adv Health Sci Educ 2011;16(4):529-545.

14. Epstein RM. Hundert EM. Defining and assessing professional competence. JAMA 2002;287(2):226-235.

15. Friedman Ben David M, Davis MH, Harden RM, Howie PW, Ker J, Pippard MJ. AMEE Medical Education Guide no.24: Portfolios as a method of student assessment. Med Teach 2001;23(6):535-551.

16. Sandars J. The use of reflection in medical education: AMEE Guide no 44. Med Teach 2009;31(8):685695.

17. Moon JA. A Handbook of Reflective and Experiential Learning. London: Routledge 1999.

18. Boud D, Walker D. Promoting reflection in professional courses: The challenge of context. In: Harrison R, Reeve F, Hansen A, Clarke J. (Eds.). Supporting Lifelong Learning, Vol. 1. Perspectives on Learning. London: Routlegde Falmer 2002:91-110.

19. Grant A, Kinnersley P, Metcalf E, Pill R, Houston H. Students' views of reflective learning techniques: an efficacy study at a UK medical school. Med Educ 2006;40(4):379-88.

20. Mann K, Gordon J, MacLeod A. Reflection and reflective practice in health professions education: a systematic review of the literature in the health professions. Adv Health Sci Educ 2009;14(4):595-621.

21. Azer SA, Guerrero APS, Walsh A. Twelve tips. Enhancing learning approaches: Practical tips for students and teachers. Med Teach 2013;35(6):433-443.

22. Charon R. Narrative Medicine: Honoring the Stories of Illness. New York: Oxford 2006.

23. Moulton CE, Regehr G, Mylopoulos M, MacRae H. Slowing down when you should: a new model of expert judgment. Acad Med 2007;82(Suppl):s109-116.

24. Wald HS, Borkan JM, Taylor JS, Anthony D, Reis SP. Fostering and Evaluating Reflective Capacity in Medical Education: Developing the REFLECT Rubric for Assessing Reflective Writing. Acad Med 2012;87(1):41-50.

25. While AE. Competence versus performance: which is more important? J Adv Nurs 1994;20(3):525-531. 
26. Fleming V, Pehlke-Milde J, Reg Cur D, Davies S, Zaksek T. Developing and validating scenarios to compare midwives' knowledge and skills with the International Confederation of Midwives' essential competencies in four European countries. Midwifery 2011;27(6):854-860.

27. Embo MPC, Driessen EW, Valcke M, van der Vleuten CPM. Assessment and feedback to facilitate selfdirected learning in clinical practice of Midwifery students. Med Teach 2010;32(7):e263-269.

28. Brace N, Kemp R, Snelgar R. SPSS for psychologists. UK: Palgrave Macmillan 2012.

29. Norman G, Swanson D, Case S. Conceptual and methodology issues in studies comparing assessment formats. Teaching and Learning in Medicine 1996;8(4):208-16.

30. van der Vleuten CPM, Schuwirth LW, Scheele F, Driessen EW, Hodges B. The assessment of professional competence: Building blocks for theory development. Best Pract Res Clin Obstet Gynaecol 2010;24:703719.

31. Takayesu JK, Kulstad C, Allenstein MD, Gallahue F, Gordon D, Leone K, Kessler C. Assessing Patient Care: Summary of the Breakout Group on Assessment of Observable Learner Performance. Acad Emerg Med 2012;19(12):1379-1389.

32. Driessen EW, van Tartwijk J, Vermunt JD, van der Vleuten CPM. Use of portfolios in early undergraduate medical training. Med Teach 2003;25(1):18-23. 


\section{CHAPTER 6}

\section{Integrating learning assessment and supervision in a competency framework for clinical workplace education}

Mieke Embo

Erik W. Driessen

Martin Valcke

Cees P.M. van der Vleuten

Nurse Education Today 2014;

http://dx.doi.org/10.1016/j.nedt.2014.11.022

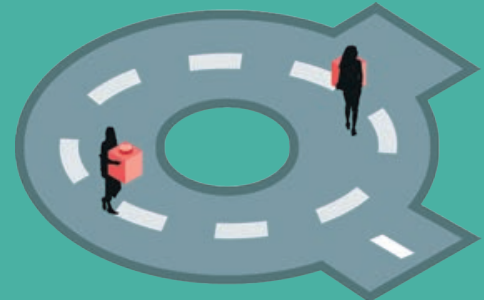




\section{ABSTRACT}

Although competency-based education is well established in health care education, research shows that the competencies do not always match the reality of clinical workplaces. Therefore, there is a need to design feasible and evidence-based competency frameworks that fit the workplace reality. This theoretical paper outlines a competency-based framework, designed to facilitate learning, assessment and supervision in clinical workplace education. Integration is the cornerstone of this holistic competency framework. 


\section{INTRODUCTION}

Competency-based education is well established in health care education but there is still much work that needs to be done to make it a workable reality in clinical education. ${ }^{1}$ Current literature identifies some areas that make the practical implementation of competency-based education problematic: 1) divergent values among stakeholders as a result of the lack of consensus on the definition of competence within health care; ${ }^{1}$ 2) imbalance between specific and general competencies; ${ }^{1}$ 3) problematic holistic assessment of clinical competence (competence is more than the sum of individual competencies); ${ }^{1-3} 4$ ) discontinuous supervision; ${ }^{4-5} 5$ ) inadequate guidance of developing reflective ability; ${ }^{6}$ and 6) a lack of a consistent ${ }^{1}$ and programmatic approach. ${ }^{7}$ The authors wanted to address these problems and to contribute to competence future by designing an 'Integrated Learning Assessment and Supervision Competency Framework' for clinical workplace education. Within this theoretical paper, we will describe the underpinning theoretical perspectives, and the pedagogical concepts that are relevant in the framework. Figure 1 shows the workplace framework and figure 2 illustrates the underlying workplace learning instrument.

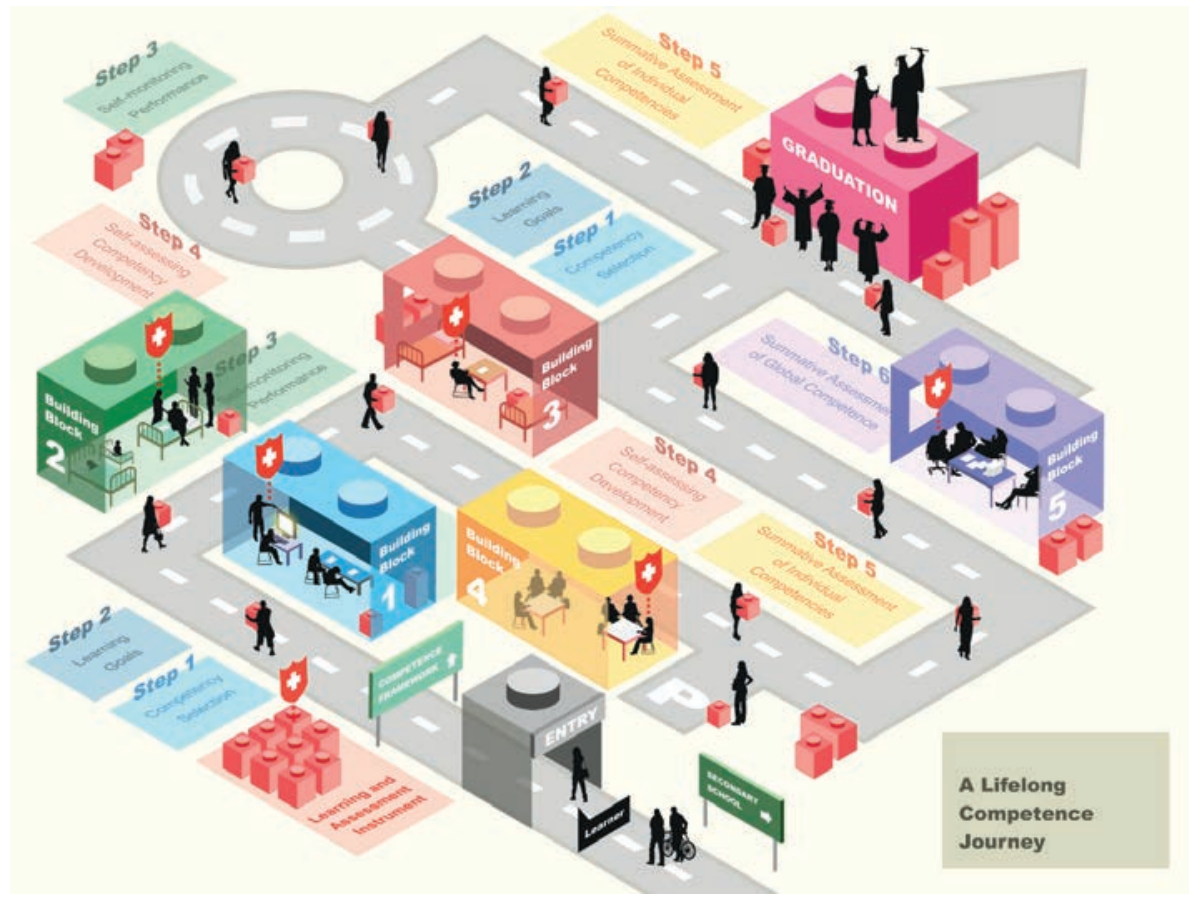

Figure 1. Integrated Learning Assessment and Supervision Competency Framework 


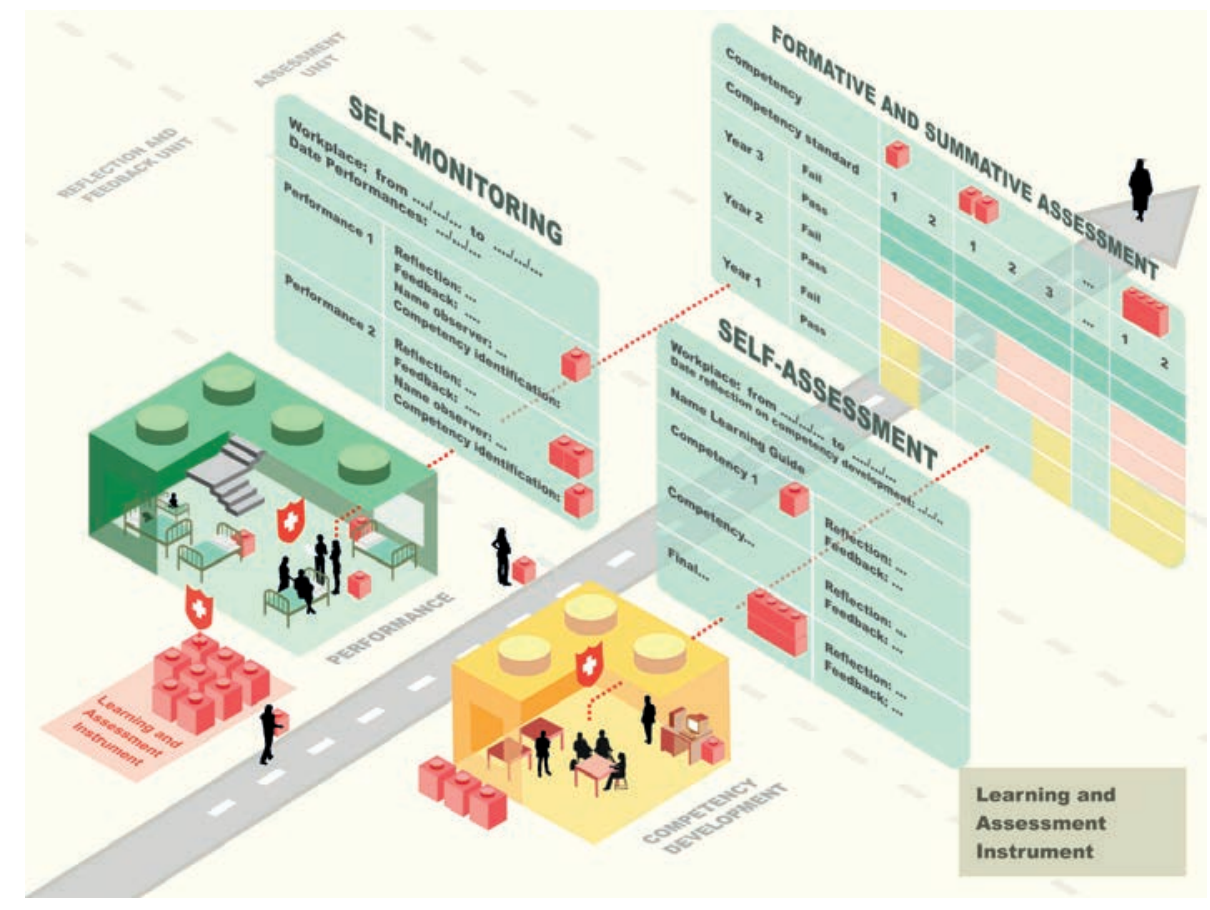

Figure 2. Integrated Learning and Assessment Instrument

\section{METHODS}

Reviews of the relevant workplace literature and four empirical studies that were conducted during a doctoral research project resulted in the design of this framework. Two qualitative studies used a content analysis approach to explore students' and supervisors' perceptions on how this framework facilitated learning, assessment and supervision. ${ }^{8-9}$ A subsequent mixed-method study explored how two reflective writing activities stimulated reflection at different degrees of granularity during workplace learning. ${ }^{10}$ A cross-sectional and retrospective-longitudinal correlation cohort study was used to investigate the relationship between reflection and performance and how reflection contributes to development. ${ }^{11}$ The framework was developed in the context of midwifery education at the University College Arteveldehogeschool Ghent (Belgium). 


\section{THE WORKPLACE FRAMEWORK COMPONENTS}

We describe successively the different components of this workplace framework: 1) competency-based education and competency framework; 2) workplace stakeholders; 3) workplace learning, assessment and supervision; 4) learning and assessment instrument; 5) programmatic learning and assessment; and 6) essential conditions for a successful integrated workplace learning design.

\section{Competency-based education and competency framework}

The framework is embedded in a competency-based approach to clinical education. Learners start education (e.g. undergraduate, postgraduate, residency education) in order to graduate as a competent professional (e.g. nurse, midwife, doctor) fit for practice. Developing professional competence is a lifelong learning process, rather than 'a state to be achieved' at the moment of graduation. ${ }^{2,12,13}$ We use the analogy of a Lifelong Competence Journey (figure 1). Competencies are learned and assessed during a programme, consisting of building blocks of in-school and workplace learning and assessment.

Competency-based education is defined as an education in which 'assessments ensure that graduates have the essential knowledge, skills, and attitudes to enter the workforce and begin functioning in entry-level positions. ${ }^{14}$ This definition emphasises an outcome-based educational approach. ${ }^{1}$ The Competency framework provides the structure for the education of the professional. It provides the opportunity for all the stakeholders, involved with learning and assessment to share the same concepts and values (problem 1).

The concepts used in this framework are competency and professional competence, concepts that are often used interchangeably in the literature. ${ }^{1}$ Competency represents the integration of knowledge, skills, values and attitudes ${ }^{1,12,15,16}$ that are demonstrated at a defined level of proficiency in the particular context of education and practice. ${ }^{17}$ The competencies within this framework consist of specific and general competencies (problem 2). General competencies are valid across different clinical contexts, whereas specific competencies are linked to specific areas of practice. ${ }^{12}$ The second concept, professional competence, refers to a quality or state of being. It is a holistic term that refers to a person's overall capacity or ability to do something successfully. ${ }^{18,19}$ The view of professional competence considers that the competent person 'not only possesses the requisite competencies but is also able to use them ${ }^{12}$ and make appropriate decisions and judgements according the context. ${ }^{1}$ 


\section{Workplace stakeholders}

Clinical workplaces are socio-cultural communities of practice. Current socio-cultural theories of workplace learning claim that learning and learning outcomes emerge through active participation in activities and in interaction with complex and dynamic systems of the clinical work environment. ${ }^{13,20}$ Active participation and interaction within clinical workplaces involve that clinical supervision is no longer regarded as instruction, but as facilitation of learning. ${ }^{21}$ Supervisors need to view their role as that of providing learning experiences, giving useful feedback and trusting learners to take responsibility for their learning. Learners' need to value the ability to identify gaps and document improvement, rather than 'gun' for the ' $A$ '. ${ }^{22}$

Based on the community of learning theory, it is important that all the workplace members share the responsibility for learners' performance improvement and competency development. ${ }^{23}$ Self-directed learners are expected to take the initiative in their learning but they need support and collaboration of others. ${ }^{24}$ Collaboration of others refers to professionals in workplaces and professionals in schools. Educators need to establish effective collaboration with professionals in clinical workplaces and standards are needed to clarify the roles and responsibilities of the supervisors at the workplace. ${ }^{4}$

Within this framework, a collaboration between learners, workplace and school is established by defining the following roles: learner, observer, learning guide, and school committee. All community members who meet learners during individual instances of patient care are observers. Observers might be patients, peer learners, or professionals from the workplace and school. Learning guides have an intermittent but longitudinal relationship with the learner during the work placement. This framework makes a distinction between learning guides from the workplace (supervisors) and learning guides from school (teachers). The assessment school committee consists of all the teachers. The roles of the stakeholders will be clarified by describing the learning, assessment and supervision processes in the next paragraph.

\section{Workplace learning, assessment and supervision}

We will describe the workplace processes that exemplify a random work placement in six steps (figure 1).

\section{Step 1: Competency selection}

Each placement starts by defining which competencies from the competency framework can be learned and assessed in the context of that workplace. This step emphasis- 
es the importance of context in workplace learning. ${ }^{19}$ The selected competencies at the start are the outcomes expected of the learner at the end of the placement. An underlying assumption is that a clear set of competencies can help learners to selfdirect their own learning. ${ }^{25}$ This step is guided by the supervisor and the teacher.

\section{Step 2: Learning goals}

After selecting relevant competencies, learners start their learning plan by formulating learning goals in relation to each competency. These competencies and learning goals are important for learners and learning guides in order to plan for and monitor progression to each learning outcome. ${ }^{22,25}$

\section{Step 3: Self-monitoring performance}

Learners are instructed to take the initiative to write reflections on daily performances and to ask for feedback. Observers have an essential role in guiding individual performances by observing performances, inviting learners to reflect before giving feedback, reading written reflections, and providing effective feedback. There are different reasons why it is important that learners first write down reflective notes before asking for feedback: learners are encouraged to reflect on their abilities and opportunities for improvement, supervisors are more likely to give more feedback for reflective learners, and reading learners' reflective notes before giving or writing feedback makes individual supervision easier. ${ }^{8,9}$ High quality reflections and feedback on daily performances facilitate the development of self-monitoring competencies, a process that is further enhanced by observers and learning guides (supervisor and/or teacher). By comparing daily collected written information with competency standards, learners are able to diagnose their learning needs and to evaluate their learning. Importantly, to encourage self-directed learning, it is the learners' responsibility to ensure that sufficient feedback on all the competencies has been collected at the end of the placement.

\section{Step 4: Self-assessing competency development}

Repeating reflections on competency development allows for the self-assessment of the overall progress. Although this fourth step is more abstract and complex than step three, reflection on progress is essential for continuous competence development. ${ }^{26}$ Learners are instructed to reflect on competency development over a longer period of time in order to learn how to take a more objective and comprehensive view of their progress. ${ }^{27}$ Learners and learning guides review the written reflections, and assess these against the learning goals and competency standards. It is important that this review is 
then discussed between the learner and the learning guide (supervisor and/or teacher) in order to support the development of a personal learning plan for the future. Essential conditions are: 1) a limited number of competencies, 2) a long interval between two reflections on competency development, and 3) time for discussing these reflections. ${ }^{9}$

\section{Step 5: Summative assessment of individual competencies}

Although formative learning and assessment is important (steps 1 to 4), ultimately, patients and society place strong emphasis on summative assessment (steps 5 and 6). Summative assessment provides assurance that graduates have met minimum standards and are 'fit for practice'. ${ }^{28}$ Summative assessment of individual competencies takes place during the assessment meeting at the end of each placement with both the learner and learning guides. Before entering the assessment meeting, learners completed a competency-based assessment checklist with pass/fail decisions and they write a reflection on competency development (step 4). During the meeting, written information is compared with the competency standards and a final pass/fail decision for each selected competency is discussed. Enough time to carry out assessment discussions, and awareness of the supervisor's role in summative assessment are essential conditions for high quality individual competency judgements. ${ }^{8-10}$

Step 6: Summative assessment of global professional competence

Summative assessment of professional competence takes place in school. This is an overall judgement of specific and generic competencies within each particular context. $^{2,12}$ The assessment school committee aggregates pass/fail judgements on individual competency level into a final judgement on professional competence (score from 1 to 20). This step addresses the importance of holistic assessment of competence (problem 3). Learners are advised of the score and have the opportunity to ask for feedback from the teachers. These teachers took part in the assessment meetings in the workplace and in the school committee. In this way, teachers can be seen as learning assistants, generating a unique 'competence fingerprint' for each student. ${ }^{1}$

\section{Workplace learning and assessment instrument}

To facilitate competency-based learning, assessment and supervision in clinical workplaces, we designed an instrument that fits the complex workplace reality (figure 2). This instrument is competency-based, it integrates a learning- and assessment unit, it recognizes different roles for workplace stakeholders, and it unfolds the six steps of the learning processes. The instrument presents a paper and pencil format to document 
continuously the evolving nature of the competencies in the workplace, and this following the six steps. Each step is supported with clear guidelines and a tailored educational structure to facilitate the educational processes.

The instrument presents the competencies following a framework. For each internship, the relevant competencies in the framework can be selected (step 1), and learning goals are formulated (step 2). The instrument presents a format for both the feedback unit and the assessment unit. The learning unit focuses on reflection and feedback in relation to performance (step 3) and competency development (step 4). Importantly, the structure of the learning unit is different for performances and competency development. The performance learning unit consists of a blank sheet for each day with the following categories: 1) performance (e.g. blood puncture), learner's reflection, 2) observer's feedback, 3) observer's name for validation of written information, and 4) learner's identification of competencies that are relevant for the performance. Daily collected written information is important to optimize continuity in supervision (problem 4) and to guide the reflective learning process (problem 5). ${ }^{9}$ The competency development learning unit, is a blank sheet for each selected competency instead of a blank sheet for each day. Learners reflect on competencies and learning guides (supervisors and/or teachers) give verbal and written feedback on these reflections.

The learning unit is linked to a competency-based assessment unit. This assessment unit contains a checklist of the selected competencies that learners must develop during the clinical placement. Each competency has a set of context-specific competency standards. These standards are defined and expressed in concrete terms in order to facilitate learning, assessment and supervision. In the checklist, different competency levels are labelled with a colour code reflecting the year of the curriculum to which the placement has been assigned. This integrated learning and assessment instrument recognizes that professional competence is a developmental process and that it is these more specific developmental aspects that should be attained at different stages of learning., ${ }^{2,19}$ The checklist helps learners to indicate whether the learning outcomes for that specific year have been achieved (Pass) or not (Fail). The checklist is used by learners for selfmonitoring (step 3) and self-assessment (step 4). It is used by learning guides to direct formative learning and assessment, and in turn also by learning guides and the school committee to support the summative assessment (steps 5 and 6).

\section{Programmatic learning and assessment}

Let us move from the individual work placement to the importance of linking individual workplaces in the context of the overall learning programme. A final problem of 
competency-based education is a lack of a consistent and programmatic approach. Programmatic learning and assessment is essential to guarantee learners' readiness to practice at the novice level at the end of the educational programme. ${ }^{29}$ We documented workplace processes of one single work placement in six steps (figure 1). These steps facilitate the design of a programmatic framework. By repeating the six steps for each work placement in the programme, all the competencies will be learned and assessed in a consistent and programmatic way. This is a traditional view on programmatic learning and assessment. A more contemporary programmatic view recommends 'to employ a continuous - and even purposive - collection of assessment information about each student, which would only then lead to decision moments when the collected information is rich enough'. An important feature is a disconnection between assessment and decision moments. ${ }^{7}$ Within this framework, assessment of individual competency levels might be seen as assessment moments (step 5), assessment of professional competence (step 6) as decision moments. We explain this second programmatic view with an example. At the end of the first placement, learners have a clear view about each competency (steps 1 to 5) but they don't receive a professional competence score (step 6). When they arrive in the second placement, the same educational activities are followed (steps 1 to 5). If professional competence can be assessed after this second placement, the assessment school committee will decide about this grade (step 6).

\section{Essential workplace learning conditions}

The success of implementing an integrated workplace learning model is strongly dependent on the extent to which essential conditions are met. An important condition is the provision of time for reflection, feedback and dialogue. The time-issue is related to the educational structure of the learning instrument. Learners ${ }^{8,10}$ and supervisors ${ }^{9}$ perceived difficulties to write reflections and feedback about performance and competency development. Clearly demarcated expectations are essential to engage learners in self-directed learning and supervisors in observing and guiding learners. However, it is important to adapt the instructions to the reality of busy workplace learning environments. Therefore, reflection and feedback on performance can be limited to striking learning experiences (instead of daily reflections), and reflection and feedback on competency development can be limited to longer periods of time and a limited number of competencies. ${ }^{10}$ Supervisors don't have time to read extensive reflection bundles $^{9}$ and learners prefer less reflective writing so that there is more time for a dialogue. Furthermore, supervisors worried about the writing activity of their colleagues that might hamper the value of learners' collected evidence. ${ }^{9}$ Learners and supervisors must be trained to be prepared for their workplace learning role and they need support 
from a range of members of the health care team. This brings us to the importance of creating an effective workplace learning culture in health care.

\section{DISCUSSION}

We have described an Integrated Learning Assessment and Supervision Competency Framework to deliver competency-based education in clinical workplaces. The cornerstone of this framework is integration. Integrating learning (reflection and feedback), assessment (self-, formative, summative) and supervision (observer, learning guide, school committee) in a competency framework can contribute to solve the problems of competency-based clinical education this study set out to address. We will use our empirical studies to discuss how this framework can contribute to addressing these problems. We will discuss strengths and weaknesses of the framework as well as opportunities for further research.

A first important strength of this framework is the competency-based educational structure. The competencies of the professional are central in the workplace processes (figure 1, steps 1 to 6 ) and in the workplace instrument (figure 2). The results in Embo et al. ${ }^{9}$ showed that a competency structure promotes a focus on realistic outcomes, and that the integration of specific and generic competencies is valuable when considering a more complete list of competencies. Also Pijl-Zieber et al. ${ }^{29}$ described that using established competencies promotes uniformity between educational preparation and workplace expectations, and provides a common language between stakeholders. Despite the advantages of this structure, the results in our studies confirmed the complexity of competency-based education in clinical practice. ${ }^{8-10}$ Therefore, an important difference was made in the structure of the learning units (figure 2). Specifically, the structure for reflection on performances was adapted to the performance reality in clinical workplaces. Within the current structure, performances mustn't be unravelled in competencies but competencies are detected in the performance stories. This structure is intended to optimize learners' reflection and observers' feedback behaviour. Further research is important to measure this effect.

A second strong point of this study is the underlying socio-cultural learning theory, that of underpinning workplace learning as partnership and collaboration between learners, workplace and school. Different roles are described with respect of the clinical workplace reality, characterized by high workload and conflicting demands of service and education. ${ }^{8}$ A profound collaboration between all the stakeholders could prevent current problematic divergent values among stakeholders, ${ }^{1}$ discontinuity in supervi- 
sion, ${ }^{5}$ inadequate reflection guidance, ${ }^{6}$ and fragmental competence assessment. ${ }^{1-3}$ The newly designed instrument (figure 2 ) is potentially valuable on facilitating this collaboration because all the stakeholders use the same instrument. Notwithstanding the importance of this instrument, learners confirmed the importance of supervisors over learning instruments. ${ }^{8}$ This aligns with the findings in a recent review that most enablers and barriers to quality student workplaces relate to socio-cultural aspects of the workplace, rather than to micro-skills in supervising learners. ${ }^{30}$

A third strength is that of a twofold reflective learning strategy, in the development and guidance of reflective learning. ${ }^{6}$ Workplace learning in health care education starts with experiences during patient care. The importance of experience and reflection in relation to learning is well-known. ${ }^{6}$ New in this framework is a reflective learning strategy consisting of two reflective writing activities: reflection on performances and reflection on competency development. This strategy is based on the theoretical and methodological distinction between self-monitoring performance in the moment (step 3) and selfassessment as a cumulative evaluation of overall performance (step 4). ${ }^{26} \mathrm{~A}$ longitudinal reflective writing strategy is important to enable continuous development of professional competence. ${ }^{11}$ The long-term effect of this twofold reflective writing strategy on lifelong learning is an interesting topic for further research.

The fourth feature is the twofold holistic assessment approach, addressing the problem of fragmental competence assessment. ${ }^{1-3}$ Holistic assessment of competencies and professional competence is achieved by integrating learning and assessment. We integrate self-, formative and summative assessment and a twofold summative assessment strategy. The focus of this framework is the ongoing evaluation and provision of feedback to improve performance and competency development. This focus is in line with current workplace assessment literature. ${ }^{13,28,31}$ A twofold assessment strategy fits current thinking to rehabilitate subjective judgement. ${ }^{32}$ In Embo et al., ${ }^{11}$ we found a significant correlation between the ability to reflect on own performance and professional competence scores, for all the midwifery learners. Further research on the topic of summative judgements is necessary to optimize competency-based education in clinical workplaces.

The fifth feature is the programmatic view on learning and assessment. We documented how this framework contributes to a traditional and contemporary view on programmatic learning and assessment. Further research on programmatic education would contribute to the implementation of an essential holistic competency-based education philosophy in clinical workplaces. 
The sixth and final feature is the identification of essential conditions for a successful implementation of an integrated workplace learning design. Ideally workplaces should encourage and motivate learning leading to personal and professional growth. ${ }^{33}$ However, many contextual factors have been established as necessary elements for students to learn in the workplace. ${ }^{34}$ As our model integrates different components of workplace learning, successful implementation will rely on the integration of all the conditions that were described in relation to the separate components in the workplace learning literature. This is not only about the tips for effective reflection, ${ }^{35,36}$ feedback, ${ }^{37,38}$ assessment, ${ }^{13,28}$ or supervision. ${ }^{4}$ The challenge for the future is to implement the evidence-based approaches in practice and to create an effective workplace learning culture in health care education.

The main weakness of this study is that the framework design has been implemented in just one Midwifery department in Belgium, which inevitably limits the generalizability of the framework. However, the framework described could be useful as a guide to other health care disciplines who wish to plan, implement and evaluate a competency-based model of workplace learning in their educational programmes.

\section{CONCLUSION}

Competency-based education in clinical workplaces is complex. The complexity of workplace learning is conceptualized in an Integrated Learning Assessment and Supervision Competency Framework. Promoting continuous competence development requires an integration of competencies, learning (reflection and feedback on performance and on competency development), assessment (self-, formative and summative) and supervision (observers, learning guides and school committee). Creating a collaborative workplace culture where all the stakeholders share the responsibility for the quality of complex but inseparable workplace learning, assessment and supervision processes can optimize competency-based education in clinical practice. The authors hope that this framework will contribute to the competence future in clinical health care and education. 


\section{REFERENCES}

1. Pijl-Zieber M, Barton S, Konkin J, Awosoga O, Caine V. Competence and competency-based nursing education: Finding our way through the issues. Nurse Educ Today 2014;34(5):676-678.

2. Garside JR, Nhemachena JZZ. A concept analysis of competence and its transition in nursing. Nurse Educ Today 2013;33(5):541-545.

3. Zibrowski EM, Sing SI, Goldszmidt MA, Watling CJ, Kenyon CF, Schulz V, Maddocks HL, Lingard L. The sum of the parts detracts from the intended whole: competencies and in-training assessments. Med Educ 2009;43(8):741-748.

4. Sundler AJ, Björk M, Bisholt B, Ohlsson U, Engström AK, Gustafsson M. Student nurses' experiences of the clinical learning environment in relation to the organization of supervision: A questionnaire survey. Nurse Educ Today 2014;34(4):661-666.

5. Sweet LP, Glover P, McPhee T. The midwifery miniCEX - A valuable clinical assessment tool for midwifery education. Nurse Educ Pract 2013;13(2):147-153.

6. Mann K, Gordon J, MacLeod A. Reflection and reflective practice in health professions education: a systematic review of the literature in the health professions. Adv Health Sci Educ 2009;14(4):595-621.

7. van der Vleuten CPM, Schuwirth LWT, Driessen EW, Dijkstra J, Tigelaar D, Baartman LKJ, van Tartwijk J. A model for programmatic assessment fit for purpose. Med Teach 2012;34(3):205-214.

8. Embo MPC, Driessen EW, Valcke M, van der Vleuten CPM. Assessment and feedback to facilitate selfdirected learning in clinical practice of Midwifery students. Med Teach 2010;32(7):e263-269.

9. Embo M, Driessen E, Valcke M, van der Vleuten CPM. A framework to facilitate self-directed learning and supervision In Midwifery practice: A qualitative study of supervisors' perceptions. Nurse Educ Pract 2014;14(4):441-446.

10. Embo M, Driessen E, Valcke M, van der Vleuten CPM. Scaffolding reflective learning in clinical practice: a comparison of two types of reflective activities. Med Teach 2014;36(7):602-607.

11. Embo M, Driessen E, Valcke M, van der Vleuten CPM. Relationship between reflection ability and clinical performance: a cross-sectional and retrospective-longitudinal correlation cohort study in midwifery. Midwifery 2015;31(1):90-94.

12. Eraut M. Developing Professional Knowledge and Competence. Abingdon: Routledge 1994.

13. Govaerts $M$, van der Vleuten CPM. Validity in work-based assessment: expanding our horizons. Med Educ 2013;47(12):1164-1174.

14. Anema M. Vision on competency-based education. In: Anema M, McCoy J. (Eds.). Competency Based Nursing Education: Guide to Achieving Outstanding Learner Outcomes. New York: Springer 2009.

15. Carraccio C, Wolfsthal SD, Englander R, Ferentz K, Martin C. Shifting Paradigms: From Flexner to Competencies. Acad Med 2002;77(5):361-367.

16. Frank JR, Snell LS, Cate OT, Holmboe ES, Caraccio C, Swing SR, Harris P, Glasgow NJ, Campbell C, Dath D, Harden RM, Lobst W, Long DM, Mungroo R, Richardson DL, Sherbino J, Silver I, Taber S, Talbot M, Harris KA. Competency-based medical education: Theory to practice. Med Teach 2010;32(8):638-645.

17. Fullerton JT, Thompson JB, Severino R. The International Confederation of Midwives essential competencies for basic midwifery practice. An update study: 2009-2010. Midwifery 2011;27(4):399-408.

18. ten Cate O, Scheele F. Competency-based postgraduate training: Can we bridge the gap between theory and clinical practice? Acad Med 2007;82(6):542-547.

19. Epstein RM, Hundert EM. Defining and assessing professional competence. JAMA 2002;287(2):226-235.

20. Mann KV. Theoretical perspectives in medical education: past experience and future possibilities. Med Educ 2011;45(1):60-68.

21. Fox RD, Bennett NL. Continuing medical education: Learning and change: implications for continuing medical education. BMJ 1998;316:466. 
22. Dannefer EF, Beyond assessment of learning toward assessment for learning: Educating tomorrow's physicians. Med Teach 2013;35(7):560-563.

23. Irby BJ, Brown G, Lara-Alecio R, Jackson S. The Handbook of Educationals Theories. Charlotte, North Carolina (USA): Information Age Publishing 2013.

24. Hammond M, Collins R. Self-Directed Learning: Critical Practice. New York: Nichols/ GP Publishing 1991.

25. Harden RM. Learning outcomes as a tool to assess progression. Med Teach 2007;29(7):678-682.

26. Eva KW, Regehr G. Exploring the divergence between self-assessment and self-monitoring. Adv Health Sci Educ 2011;16(3):311-329.

27. Yuan HB, Williams BA, Fang JB, Pang D. Chinese baccalaureate nursing students' readiness for selfdirected learning. Nurse Educ Today 2011;32(4):427-431.

28. Norcini J, Anderson B, Bollela V, Burch V, Costa MJ, Duvivier R, Galbraith R, Hays R, Kent A, Perrott V, Roberts T. Criteria for good assessment: Consensus statement and recommendations from the Ottawa 2010 Conference. Med Teach 2011;33(3):206-214.

29. Pijl-Zieber M, Barton S, Konkin J, Awosoga O, Caine V. Mind the gap: Quantifying the performance gap between observed and required clinical competencies in undergraduate nursing students. Nurse Educ Today 2014;34(5):667-669.

30. Trede F, McEwen C, Kenny A, O'Meara P. Supervisors' experiences of workplace supervision of nursing and paramedic students in rural settings: A scoping review. Nurse Educ Today 2014;34(5):783-788.

31. Norcini J, Burch V, Workplace-based assessment as an educational tool: AMEE Guide No. 31. Med Teach 2007;29(9-10):855-871.

32. Hodges B. Assessment in the post-psychometric era: Learning to love the subjective and collective. Med Teach 2013;35(7):564-568.

33. Newton JM, Henderson A, Jolly B, Greaves J. A contemporary examination of workplace learning culture: An ethnomethodology study. Nurse Educ Today 2014;http://dx.doi.org/10.1016/j.nedt.2014.07.001.

34. Dornan T, Muijtjens A, Graham J, Scherpbier A, Boshuizen H. Manchester Clinical Placement Index (MCPI). Conditions for medical students' learning in hospital and community placements. Adv Health Sci Educ 2012;17(5):703-716.

35. Aronson L. Twelve tips for teaching reflection at all levels of medical education. Med Teach 2011;33(3):200-205.

36. Walker R, Cooke M, Henderson M, Creedy DK. Using a critical reflection process to create an effective learning community in the workplace. Nurse Educ Today 2013;33(5):504-511.

37. Archer JC. State of the science in health professional education: effective feedback. Med Educ 2010;44(1):101-108.

38. Ramani S, Krackov SK. Twelve tips for giving feedback effectively in the clinical environment. Med Teach 2012;34(10):787-791. 

CHAPTER 7

\section{Discussion}

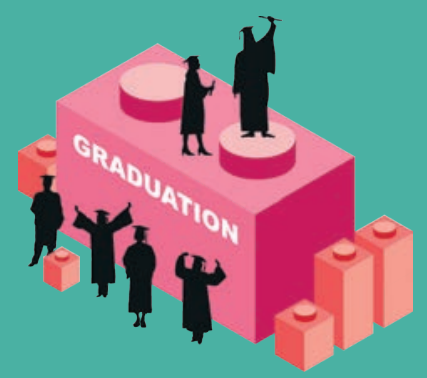



Workplace learning plays a crucial role in the development of professional competency in health care education. In the present doctoral thesis it was argued that competency development in the clinical workplace should be a continuous self-directed process of performance improvement and personal and professional development. Yet, developing and assessing competencies and guiding a continuous developmental process against a backdrop of discontinuous clinical workplaces turned out to be a complex undertaking. The research project departed from the assumption that integrating learning, assessment and supervision can facilitate self-directed learning and continuous competency development in a discontinuous clinical workplace learning programme. In this discussion chapter, we call to mind the three guiding research questions that build on this general assumption. We analyse the extent to which the results of the subsequent empirical studies have helped to answer these three questions.

\section{RESEARCH QUESTION 1}

How can learning, assessment and supervision in the workplace be integrated with the aim to support a continuous developmental process?

The answer to this first research question is reported in chapter 6 . Review of the workplace literature, together with the findings of the empirical studies reported in chapters 2 to 5, have helped to support the design of an evidence-based and feasible workplace learning model: the Integrated Learning Assessment and Supervision Competency Framework. Integration, continuity and collaboration are the cornerstones of this holistic and competency-based workplace learning model. Continuous competency development within and across workplaces is fostered when (a) different components of workplace learning are integrated, (b) workplace learning and assessment are described in six steps, and (c) when stakeholders are encouraged to collaborate along the lines of the same integrated learning and assessment instrument.

The following elements we found in the literature on workplace learning were incorporated in the design of the workplace learning model: 1) workplace learning theory; 2) competency framework; 3) curriculum structure; 4) stakeholders; 5) instrument; 6) processes; 7) educational conditions; and 8) educational continuity. In order to establish a workplace learning continuum, we adopted a 'Lifelong competence journey'metaphor (chapter 6, figure 1). The implementation of an educational continuum, however, proved elusive and difficult to achieve in practice. ${ }^{1}$ This could mainly be attributed to the fact that an accepted framework for such a continuum was lacking. ${ }^{1-3}$ To revise the workplace learning curriculum so as to achieve an educational continuum, 
one should raise awareness of the competencies a learner should possess. Nevertheless, some supervisors indicate that there's a lack of familiarity with the competency structure (chapter 3), which reconfirm the complexity of implementing competencybased education in a clinical practice setting. ${ }^{4}$ It also remains a challenge for educators to preserve the holistic competency-based view on learning and assessment. Therefore, as mentioned in the introduction, we adopted two different concepts to support this holistic view: 'individual competencies ${ }^{5}$ and 'professional competence'. ${ }^{6}$ The workplace learning model was designed to help learners and supervisors in making a clear difference and a logical order between both concepts. Learning (reflection and feedback) and assessment of individual competencies formed the essential basis for learning and assessment of professional competence.

It was shown that it helped to identify different learning and assessment processes within the framework, when trying to achieve continuous competency development. The following processes, defined as steps, were identified: 1) selecting competencies; 2) formulating learning goals; 3) monitoring one's own performance; 4) assessing one's own competency development; 5) applying summative assessment of individual competencies; and 6) applying summative assessment of global professional competence. Together, these ever-recurring six steps constitute the workplace learning and assessment cycle, which stimulates continuous competency development in a clinical workplace programme. Furthermore, these steps facilitate the adoption of a programmatic view on learning and assessment, as explained in chapter 6 . This meets the call for new clinical education models that eliminate a lack of connection or continuity between different learning experiences. ${ }^{1,7}$

The final element of an integrated workplace model that supports a continuous developmental process, is the application of an integrated learning and assessment workplace instrument (chapter 6, figure 2). This competency-based instrument emphasises how important it is to clearly delineate workplace learning objectives, an act which helps to improve performance, which furthers the development of competencies, and which facilitates the assessment of professional competence. ${ }^{1,8}$ Integrating learning and assessment in a competency-based learning instrument also finds support in current assessment literature focusing on 'assessment for learning'. 9,10 


\section{RESEARCH QUESTION 2}

\section{What are the implications for the design of workplace learning when integrating learning, assessment and supervision in the workplace context?}

The integration of learning, assessment and supervision in a workplace learning model has important implications for the design of the workplace learning programme. The programme needs to be revised in such a way that: 1) a formative reflection and feedback continuum is established, 2) active involvement in learning and supervision is encouraged, and 3) collaboration in learning is facilitated. The next paragraphs will further elaborate on these suggested revisions. After that, we describe the essential conditions for a successful integrated workplace learning design.

\section{Creating a formative reflection and feedback continuum}

In our endeavour to integrate learning, assessment and supervision, we found the creation of a formative reflection and feedback continuum within and across workplaces to be of paramount importance. This continuum was established by implementing a twofold reflective learning strategy (reflection on performances and reflection on competency development). The integrated learning and assessment instrument allowed for a more smooth adoption of this strategy, as was previously discussed.

The twofold reflective learning strategy (chapter 6, steps 3 and 4) builds on the research of Eva and Regehr who state that developing self-directed competency development is based on different cognitive processes: self-monitoring of performances and selfassessment of learning (a cumulative evaluation of overall performance). ${ }^{11,12}$ Selfmonitoring is a day-to-day activity, whereas self-assessment is an activity that is done with larger time intervals on the learning continuum. The results revealed a marked preference for self-monitoring of performances, because of the immediately perceived learning effects on performance improvement. These findings are consistent with the work of Eva and Regehr, ${ }^{12}$ who reported an apparent divergence between poor overall self-assessment and effective self-monitoring. Based on our longitudinal study of learner perceptions of two reflective writing activities, we found that graduates recognised - more often than undergraduates - that reflective writing on one's own competency development was useful, because it facilitated longitudinal learning across internships. The nature of these perceptions was confirmed by the results of the quantitative study in chapter 5 , a study investigating the relationship between reflection ability (self-assessment) and clinical performance (professional competence). We found that reflection scores of earlier years were significantly related with clinical perfor- 
mance scores of subsequent years, a finding supporting the evidence that learners must practice these skills from the start in an educational process. ${ }^{3,13}$

The results of the study reported in chapter 5 point to a significant correlation between the ability to reflect and clinical performance. These results confirm previous studies demonstrating the importance of 'informed self-assessment' ${ }^{13-15}$ Indeed, accurate selfassessment depends on high-quality data, ${ }^{16}$ and the workplace learning instrument might have contributed to the nature and quality of the data collection. Students (chapters 2 and 4 ) and supervisors (chapter 3 ) stated that the continuous and longitudinally collected written information enabled them to read and reread information presented during the learning period. This written information was labelled 'memory support', referring to its importance of cognitive processing during self-assessment and competency development. ${ }^{11,16,17}$ Furthermore, the integration of internal (reflection) and external (feedback) data within one assessment instrument was considered valuable for its potential to help assess current performance and to promote future learning. ${ }^{16}$ Finally, in the first two qualitative studies, both students and teachers were generally positive about the inclusion of an assessment unit in the learning module. As supported by the literature, high-quality external data, such as formal, standardised assessments, help learners formulate self-assessments when these data are presented in a coherent, timely, nonthreatening, and digestible format. ${ }^{16,18,19}$

\section{Encouraging active involvement in learning and supervision}

The second implication on the programme design - the necessity to encourage active involvement in learning - resulted from a qualitative data analysis. Learners found that integrating learning and assessment, by collecting, writing, asking, reading and rereading feedback, enhanced their active involvement in learning. It helped them to take responsibility for their own learning. The integrated learning and assessment instrument, moreover, allowed them to play an active role in their own development (chapters 2 and 4). Supervisors confirmed that learners were indeed stimulated to reflect on their abilities and opportunities for improvement. They also found that active reflective learners stimulated them to provide more feedback and that reading the students' reflective notes before giving or writing feedback facilitated individual supervision. The latter is important to support self-directed learning and student-centred supervision in clinical practice (chapter 3).

Various inferences can be drawn from the studies, which are in line with Archer's findings: ${ }^{20}$ (1) undergraduates, graduates and supervisors (chapters 2 to 4 ) are favourable to the implementation of feedback-seeking instructions; (2) longitudinal written 
feedback is inherently linked to the conceptualisation of feedback as a supported sequential process, rather than a series of unrelated events; and (3) active feedbackseekers stimulate a two-way communication process during clinical practice. This latter inference is important and central to collaborative learning theory. According to this theory, the notion of collaborative relationship and collective conversation involves dynamic and non-hierarchical two-way exchanges. ${ }^{21}$ This leads us to the third implication.

\section{Facilitating collaboration in learning}

Integration promotes collaboration between all stakeholders involved in workplace learning. Establishing connections and collaboration between stakeholders is critical to the establishment of a productive learning community ${ }^{1}$ where learners are encouraged to improve performances and to engage in continuous self-directed competency development. Our research revealed that there are two distinct processes of reflective learning: immediate performance improvement and longitudinal competency development. These learning processes, in turn, require different types of supervision: that of learner performances on the one hand, and that of the learner's continuous process on the other (chapter 4). In order to optimise continuous competency development in current complex and discontinuous learning environments, supervisors should be assigned specific guiding roles for both processes, and they should be supported in their respective roles. To date, this topic has received limited recognition in research on workplace learning. ${ }^{22,23}$

In our workplace model we distinguish the roles of 'observer' and 'learning guide' (or mentor) (chapter 6). Observers scrutinise performances (single learning events). They do so by inviting learners to reflect immediately on performances, by checking their reflections, and by providing feedback on performances and these reflections. Learning guides (or mentors) play a role in monitoring the longitudinal process of competency development by weighing evidence against performance standards, deciding on learning needs and progress, and by developing action plans in collaboration with learners. $^{10,24-26}$

\section{Essential conditions for a successful integrated workplace learning design}

Students and supervisors noted important barriers to the positive effects of the workplace model on the learner's developmental process. This led us to conclude that essential conditions must first be met before the positive effects of an integrated learning, assessment and supervision workplace learning design can become manifest. 
An important barrier encountered by learners and supervisors was a lack of time for reflection and feedback. The same barrier - time - was also found in the literature on portfolio and workplace-based assessment. ${ }^{27,28}$ Making time available for reflection, feedback and dialogue, is therefore an important condition if one wishes to improve performance and competency development at the workplace. The literature on clinical education upholds this view.

The lack of time was often related to the competency-based structure of the learning instrument. Most learners were positive about the effects of reflective writing, but preferred a less structured and detailed instrument so that writing would take less time and could be discussed with the clinical supervisor (chapter 2). Supervisors also confirmed that 'they had no time to read such a bundle' and they stressed the difficulty to write feedback on observed performances in an educational competency structure (chapter 3). Therefore, the original MAFI-instrument (chapters 2 and 3) was redesigned to embody a different structure for reflection and to include the provision of feedback on both performance and competency development (chapter 6, figure 2).

This sense of having a lack of time, however, was also triggered by the nature of the instructions received. As learners were expressly asked to reflect on performance and to collect written feedback on their competencies in preparation for their final assessment, this was regarded by many as a time consuming job, although they agreed that it helped them to become more actively engaged in learning (chapter 2). The same impact of clearly demarcated expectations and structured formats to document personal development on learning was also found in postgraduate medical education. ${ }^{28,29}$

The foregoing brings us to another condition in the workplace setting, i.e. the need for a 'culture of reflection and feedback'. Despite the importance of scaffolding reflection with feedback, in reality only a minority of supervisors gives feedback on students' written reflections (chapter 3 ). Both learners and supervisors mentioned several factors that contributed to a suboptimal culture of reflection and feedback. Besides a lack of time, they mentioned a lack of observation of student-patient interactions. Unobserved performances resulted in a lack of feedback on and dialogue about the work (chapters 2 to 4). Another factor that proved detrimental was signalled by supervisors who detected inconsistent feedback behaviour within their team. Instead of providing detailed contextualised feedback that can guide ongoing performance improvement, supervisors knew that some colleagues didn't write feedback, and that others avoided writing negative feedback (chapter 3 ). These results reiterate concerns regarding effective feedback as reported in the literature. ${ }^{16,29}$ Unquestionably, there is a need for timely, 
specific feedback that is validated by direct observation. ${ }^{24,29-31}$ This, in particular, is essential for creating a learning and assessment continuity.

Another barrier encountered was a lack of training. Supervisors should be trained to make a distinction between monitoring single performances on the one hand, and monitoring a continuous learning process on the other. In addition, they should be trained to apply the integrated learning instrument to its full potential (chapter 3 ) and to ask students to reflect before giving feedback. In this way, workplace learning and supervision can be tailored to the learner's individual and evolving needs. This is an essential, but undervalued aspect of guiding a developmentally progressive workplace learning curriculum. ${ }^{1}$

Finally, to face the workplace reality of discontinuity and complexity, it might be helpful to define different roles for professionals who guide performances and who guide the continuous learning process (chapter 6 ). The results of chapter 4 suggest that reflective writing activities - addressing different learning goals (reflection on actions and reflection on development) - might require different educational arrangements when it comes to timing, length of the reflective learning cycle and content of reflection and feedback. Mentors can be aided in their efforts to foster continuous competency development. When all community members observe students during patient care, when they invite learners to reflect immediately on performances, when they read reflections and when they write feedback on observed performances and reflections. Although there's evidence available that stresses the importance of frequent meetings between students and mentors for regular review feedback and reflection on progress, ${ }^{10}$ learners felt progress meetings were missing, either because they just weren't organised or because the quality was suboptimal (chapters 2 and 4). This could mainly be attributed to the fact that supervisors were inadequately prepared for fostering learning in a clinical setting; they did not have enough time at their disposal to assist learners; and they met with clinical teams that had a poor understanding of the student's learning needs (chapters 2 to 4). Similar barriers to adequate mentoring were found in the literature. ${ }^{23}$ Collecting and connecting high-quality information on observed individual performances will support the assessment committee in their summative assessment role. This brings us to the third research question. 


\section{RESEARCH QUESTION 3}

\section{What is the effect of integrating learning, assessment and supervision in the workplace on summative assessment?}

The last research question addresses the effect integration of the three components has on summative assessment. This effect is twofold and can be denoted as follows: 1 ) it creates an assessment continuum; and 2) it facilitates collaboration in assessment.

\section{Creating an assessment continuum}

By integrating learning, assessment and supervision, one aims at the continuous and longitudinal collection of data about performance and competency development. Such a fusion is indispensable in the context of a discontinuous clinical training programme. As we discussed in the previous paragraph, such an integrated approach can foster selfassessment and formative assessment. In this paragraph, however, we will discuss the effects the approach has on summative assessment.

First, we consolidated the educational continuum (chapter 6 , steps 1 to 4 ) by introducing a new two-step summative assessment strategy (chapter 6, steps 5 and 6): summative assessment of individual competencies (step 5) and summative assessment of global professional competence (step 6). The resulting assessment continuum is consistent with the findings in the literature, where assessment is often understood to include both 'formative' and 'summative' assessment. Formative assessment, on the one hand, is essentially about providing feedback to students in order to support and enhance their learning. Summative assessment, on the other hand, is about measuring students' achievement for grading purposes or for informing decisions about progress. ${ }^{32,33}$ In our workplace model, we present the programmatic learning and assessment approach, and elaborate on the role a 'member of the summative assessment committee' performs (chapter 6).

Second, the competency structure in this integrated workplace learning model called for accountability in different ways. Assessment was organised within the externally defined framework of midwifery requirements. ${ }^{34}$ Furthermore, summative assessment of individual competencies (step 5) was important to guarantee the acquisition of all competencies. ${ }^{4}$ Finally, assessment of professional competence (step 6) in the final year guarantees a professional judgement about 'fitness for practice' ${ }^{33}$ 


\section{Facilitating collaboration in assessment}

The integrated workplace learning model, and its inherent learning instrument, revolves around the continuous collection of written information by scaffolding reflection with feedback from all stakeholders involved in the workplace learning process. We expect this information to help assessors in making their summative judgements. However, we found contradicting results when analysing qualitative perceptions of learners (chapter 2) and quantitatively significant correlation scores between reflection ability and performance (chapter 5). Learners, especially second and third year students, found the integration of learning, assessment and supervision to have a positive effect on selfassessment and formative assessment. The effect on summative assessment, however, was contested (chapter 2). For instance, they contended that many supervisors didn't use the checklist and that the clinical supervisor often was not involved in the final assessment meeting between the student and the teacher from school, which they regretted. This underlines the importance of collaboration when integrating learning and assessment. As we pointed out before, the workplace learning instrument can be useful to collect data, but all workplace stakeholders should share the responsibility for collecting evidence in order to support summative assessment. Students' perceptions about summative assessment can be translated into students' concerns about the subjectivity of assessments, a finding that was also reported in the literature. ${ }^{35,36}$

\section{IMPLICATIONS FOR THEORY AND PRACTICE AND DIRECTIONS FOR FURTHER RESEARCH}

In this section, we will outline the implications our research may have for theory and practice and suggest certain topics that may require further research.

\section{Continuity}

\section{Continuity as an organising principle}

New models for continuous learning in health care education should be implemented in order to prepare graduates for the challenges they will face in a health care system that is becoming ever more complex. ${ }^{13,37-40}$ Undergraduates and graduates should be able to address learning needs at any stage of the educational continuum. ${ }^{13}$ Further research into the concept of 'continuity' or vertical integration as an organising principle seems essential for further clinical education reform. ${ }^{1}$ The literature also stresses the importance of patient continuity. ${ }^{1}$ We did not address this matter in our studies. Never- 
theless, we are convinced that a focus on continuity in learning experiences is an essential condition for the improvement of future workplace learning.

\section{The cognitive learning continuum}

Further research into continuous competency development will be closely linked to research on cognitive sciences and educational psychology, because of its focus on the implications for the processing of information. We already referred to metacognitive processes in the context of reflection and self-regulation. Also, cognitive load theory could be employed, considering the competing demands from the learning environment and the workplace on the available cognitive resources. Successful self-directed competency development in the workplace requires an interplay of multiple processes, which is something that can only be developed over time. These processes comprise those in the cognitive-affective (i.e. motivation and emotion), social (i.e. interaction with experience of others), environmental (i.e. location or setting) and meta-cognitive (i.e. thinking about one's thinking) domain. ${ }^{17}$ Given the complexity of learning, and workplace learning in particular, it is not surprising that many sometimes competing and often overlapping theories of learning have gained momentum. As an example, this paragraph will draw further on Cognitive Load Theory. This theory is increasingly receiving recognition in the literature on medical education. When the cognitive load associated with an activity exceeds the learner's working memory capacity, learning and performance are being impaired. This is especially the case when designers of the learning environment don't seek to reduce the extraneous cognitive load that results from a weaker presentation and representation of the problem/task. Extraneous cognitive load can be invoked when prior knowledge has not been activated or when the structure of the task is confusing. This could have been the case with first- and second-year learners in our studies, when they were asked to write self-assessments on competency development (chapter 4). To reduce the extraneous cognitive load, we can provide this group of learners with scaffolds. When a task is very complex, peer collaboration has also been recommended to diminish individual cognitive load. ${ }^{41}$ Therefore, scaffolding individual learning and optimising peer learning at the clinical workplace could be used to minimise the extraneous cognitive load. ${ }^{17}$

\section{Collaboration}

A growing body of literature underlines the importance of collaboration in education. $^{21,39,42}$ More fundamental research is necessary to understand the processes involved in collaborative learning and the ways in which collaboration can nurture continuous competency development during a clinical workplace programme. 


\section{Collaboration, relationships and dialogue}

Central to collaboration is the notion of a collaborative relationship and a dialogic conversation in order to evoke new learning. ${ }^{21}$ In this doctoral thesis, we found that learners want to engage more in dialogue with their teachers (chapters 2 and 4). Although collaborative learning is often viewed as unstructured learning, state-of-theart conceptions of collaborative learning emphasise structure. In this context, some authors provide 'scripts' or 'roles' to guide the interaction. ${ }^{43,44}$ The teacher must trust the collaborative-dialogic process and must trust the students. This is different from the traditional hierarchical and dualistic teacher-student relationships in the teaching setting to which students are accustomed. We argue that longitudinal internships, with longer student-teacher relationships, can optimise collaborative learning. ${ }^{45}$

\section{Collaboration and collective competency}

Educators of the future will create environments in which students learn collaboratively. This is somewhat in contrast with the focus of the current doctoral thesis on the individual learning process in a clinical workplace setting. Nevertheless, self-directed learning is not about learning in isolation. ${ }^{39,42}$ Therefore, students should move away from a setting in which traditional individual competitive learning is stimulated and be guided towards a new setting in which sharing, inquiry and co-construction are central activities. This will lead students to become active agents of their learning, to enhance each other's learning and to share with one another the responsibility for their own and the others' learning at the workplace. ${ }^{42}$ Thus, to achieve lifelong competency development, we should focus on both the individual ('individual competency') and the system ('collective competency'). ${ }^{44}$ A way to render this process overt is to institutionalise processes of individual and collegial reflection, ${ }^{42,46,47}$ and to add a team evaluation to individual evaluation. ${ }^{21}$ Future research might focus on the emerging discourse on 'collective competency' to avoid educating competent individuals and educate competent teams instead. ${ }^{48,49}$

\section{STRENGTHS AND LIMITATIONS}

The concrete design of a feasible conceptual framework - based on empirical research is one of the strengths of the studies presented in this doctoral thesis. This framework addresses the need of competency-based frameworks that support continuous professional competence development in the workplace, with respect for the daily reality of complex and discontinuous clinical workplace learning settings. ${ }^{4}$ 
An additional strength of our framework is that it integrates various components of workplace learning. In the literature, there is no unifying or single theory that covers all aspects of learning in the clinical workplace. Available research often merely addresses single components, instead of embracing a more holistic understanding of workplace learning. Therefore, as mentioned in the introduction, our framework integrates not only cognitive and sociocultural approaches, but also different components of workplace learning. We conceptualised an Integrated Learning Assessment and Supervision Competency Framework. This framework has shown to be helpful to understand and meet the complexity of developing, guiding and assessing continuous and self-directed competency development in the workplace. It has the potential to conceptualise competency development as an educational continuum from undergraduate over postgraduate education towards a lifelong engagement in continuous professional development.

A challenge - shared in the field of (medical) education - is the conceptual confusion in relation to the concepts used in our studies. ${ }^{50,51}$ Divergent definitions of competency and competence, in particular, invoke interpretation problems. ${ }^{52}$ We tried to eliminate this confusion by making a clear distinction between the concept of professional competence and the concept of individual competencies.

The fact that our studies were consistently conducted in one single Midwifery department, introduces a potential weakness of our work. As with any single institution study we have to be cautious when extrapolating findings to other contexts. However, our choice to be consistent is also a strength, since it allowed us to conduct more in-depth qualitative and quantitative research. We could combine both the results of longitudinal quantitative research, and the analysis of, e.g., student and clinical supervisor perceptions. A limitation, however, is that we didn't include the perceptions of the supervisors from the Midwifery department in our study. This could have allowed us to develop a more $360^{\circ}$ perspective.

Another limitation is that we designed a workplace learning model to stimulate selfdirected continuous competency development during undergraduate Midwifery education. As a consequence, caution is required when extrapolating our findings to postgraduate programmes and other programmes in health professions education.

In conclusion, we proposed a conceptual framework of workplace learning in health care education to advance the science of competency-based education in clinical practice. The framework enabled to conceive new lines of research and add empirical evidence to the existing body of knowledge relevant to workplace learning. Therefore, 
we hope this doctoral thesis, resulting in an Integrated Workplace Learning Assessment and Supervision Competency Framework, will inspire broader international research. We invite educators and professionals in health care to adopt this framework and to collaborate on further research.

\section{FINALLY}

We started this doctoral thesis by referring to the challenge a health professions educator is faced with: 'How can workplace learning be conceptualised as a continuous developmental process within discontinuous communities of clinical practice?'. The research project that was set up to tackle this challenge resulted in the design and implementation of a holistic and competency-based model that has the potential to facilitate continuous and self-directed competency development in clinical education. The 'Integrated Learning Assessment and Supervision Competency Framework', seems a useful workplace learning model for $21^{\text {st }}$-century undergraduate Midwifery education that is featured by complex and discontinuous clinical learning environments. The studies indicate that various components of workplace learning must be integrated if one wishes to encourage continuous self-directed competency development in health care education. Central to the model are: integration, collaboration and continuity. This model integrates learning (reflection and feedback on performances and competency development), assessment (self-, formative and summative assessment) and supervision (observation, mentoring, and assessment roles at the workplace and in school) in a competency framework. Workplace learning models shouldn't be reduced to single components, such as workplace learning instruments. Instead, educators and health care professionals should seek to cultivate a workplace learning environment in which students and supervisors from the workplace and school collaborate and share responsibility for the quality and integration of complex but inseparable components of workplace learning. This integrated and collaborative focus on the continuous development of self-directed learning of competencies during clinical education will teach learners how to meet the expectations of continuous professional development also after graduation. $39,40,45,50$ 


\section{REFERENCES}

1. Hirsch DA, Ogur B, Thibault GE, Cox M. "Continuity" as an Organizing Principle for Clinical Education Reform. N Engl J Med 2007;356(8):858-866.

2. Harden RM. Outcome-Based Education: the future is today. Med Teach 2007;29(7):625-629.

3. McKauge L, Stupans I, Owen SM, Ryan G, Woulfe J. Building Critical Reflection Skills for Lifelong Learning in the Emergent Landscape of a National Registration and Accreditation Scheme. J Pharm Pract 2011;24(2):235-240.

4. Pijl-Zieber M, Barton S, Konkin J, Awosoga O, Caine V. Competence and competency-based nursing education: Finding our way through the issues. Nurse Educ Today 2014;34(5):676-678.

5. Stoof A, Martens R, Van Merriënboer R, Bastiaens T. The Boundary Approach of Competence: A Constructivist Aid for Understanding and Using the Concept of Competence. Human Resource Development Review 2002;1(3):345-365.

6. Epstein RM, Hundert EM. Defining and assessing professional competence. JAMA 2002;287(2):226-235.

7. van der Vleuten CPM, Schuwirth LWT, Driessen EW, Dijkstra J, Tigelaar D, Baartman LKJ, van Tartwijk J. A model for programmatic assessment fit for purpose. Med Teach 2012;34(3):205-214.

8. Zibrowski EM, Sing SI, Goldszmidt MA, Watling CJ, Kenyon CF, Schulz V, Maddocks HL, Lingard L. The sum of the parts detracts from the intended whole: competencies and in-training assessments. Med Educ 2009;43(8):741-748.

9. Schuwirth LWT, van der Vleuten CPM. Programmatic assessment: From assessment of learning to assessment for learning. Med Teach 2011;33(6):478-485.

10. Dannefer EF. Beyond assessment of learning toward assessment for learning: Educating tomorrow's physicians. Med Teach 2013;35(7):560-563.

11. Eva KW, Regehr G. Knowing when to look it up: A new conception of self-assessment ability. Acad Med 2007; 82(10 Suppl):s81-84.

12. Eva KW, Regher G. Exploring the divergence between self-assessment and self-monitoring. Adv Health Sci Educ 2011;16(3):311-329.

13. Miller BM, Moore DE, Stead WW, Balser JR. Beyond Flexner: A New Model for Continuous Learning in the Health Professions. Acad Med 2010;85(2):266-271.

14. Sargeant J, Armson II, Chesluk B, Dornan T, Eva K, Holmboe E, Lockyer J, Loney E, Mann K, van der Vleuten $C$. The processes and dimensions of informed self-assessment: A conceptual model. Acad Med 2010;85(7):1212-1220.

15. Sargeant JM, Eva KW, Armson H, Chesluk B, Dornan T, Holmboe E, Lockyer JM, Loney E, Mann KV, van der Vleuten CPM. Features of assessment learners use to make informed self-assessment of clinical performance. Med Educ 2011;45(6):636-647.

16. Epstein RM, Siegel DJ, Silberman J. Self-Monitoring in Clinical Practice: A Challenge for Medical Educators. J Contin Educ Health Prof 2008;28(1):5-13.

17. Young JQ, Van Merrienboer J, Durning S, Ten Cate O. Cognitive Load Theory: Implications for medical education: AMEE Guide No. 86. Med Teach 2014;36(5):371-384.

18. Epstein RM, Dannefer EF, Nofziger AC, et al. Comprehensive assessment of professional competence: The Rochester experiment. Teach Learn Med 2004;16(2):186-196.

19. Van der Vleuten CP, Schuwirth LW. Assessing professional competence: From methods to programmes. Med Educ. 2005;39(3):309-317.

20. Archer JC. State of the science in health professional education: Effective feedback. Med Educ 44(1):101-108.

21. Anderson H. Collaborative Learning Communities. A Postmodern Perspective on Teaching and Learning. In: Irby BJ, Brown G, Lara-Alecio R, Jackson S (Eds.). The Handbook of Educational Theories. Charlotte, North Carolina (USA): Information Age Publication 2013:515-527. 
22. Gurling J. Link mentorship: improving support for pre-registration students and mentors. Br J Comm Nurs 2011;16(9):e435-440.

23. Henderson A, Eaton E. Assisting nurses to facilitate student and new graduate learning in practice settings: what 'support' do nurses at the bedside need? Nurse Educ Pract 2013;13(3):197-201.

24. Hauer KE, Holmboe ES, Kogan JR. Twelve tips for implementing tools for direct observation of medical trainees' clinical skills during patient encounters. Med Teach 2011;33(1):27-33.

25. Knowles M. Self-Directed Learning: A Guide for Learners and Teachers. Chicago: Follet 1975.

26. Yuan HB, Williams BA, Fang JB, Pang D. Chinese baccalaureate nursing students' readiness for selfdirected learning. Nurse Educ Today 2012;32(4):427-431.

27. Driessen E, van Tartwijk J, van der Vleuten C, Wass V. Portfolios in medical education: Why do they meet with mixed success? A systematic review. Med Educ 2007;41(12):1224-1233.

28. Hrisos S, Illing JC, Burford BC. Portfolio learning for foundation doctors: early feedback on its use in the clinical workplace. Med Educ 2008;42(2):214-223.

29. Delva D, Sargeant J, Miller S, Holland J, Alexiadis Brown P, Leblanc C, Lightfoot K, Mann K. 2013. Encouraging residents to seek feedback. Med Teach 2013;35(12):e1625-e1631.

30. Dornan T. Experience Based Learning. Learning clinical medicine in workplaces. Maastricht: Universitaire Pers 2006.

31. Kogan JR, Holmboe ES, Hauer KE. Tools for Direct Observation and Assessment of Clinical Skills of Medical Trainees. JAMA 2009;302(12):1316-1326.

32. Cantillon P, Sargeant J. Giving feedback in clinical settings. BMJ 2008;337:a1961.

33. Norcini, J., Anderson, B., Bollela, V., Burch, V., Costa, M.J., Duvivier, R., Galbraith, R., Hays, R., Kent, A., Perrott, V., Roberts, T. Criteria for good assessment: consensus statement and recommendations from the Ottawa 2010 Conference. Med Teach 33(3), 206-214.

34. Slowther A, Spicer J. Ethical and legal issues. In: Medical Education and Training. Carter Y, Jackson N (Eds.). United Kingdom: Oxford University Press 2009:339-350.

35. Driessen $E$, Scheele $F$. What is wrong with assessment in postgraduate training? Lessons from clinical practice and educational research. Med Teach 2013;35(7):569-574.

36. Hodges B. Assessment in the post-psychometric era: Learning to love the subjective and collective. Med Teach 2013;35(7):564-568.

37. Plsek PE, Greenhalgh T.The challenge of complexity in healthcare. BMJ 2001;323:625-628.

38. Fraser SW, Greenhalgh T. Coping with complexity: Educating for capability. BMJ 2001;323:799-803.

39. Dunlap JC, Grabinger S. Preparing for Lifelong Learning: A Review of Instructional Features and Teaching Methodologies. Performance Improvement Quaterly 2003;16(2):6-25.

40. Mukhopadhyay S, Smith S, Cresswell J. Lifelong Learning in obstetrics and gynaecology: how theory can influence clinical practice. J Obstet Gynaec 2011;31(6):476-479.

41. Schunk DH. Learning theories: An educational perspective. Boston: Pearson 2012.

42. Frankford DM, Patterson MA, Konrad TR. Transforming Practice organizations to Foster Lifelong Learning and Commitment to Medical Professionalism. Acad Med 2000;75(7):708-717.

43. Weinberger A, Reiserer M, Ertl B, Fischer F, Mandl H. Facilitating collaborative knowledge construction in computer-mediated learning environments with cooperation scripts. In: Bromme R, Hesse FW, Spada $\mathrm{H}$ (Eds.). Barriers and Biases in Computer-Mediated Knowledge Communication. Boston: Kluwer 2005:15-38.

44. Lindgren S, Gordon D. Lifelong quality improvement. Med Educ 2012;46(1):11-12.

45. Teherani A, Irby DM, Loeser H. Outcomes of different clerkship models: Longitudinal integrated, hybrid, and block. Acad Med;88(1):35-43.

46. Grol R. Changing Physicians' Competence and Performance: Finding the Balance between the Individual and the Organization. J Contin Educ Health Prof 2002;22(4):244-251.

47. Mann KV. Theoretical perspectives in medical education: past experience and future possibilities. Med Educ 2011;45(1):60-68. 
48. Lingard I. What we see and don't see when we look at 'competence': notes on a god term. Adv in Health Sci Educ 2009;14(5):625-628.

49. Gonzalo JD, Haidet P, Wolpaw D. Authentic clinical experiences and depth in systems: toward a $21^{\text {st }}$ century curriculum. Med Educ 2014;48(2):104-112

50. Dochy FJRS, Alexander PA. Mapping Prior Knowledge: A Framework for Discussion among Researchers. Eur J Psychol Educ 1995;10(3):225-242.

51. Teunissen PW. Unravelling learning by doing. A study of workplace learning in postgraduate medical education. Amsterdam: Vrije Universiteit Amsterdam 2008.

52. Walton MM, Elliott S. Improving safety and quality: how can education help? Medical Journal of Australia 2006;184(10):S60-S64. 


\section{Summary}

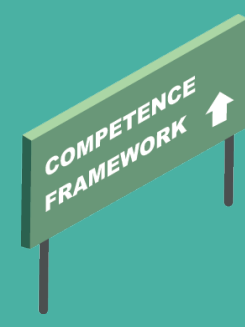





\section{CHAPTER 1}

Clinical workplaces continue to be important learning environments in the $21^{\text {st }}$ century. In order to derive the most benefit from them, learners must take an active part in their own education by setting goals, and monitoring their progress towards those goals. Self-directed learning at the clinical workplace is a continuous process of personal and professional development. Self-directed learners are expected to take the initiative, but in doing so, they must be able to count on the support of their supervisors.

The literature on workplace learning stresses the fact that developing, assessing and guiding a continuous developmental process at the clinical workplace is a complex undertaking. Traditional models of workplace learning often do not match the reality of today's clinical workplaces. These workplaces are characterised by diversity, unpredictability, unstructured learning experiences, short and discontinuous relationships with supervisors, work pressure, complex learning in inter-professional groups and by the learner's dual task of receiving professional training while at the same time providing medical care to real patients. What's more, clinical workplace programmes are short in duration, they differ in kind, and take place in different settings. To accommodate these short-lived and dissimilar clinical workplace programmes into the educational programme in such a way that a continuation of the developmental progress is guaranteed, poses a major challenge to educators. This dissertation has sought to answer the following research questions: 1) How can learning, assessment and supervision in the workplace be integrated with the aim to support a continuous developmental process?; 2) What are the implications for the design of workplace learning when integrating learning, assessment and supervision in the workplace context?; and 3) What is the effect of integrating learning, assessment and supervision in the workplace on summative assessment? Answers to these questions were based on qualitative and quantitative research studies, which are set out in chapters 2 to 5 . Chapter 6 introduces an integrated workplace learning model for health care education. The final chapter discusses the answers to the research questions, strengths and limitations of this dissertation, and potential topics for additional research.

\section{CHAPTER 2}

Before the present dissertation was drafted, we developed an Integrated Midwifery Feedback and Assessment Instrument (MAFI) to support competency-based education in clinical practice. In doing so, we used a qualitative research design to gain insight into student' perceptions. The results are based on four focus group discussions with second 
and third year Midwifery students (Ghent). The results show that all students shared the opinion that everyday writing in the feedback unit contributed positively to the development of reflection skills and strategies to optimise self-directed learning in the workplace. However, they differed in their motivation to write reflections and feedback according to their maturity in the educational process. Third year students, for instance, were motivated intrinsically by the effect it had on their competency development, whereas second-year students were mostly motivated by external factors, such as assessment and guidance. Furthermore, students were positive about the effects of the MAFI-instrument's second unit. They found that the checklist with detailed competency-based assessment criteria could serve as a 'quick scan'. In this case, such an elaborate overview was regarded as added value, whereas students of the first unit preferred a less detailed instrument. Students found that the integration of both units helped to advance their self-assessment and formative assessment. It is important to mention, moreover, that students had different perceptions about the value of the integrated instrument for summative assessment. We concluded that the instrument can be optimised if feedback is assured to be effective and if sufficient time is provided for the writing process, as well as for the discussion with the supervisors. This research clearly shows the important role supervisors play in facilitating and supporting a self-directed learning process.

\section{CHAPTER 3}

After having investigated the subject from a student's point of view, we became curious about the experiences supervisors had with the integrated MAFI-instrument. To this end, we conducted interviews with fifteen clinical supervisors. In general, supervisors agreed with the students that the MAFI-instrument encouraged self-directed learning as it fostered active involvement in learning and continuity in supervision. They found that the competency structure in the feedback and assessment unit helped to define learning outcomes and sharpened their focus on competency development. Furthermore, they found that instructing students to write reflections helped them to respond to the student's individual needs more effectively and to improve their feedback. Nevertheless, supervisors agreed with students that the learning effect was suboptimal because not all the team members were equally involved in the student's learning process. Some colleagues were not motivated to observe performances, read reflections and write feedback. According to the supervisors, more benefits can be derived from the integration of learning and assessment, when an assessment and feedback culture is created in which learners and supervisors share the responsibility for the selfdirected learning process. This takes us to the cornerstone of socio-cultural learning 
theories, which regard partnership and collaboration as key elements of effective learning in a community of practice.

\section{CHAPTER 4}

The development of reflection is a continuous self-regulating process, consisting of continuous self-monitoring of performances and delayed self-assessment of competency development. In order to stimulate both cognitive activities, we added a second reflection activity to the existing immediate reflection on actions (daily reflections in MAFI), specifically delayed reflection on competency development (at the end of the work placement). This study has sought to unravel learners' perceptions of the effects of both reflective writing activities. A total of 142 respondents (first-, second- and thirdyear students, as well as recent graduates) completed a questionnaire with open and closed questions for each reflection activity. Quantitative and qualitative data were triangulated. Immediate reflection-on-action was valued more than delayed reflectionon-competency development, because it facilitated day-to-day improvement and twoway feedback. Delayed reflection was taken to facilitate overall self-assessment, selfconfidence and continuous improvement across workplaces. These perceptions were mainly shared by graduates who give the highest rating to this delayed reflection activity. The results implied that the learning effect of both reflection activities is reliant on several factors. It was concluded that the inclusion of both reflective writing activities in the programme can foster continuous performance improvement and competency development, as long as their distinct nature is taken into account. An important difference was related to the structure of reflective writing. It proved difficult to reflect on performances along the lines specified by the competency framework. Therefore, the MAFI-structure was adapted to the reality of clinical workplaces and redesigned in such a way that performances did not have to be expressed in terms of competencies, but they could be described as they saw fit. The competencies could then be derived from the performance descriptions.

\section{CHAPTER 5}

Reflection is increasingly being considered as a core competency of performance (professional competence), but empirical research into the relationship between reflection and clinical performance is scarce. The concept of performance in this study refers to the concept of 'professional competence', referring to the overall ability of performance. The implementation of reflection-on-competency-development in 2009, 
made it possible to correlate reflection and performance assessment scores. We conducted a quantitative cross-sectional and retrospective-longitudinal cohort study with assessment scores from first-, second- and third-year Midwifery students. When adopting a cross-sectional perspective, all correlation values were significant $(p<0.01)$ and above 0.4, with the exception of the third-year correlations. Assuming perfect reliability of our measurements, the adjusted correlations for years 2 and 3 indicated a high association between reflection and performance $(>0.6)$. The results based on the retrospective-longitudinal dataset explained a moderate proportion of the variance after correction for attenuation. The results in this data set also showed that the reflection scores from earlier years correlated significantly with performance scores of the subsequent years. This study confirms findings reported in the workplace learning literature: reflection is crucial to the development of professional competence and a reflective learning strategy supports competence growth. In sum, a reflective learning strategy should best be introduced at an early stage of the curriculum and reflection scores provide useful information to support assessment of professional competence.

\section{CHAPTER 6}

This chapter focusses on the complexity of implementing competency-based education in clinical practice. Reviews of the relevant workplace literature and four empirical studies (chapters 2 to 5) resulted in the design of an Integrated Learning Assessment and Supervision Competency Framework. The promotion of continuous and selfdirected competency development during a workplace learning programme requires an integration of competencies, learning (reflection and feedback on performance and on competency development), assessment (self-, formative and summative assessment) and supervision (observers, learning guides and a school assessment committee). This model emphasises the importance of creating a workplace learning continuity in which all stakeholders share the responsibility for the quality of workplace learning. They have to integrate the complex but inseparable processes of workplace learning. The designers of this workplace model hope that the framework will contribute to the development of competencies in future health care education.

\section{CHAPTER 7}

In the final chapter we revisit the theories and questions that were the driving force behind our research project. This thesis results in a holistic and competency-based model that offers possibilities to facilitate continuous and self-directed learning at the 
workplace. The 'Integrated Learning Assessment and Supervision Competency Framework' seems useful for current complex and discontinuous clinical workplaces. The keywords for this new workplace learning model are: integration, continuity and collaboration.

The main implications of our findings for educational practice are summarised in accordance with the different workplace learning components. Of course, educational models must not be reduced to individual components. More specifically, the degree to which a model will contribute to continuous and self-directed competency development in the workplace depends on the extent to which the components are integrated by all involved in workplace learning.

1. Theory: It is important to integrate individual cognitive learning theories with sociocultural learning theories to support continuous and self-directed competency development.

2. Competency framework: A competency framework is an educational structure that offers the possibility to discuss the learning continuum. However, educators must be aware of the fact that competency-based education is difficult for professionals to put into practice. Our research shows that it is necessary to make a distinction between learning, assessing and guiding performances on the one hand, and learning, assessing and guiding competency development on the other.

3. Curriculum: A curriculum consists of several blocks with workplaces in different contexts. Reflection and feedback on actions stimulates day-to-day improvement within one workplace, whereas reflection and feedback on competency development stimulate longitudinal growth across workplaces. We are talking about two different processes on a cognitive continuum: daily self-monitoring of performances versus delayed self-assessment of competency development.

4. Stakeholders: Self-directed learning means that students must take the initiative, but they must be supported. More attention should be given to the description of different roles of the stakeholders involved in the workplace. All team members are responsible for observation, reflection and feedback on performances. One, or a small number of motivated supervisors should be responsible for reflection and feedback on competency development. Continuous progress can be viewed within or across work placements. Special attention must be given to the role of the supervisor that monitors and promotes continuity across internships. 
5. Instrument: A competency-based and integrated learning and assessment instrument, with a different structure for performances and competency development, facilitates the stakeholders in their learning, assessment and supervisory role in the workplace.

6. Processes: The learning, assessment, and guiding processes can be described in six steps: 1) selection of competencies according to context, 2) formulation of learning goals, 3) self-monitoring of performances, 4) self-assessment of competency development; 5) summative assessment of individual competencies, and 6) summative assessment of professional competence.

7. Conditions: Workplace learning is complex because countless conditions determine the effect on continuous development. Literature and empirical research in this dissertation show that it is often here where the shoe pinches. Only when certain underlying conditions are met, a professional workplace culture with enough time for observation, reflection, feedback and assessment dialogues can take root. This culture will intensify collaboration and continuous personal and professional development.

8. Continuum: This model supports the creation of a learning and assessment continuum. The development of professional competence requires a programmatic view on learning and assessment across different workplaces.

Future research should continue to focus on the promotion of this educational continuum. We believe that more research is needed to measure the effect of longitudinally organised workplaces, continuous collected information, and a programmatic view on learning and assessment. Further research on continuous competency development will be inherently involved with research on the cognitive load theory and differentiation in workplace learning and supervision. Finally, more fundamental research is necessary to understand the processes involved in collaborative learning and how collaboration can promote continuous competency development during a discontinuous clinical workplace programme. 
Samenvatting

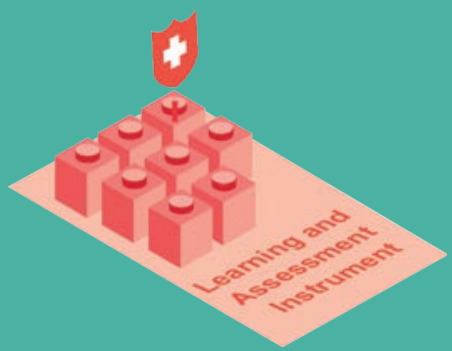





\section{HOOFDSTUK 1}

Klinische werkplekken blijven cruciale leeromgevingen voor het gezondheidszorgonderwijs van de $21^{\text {ste }}$ eeuw. Om optimaal te leren wordt van studenten verwacht dat zij het leerproces actief in handen nemen, doelstellingen formuleren, leernoden detecteren, actieplannen uitwerken en zichzelf beoordelen op het bereiken van competenties. Zelfsturend leren vertrekt bij het initiatief van de student maar begeleiders zijn cruciaal in het faciliteren van een zelfsturend leerproces. De literatuur op het gebied van werkplekleren beschrijft de complexiteit van het ontwikkelen, beoordelen en begeleiden van een continu ontwikkelingsproces op de klinische werkplek. Traditionele modellen van werkplekleren beantwoorden niet meer aan de realiteit van de huidige klinische werkplekken. Deze worden gekenmerkt door diversiteit, onvoorspelbaarheid, ongestructureerde leerervaringen, werkdruk, korte en onsamenhangende relaties met begeleiders, complexe zorg in interprofessionele teams en de moeilijkheid om de dubbele taak van zorgverlening en opleiding te combineren. Een bijkomende complexiteit ontstaat omdat klinische onderwijsprogramma's dikwijls bestaan uit korte leerperioden op werkplekken in verschillende contexten. Deze realiteit daagt het onderwijs uit om na te denken over de manier warop de ontwikkeling van een continu zelfsturend leerproces tijdens een klinisch onderwijsprogramma best kan verlopen. Dit proefschrift wil een antwoord geven op de volgende onderzoeksvragen: 1) Hoe kan leren, beoordelen en begeleiden geïntegreerd worden om een continu ontwikkelingsproces op de werkplek te stimuleren?; 2) Wat zijn de implicaties van de integratie van leren, beoordelen en begeleiden op het design van het leren op de werkplek?; en 3) Wat is het effect van de integratie van leren, beoordelen en begeleiden op de summatieve beoordeling op de werkplek? Het antwoord op deze vragen wordt onderzocht op basis van kwalitatief en kwantitatief onderzoek in vier studies (hoofdstukken 2 tot 5). Hoofdstuk 6 beschrijft een geïntegreerd klinisch werkplekmodel voor gezondheidszorgonderwijs. Het laatste hoofdstuk bevat de discussie.

\section{HOOFDSTUK 2}

Om het competentiegericht leren op de werkplek te bevorderen werd vóór de start van dit proefschrift een geïntegreerd feedback- en beoordelingsinstrument (MAFI) ontwikkeld. De studie had als doel om de percepties van tweede en derde jaar studenten verloskunde (Gent) te onderzoeken via 4 focusgroep discussies. Uit de resultaten blijkt dat alle studenten een positief effect ervaren van het dagelijks schrijven van feedback omdat het de reflectievaardigheden stimuleert en het zelfsturend leren optimaliseert. Studenten ervaren een actieve betrokkenheid bij het leerproces omwille van het 
verzamelen, vragen, schrijven, lezen en herlezen van feedback. Toch blijkt dat de motivatie om feedback te schrijven afhangt van de maturiteit van de student. Daar waar studenten van het derde jaar over het algemeen meer intrinsiek gemotiveerd zijn omwille van het effect op persoonlijke competentiegroei zijn studenten van het tweede jaar vooral gemotiveerd door externe factoren zoals beoordeling en begeleiding. Studenten ervaren ook een positief effect van het beoordelingsluik. Zij vinden de gedetailleerde competentiegerichte beoordelingscriteria handig om te gebruiken als 'quick scan'. De gedetailleerdheid wordt hier gezien als een meerwaarde terwijl studenten voor het eerste deel een minder gedetailleerd instrument wensen. De integratie van het feedback- en beoordelingsdeel in één instrument heeft een positief effect op de zelfbeoordeling en de formatieve beoordeling aangezien de verzamelde informatie continu kan vergeleken worden met de beoordelingscriteria. Studenten hebben verschillende meningen over de waarde van het geïntegreerd instrument voor de summatieve beoordeling. In elk geval zijn de studenten het erover eens dat het effect van het leerinstrument zou geoptimaliseerd worden indien de feedback zou voldoen aan de kwaliteitscriteria en indien voldoende tijd zou voorzien worden voor het schrijfproces, alsook voor de bespreking met de begeleiders. Uit dit onderzoek blijkt duidelijk de belangrijke rol die begeleiders hebben in het faciliteren en ondersteunen van een zelfsturend leerproces.

\section{HOOFDSTUK 3}

Na de perceptiestudie bij studenten wensten we inzicht te krijgen in de ervaringen van begeleiders met het geïntegreerd MAFI-instrument. Dit perspectief van de begeleiders was een belangrijke aanvulling op het perspectief van de studenten in hoofdstuk 2 . Uit de interviews met vijftien begeleiders kwam naar voor dat zij een geïntegreerd instrument waardevol vinden om het leerproces van studenten én de begeleiding ervan te faciliteren. Zij ervaren dat de competentiestructuur de aandacht voor continue competentiegroei en de te bereiken leerresultaten bevordert. Zij erkennen ook dat studenten inderdaad veel actiever om feedback vragen waardoor sommige begeleiders zeggen dat ze hierdoor gestimuleerd werden om te vertrekken bij leerervaringen van de student. Toch geven zij, net zoals studenten, aan dat het effect van het instrument nog onvoldoende is. Het grootste probleem is volgens hen dat niet alle collega's op de werkplek bereid zijn om te observeren en feedback te geven, reflecties van studenten na te lezen en zo nodig te corrigeren of aan te vullen. Een tweede probleem is dat de geschreven informatie onvoldoende besproken wordt. Volgens begeleiders moet meer aandacht gaan naar het stimuleren van een werkplekcultuur waar een gemeenschappelijke verantwoordelijkheid gedragen wordt voor de ontwikkeling van een zelfsturend leer- 
proces bij studenten. Deze inzichten brengen ons tot de kern van de socio-culturele leertheorieën waar leren in een community of practice gekenmerkt wordt door 'partnership' en 'collaboration'.

\section{HOOFDSTUK 4}

De ontwikkeling van reflectie is een continu zelfregulerend proces dat bestaat uit continue monitoring van handelingen en discontinue zelfbeoordeling van competentiegroei. Om beide cognitieve processen te stimuleren werd aan de bestaande onmiddellijke reflectie-activiteit op handelingen (dagelijkse reflectie in MAFI) een tweede reflectie-activiteit toegevoegd namelijk uitgestelde reflectie op competentiegroei (op het einde van de stage). Via deze studie wensten we ervaringen met deze twee schriftelijke reflectievormen te vergelijken. In totaal hebben 142 respondenten van de opleiding verloskunde (studenten van het eerste, tweede en derde jaar, alsook pas afgestudeerden) per reflectievorm een vragenlijst ingevuld met gesloten en open vragen. Via triangulatie van kwantitatieve en kwalitatieve data werd de waardering en het effect onderzocht. De waardering voor de onmiddellijke reflectievorm was bij alle respondenten hoger dan de waardering voor de uitgestelde reflectievorm. Onmiddellijke reflectie zorgde voor directe bijsturing en stimuleerde een feedbackproces in twee richtingen: de student vroeg actief om feedback waardoor de begeleider meer feedback gaf. Een ander beeld werd verkregen bij de uitgestelde reflectievorm. Uitgestelde reflectie bleek effectief om een zelfbeoordeling te faciliteren, alsook om het zelfvertrouwen en het continu leerproces over stages heen te stimuleren. Deze effecten werden voornamelijk door afgestudeerden beschreven. Zij gaven ook de hoogste waardering aan deze uitgestelde reflectievorm. Vanuit de analyse werden belangrijke voorstellen verzameld om het leereffect van beide reflectievormen te verhogen. Als besluit suggereren wij dat een combinatie van beide reflectievormen zinvol is omdat ze verschillende cognitieve processen stimuleren. De waardering en het effect van beide reflectievormen zal afhangen van de mate waarin aan de verschillende onderwijskundige voorwaarden voor beide vormen voldaan wordt. Een belangrijk voorbeeld is de structuur om reflecties neer te schrijven. Uit de resultaten blijkt dat het moeilijk is om dagelijkse reflecties onder een competentiestructuur neer te schrijven. Daarom werd het MAFI-formulier aangepast zodat handelingen niet langer moeten ontrafeld worden in competenties, maar competenties moeten herkend worden in de handeling. 


\section{HOOFDSTUK 5}

In toenemende mate wordt het 'reflectievermogen' benadrukt als een kerncompetentie van het 'professioneel handelen'. Empirisch onderzoek naar de relatie tussen beide is schaars. Omdat de opleiding sinds 2009 het reflectievermogen op stage afzonderlijk beoordeelt was het mogelijk om scores van reflectievermogen en professioneel handelen met elkaar te correleren. Er werd een kwantitatieve cross-sectionele en retrospectieve-longitudinale cohortstudie uitgevoerd met beoordelingscijfers van studenten in het eerste, tweede en derde jaar van de opleiding verloskunde (Gent). In de cross-sectionele data zijn de correlaties voor jaar 1 en 2 significant $(p<0,01)$ en hoger dan 0,4. Uitgaande van een perfecte betrouwbaarheid in de meting, tonen de gecorrigeerde correlaties voor jaar 2 en 3 een nog hoger verband aan (>0.6). De resultaten op basis van de retrospectieve-longitudinale dataset verklaren een matig deel van de variantie na correctie. De resultaten in deze dataset tonen ook aan dat de reflectiescores van eerdere jaren significant gecorreleerd zijn met scores van professionele competentie van de daaropvolgende jaren. Dit onderzoek bevestigt de literatuur over werkplekleren namelijk dat reflectie een belangrijk onderdeel is van het professioneel handelen en dat schriftelijke reflectie de professionele groei stimuleert. Voor de praktijk is dit een bevestiging dat een reflectiestrategie best vroeg in de opleiding start alsook dat de reflectiescores informatie geven om de complexe beoordeling van het professioneel handelen te ondersteunen.

\section{HOOFDSTUK 6}

Dit hoofdstuk stelt de complexiteit van de implementatie van competentiegericht leren op de werkplek centraal. Op basis van de literatuur en onderzoeksresultaten van hoofdstuk 2 tot en met 5 hebben we een 'Integrated Learning Assessment and Supervision Competency Framework' ontworpen om de continue en zelfsturende competentieontwikkeling op de werkplek te bevorderen. Dit nieuw model benadrukt dat het bevorderen van een continue competentiegroei op de werkplek een integratie vereist van competenties, het leerproces (reflectie en feedback op handelingen en op competentiegroei), het beoordelingsproces (zelfbeoordeling, formatieve en summatieve beoordeling) en begeleiders die het zelfsturend leren faciliteren (observatoren, leerbegeleiders van de werkplek en de opleiding, beoordelingscomité van de opleiding). Via dit model komt opnieuw tot uiting hoe belangrijk het is om meer aandacht te geven aan de continuïteit en de context-specificiteit van een leerproces. Het gaat niet om afzonderlijke componenten van werkplekleren maar om integratie. Studenten, begeleiders en alle betrokken actoren op de werkplek moeten de verantwoordelijkheid delen om deze 
complexe maar onafscheidelijke processen te integreren. De ontwerpers van dit werkplekmodel hopen dat het raamwerk zal bijdragen tot de optimalisatie van het competentiegericht onderwijs in de gezondheidszorg.

\section{HOOFDSTUK 7}

In het laatste hoofdstuk keren we terug naar de theorieën en de vragen die het uitgangspunt waren voor dit promotieonderzoek. Dit proefschrift resulteert in een holistisch en competentiegericht model dat mogelijkheden biedt om de continue en zelfsturende professionele ontwikkeling op de werkplek te faciliteren voor studenten en begeleiders. Dit 'Integrated Learning Assessment and Supervision Competency Framework' blijkt een praktisch bruikbaar model te zijn. Het model houdt rekening met de complexiteit en discontinuïteit op de klinische werkplek van de 21ste eeuw. De kernwoorden voor dit nieuw werkplekmodel zijn: integratie, continuïteit en samenwerken.

De belangrijkste implicaties van onze bevindingen voor de onderwijspraktijk worden samengevat volgens de componenten van werkplekleren. Uiteraard mogen onderwijskundige modellen niet herleid worden tot afzonderlijke componenten. De mate waarin een model zal bijdragen tot continue en zelfsturende competentie ontwikkeling op de werkplek hangt af van de mate waarin de componenten geïntegreerd worden door alle betrokkenen bij het werkplekleren.

1. Theorie: Om de continue en zelfsturende competentie ontwikkeling te stimuleren is het belangrijk om individueel cognitieve leertheorieën te integreren met socioculturele leertheorieën.

2. Competentiekader: Een competentiekader is een onderwijskundig kader dat de mogelijkheid biedt om het leercontinuüm te bespreken. Toch moeten onderwijskundigen zich bewust zijn van de complexiteit van het competentiegericht onderwijs voor professionals op de klinische werkplek. Uit ons onderzoek blijkt dat het noodzakelijk is om een onderscheid te maken tussen het leren, beoordelen en begeleiden van handelingen versus het leren, beoordelen en begeleiden van competenties en competentiegroei.

3. Curriculum: Een curriculum bestaat uit verschillende blokken met werkplekken in verschillende contexten. Reflectie en feedback op handelingen stimuleert directe groei tijdens een blok, reflectie en feedback op competentiegroei stimuleert longitudinale groei over de blokken heen. We spreken over twee verschillende proces- 
sen die op een cognitief continuüm kunnen geplaatst worden: dagelijkse zelfmonitoring van handelingen versus uitgestelde zelfbeoordeling van competentiegroei.

4. Stakeholders: Zelfsturend leren betekent dat de student het initiatief moet nemen om te leren maar altijd moet kunnen rekenen op effectieve en faciliterende begeleiding. Meer aandacht moet gaan naar de beschrijving van verschillende rollen van stakeholders. Alle teamleden zijn verantwoordelijk voor observatie, reflectie en feedback op handelingen. Enkele begeleiders zijn verantwoordelijk voor reflectie en feedback op competentiegroei. Continue groei kan bekeken worden per blok of over de verschillende blokken heen. Speciale aandacht is nodig voor de rol van de begeleider die de continuïteit over de blokken heen bewaakt en bevordert.

5. Instrument: Een competentiegericht en geïntegreerd leer- en beoordelingsinstrument, met een afzonderlijke structuur voor handelingen en competentiegroei, ondersteunt de stakeholders en de processen in werkplekleren.

6. Processen: Het leer-, beoordelings-, en begeleidingsproces kan beschreven worden in 6 stappen: 1) selectie van competenties volgens context, 2) formuleren van doelstellingen, 3) self-monitoring van handelingen, 4) self-assessment van competentiegroei, 5) summatieve assessment van individuele competenties, 6) summatieve assessment van professionele vakbekwaamheid.

7. Onderwijskundige voorwaarden: Werkplekleren is complex omdat ontelbare voorwaarden het effect op continue competentiegroei bepalen. Literatuur en empirisch onderzoek tonen aan dat het schoentje hier vaak wringt. Indien alle condities voldaan zijn zal een werkplekcultuur ontstaan waarin tijd is voor observatie, reflectie, feedback en dialoog. Dit zal de samenwerking en de continue persoonlijke en professionele ontwikkeling bevorderen.

8. Continuüm: Dit geïntegreerd model ondersteunt de realisatie van een continuüm op gebied van het leerproces en de beoordeling. Het ontwikkelen van professionele vakbekwaamheid vereist een programmatische blik op competentiegroei over de stages heen.

Toekomstig onderzoek zal zich verder moeten richten op het stimuleren van dit onderwijskundig continuüm. Wij zijn van mening dat meer onderzoek nodig is om het effect te meten van o.a. longitudinaal georganiseerde werkplekken, continu verzamelde informatie, en een programmatisch toetsbeleid op de continue en zelfsturende compe- 
tentie ontwikkeling alsook op de summatieve toetsing van professionele vakbekwaamheid. Toekomstig onderzoek zal gericht zijn op de ontwikkeling van individuele én collectieve vakbekwaamheid. Vooreerst zal onderzoek naar de individuele cognitieve groei op de werkplek de mogelijkheid geven om te differentiëren in instructie en begeleiding. Aanvullend zal meer fundamenteel onderzoek nodig zijn naar het effect van samenwerkend leren op de individuele en collectieve competentiegroei. Omdat organisaties in de gezondheidszorg steeds meer gekenmerkt worden door interprofessionele zorg zal het collectief leren in de toekomst steeds belangrijker worden. 



\section{Valorisation}





\section{RELEVANCE}

The research presented in this doctoral thesis addresses topics about workplace learning in health care education. It provides new perspectives on continuous workplace learning in the context of a discontinuous workplace learning environment. The problem of discontinuity in the field of workplace learning is threefold: many educational programmes include short periods of training in different disciplines; learning processes are often separated from assessment processes; and it is difficult to achieve continuity in supervision, both within and across workplaces. The question therefore is how workplace learning can be organised in such a way that ongoing competency development is optimally stimulated throughout the workplace learning curriculum and that learners are prepared for lifelong learning. The relevance of this research is explained by the answers to the three research questions that were put forward in this thesis.

To begin with, we have shown that it is possible to integrate the numerous components of workplace learning into a user-friendly and evidence-based workplace learning model: the 'Integrated learning Assessment and Supervision Competency Framework'. The analogy of a 'Lifelong Competence Journey' is used to denote this model, which embraces the keywords 'integration', 'continuity' and 'collaboration'. The model moreover aims at an integration of competencies, learning (reflection and feedback), assessment (self-, formative and summative assessment), and supervision (supervision of performances and supervision of the continuous learning process). An important component of the model is the learning and assessment instrument. The model also integrates the stakeholders-component. More specifically, it integrates the perspectives of the different stakeholders who work together at the workplace: students, supervisors and assessors (from the workplace and educational institution). Finally, the workplace learning model is featured by a programmatic view on the workplace learning curriculum and a focus on the essential conditions to support continuous workplace learning.

We hope that this integrated workplace learning model will inspire professionals who are involved with workplace learning in health care. In general, the workplace learning literature is complex and often discusses single components of workplace learning without making a bridge to the continuity of workplace learning. Although there is a general consensus among health care educators to build programmes on competency frameworks, evidence-based models supporting the translation from these theorybased competency frameworks into clinical practice are scarce. Competency-based education arose from the need to attune education more to the labour market. Nowadays, some decennia later, it still seems difficult to organise competency-based 
education in clinical practice. Therefore, further research is necessary to help realise the original goal of competency-based education. The designers of the Integrated Learning, Assessment, and Supervision Competency Framework hope to be able to contribute to this research need. Finally, requirements for accreditation cause benchmarking of programmes to become more and more important. Our research findings confirm the need for standardised definitions and frameworks in the field of workplace learning. We believe that standardisation facilitates the exchange of study results and good practices between institutions.

Second, we present in this thesis the results of the impact of an integrated model on the development of a continuous self-directed learning process. The results confirm the importance of situating learning on a cognitive continuum. Research in this thesis makes a clear distinction between reflection and feedback on single performances (selfmonitoring) on the one hand, and reflection and feedback on competency-development (self-assessment) on the other. The results show that students prefer immediate reflection on performance because it allows them to remediate their performances at once. New in this thesis is the finding that graduates appear to have different views on the learning effects of the writing activity that made them reflect on their competencydevelopment. As opposed to undergraduates, graduates generally perceived a positive effect on their self-assessment, self-confidence and continuous growth. Another new finding is that reflective learning activities with different educational goals require different educational conditions to be fulfilled. These findings closely match the current tendency to pay more attention to the lifelong learning continuum. The strict distinction between undergraduate, postgraduate, and residency workplace learning might hinder continuous workplace learning. Also in international perspective, this distinction is somewhat artificial because of the differences in the length of educational programmes, the levels of diplomas, the competencies of health care professionals, et cetera. Further research will demonstrate to what extent the views of an undergraduate (midwifery) training programme contribute to research in the field of postgraduate, residency, and lifelong learning (CPD, Continuous Professional Development).

Our research on the self-directed learning continuum emphasises the key role supervisors have in a workplace learning design. There's a certain complexity to establishing supervision in the ambit of workplace learning in health care. Health care organisations are usually seen as unstructured learning environments where many professionals work together for the joint purpose of providing care to the patient. It's generally recognised that professionals have a dual task of providing health care and education at the same time. Health care organisations pay great attention to students and health care professionals, in turn, are motivated to supervise their students. Yet, they can't always 
guarantee that the essential conditions for fostering a continuous learning process (e.g. sufficient time for dialogue) will be met. Our research performed on students and supervisors of the midwifery training programme has shown that the educational design can be adjusted so as to make the educational instructions also practically feasible for supervisors in the busy reality of the workplace. This thesis has sought to stir up the dialogue between health care providers and educational organisations in the field of workplace learning. This dialogue is not only necessary on a national, but also on an international level. As students increasingly receive part of their training at foreign workplaces, an international outlook on the topic becomes indispensable in order to ensure that the learning process (reflection and feedback) is continued for the entire lifetime of a clinical training programme.

In the third place, this thesis integrated learning and assessment into the workplace learning model. It advocates the incorporation of an integrated learning and assessment continuum in the design. The results indicate that there's a tension between the continuous collection of written information for learning-purposes on the one hand, and the use of this information for assessment-purposes on the other. To overcome this tension, it was argued that learning and assessment should be embedded in a relationship of trust between the learner and supervisors/assessors. Trust is easily gained when the clinical placements last longer. New in this thesis is that it discerns different roles for both supervision and assessment. This division of roles stems from several differences in focus: for one, there's a focus on single performances, but also a focus on competency development; then there's a focus on assessment of individual competencies, which is complemented by a focus on assessment of 'professional competence'. Educators in health care are responsible for ensuring that graduates have the competency to provide safe care. Therefore, it is important that the summative decision to declare the student 'professionally competent' is made by an expert jury that takes into account the student's continuous learning process. The results in this thesis underscore the complexity of summative assessment. The findings fit in closely with current tendencies to focus on longitudinal learning projects, remediation programmes, assessment by judgement, and programmatic assessment.

\section{TARGET GROUPS}

\section{Policymakers in health care and education}

Workplace learning crosses two key policy domains: health care and education. Legislation in the field of health care affects education and vice versa. When scrutinising 
competency-based education, their mutual influence becomes all the more apparent. At the same time, however, it becomes clear that both worlds sometimes function in completely different ways. Health care educators design professional competency frameworks and curricula on the basis of legislation or guidelines from professional organisations. The purpose of these competency frameworks is to increase transparency of degrees, and to explicitly lay down professional competencies and training requirements. This thesis shows the complexity of translating competency frameworks into practice. It shows the complexity of developing, monitoring and assessing competencies in the clinical workplace. The development and implementation of workplace learning designs require specific scientific and practical expertise, as well as sufficient resources for the application of the theoretical frameworks in daily practice. Sound management and sufficient resources to achieve this will optimise the quality of education and health care, encourage exchanges of good practices, and warrant the achievement of policy objectives.

\section{Management in health care and education}

Managers of universities and health care institutions are increasingly subject to highly demanding accreditation systems. This thesis shows how empirical research contributes to a critical reflection on one's own practice. The results provide insights that are helpful in taking evidence-based decisions when designing workplace learning.

As mentioned before, workplace learning crosses both areas: health care and education. From this perspective, it seems important to further encourage joint research and to share good practices. The perception studies with students and supervisors in this thesis are an example of this partnership.

Partnerships between universities and health care institutions are also important in terms of professional training. The results in this thesis confirm the importance of training for the creation of a culture of reflection and feedback in the workplace community. This culture stimulates a positive learning climate featured by dialogue and collaboration. This culture is not only important for students' learning but also for the lifelong development of a professional team. Future research will increasingly focus on collaborative learning theories in a community of practice.

\section{Curriculum managers}

Workplace learning is organised in many different ways. This is one of the reasons why the literature in the field of workplace learning is so complex. Curriculum managers are 
responsible for designing workplace learning in an educational programme. It is evident that they have to take into account the context in which education and health care is organised. Yet, it is also important that they implement current generic research findings in their design. This thesis focusses the attention on continuous competency development in a discontinuous learning environment. It ties in nicely with the existing literature that calls for more attention to the aspect of 'continuity' in future designs of workplace learning.

\section{Teachers}

The term 'self-directed learning' can be misleading as it implies that the student learns completely independently. The opposite is true, as is shown in this thesis that explored the concept of self-directed learning in more detail. Self-directed learning requires an active, self-directed attitude of the student who can make an appeal to professional guidance. The results of our studies show that the integration of learning and assessment impacts positively on self-directed learning. Our findings confirm once again that supervisors play a crucial role in the development of learner competencies. This is the reason why the component 'supervision' was incorporated in the workplace learning model. The model introduces a clear conceptualisation of roles. It is of crucial importance that both teachers from the universities and the health care institutions previously agree on their supervisory and assessment roles in order to be able to sustain continuous supervision. A clear enunciation of roles will also render expectations and responsibilities more transparent to students and teachers.

\section{Students}

This thesis shows that educational research with students is rewarding. The studies combine quantitative and qualitative research. One study uses cross-sectional and retrospective-longitudinal data. Combining these results leads to new insights. From a survey held among students it resulted that they generally favoured more time for dialogue to reflection on paper. Salient, moreover, was the finding that students are not unanimously positive about the summative judgement of their performance at the end of the internships, an observation that does not quite match the significant correlations between reflection and performance scores that were found in another study. Therefore, further research on summative assessment is necessary. 


\section{ACTIVITIES}

This thesis contains empirical studies conducted in the context of one single Midwifery programme in Ghent (Belgium), a training programme that received a special quality label for the implementation of competency-based education in 2008 (NVAO, Nederlands-Vlaamse Accreditatieorganisatie / Accreditation Organisation of the Netherlands and Flanders). The challenge for the future is to explore the generalisability of the results in other health care programmes, both at home and abroad. All studies were presented at one or more international conferences on medical and midwifery education. All of them were also published in journals of different disciplines: midwifery, medical and nursing journals. All activities associated with this thesis, except for the mentor trainings, are listed below. The first presentations of the model at international educational congresses (ICM, June 2014; EAPRIL, November 2014) were well received. The conceptual model includes a broad framework in the field of workplace learning, creating the possibility to identify concepts and exchange good practices.

\section{Publications}

Embo M, Driessen E, Valcke M, van der Vleuten CPM. Integrating Learning, Assessment and Supervision in a Competency Framework for Clinical Workplace Education. Nurse Education Today 2014; http://dx.doi.org/10.1016/j.nedt.2014.11.022.

Embo M, Driessen E, Valcke $M$, van der Vleuten CPM. On the relationship between reflection ability and clinical performance: a cross-sectional and retrospectivelongitudinal correlation cohort study in midwifery. Midwifery 2015;31(1):90-94.

Embo M, Driessen E, Valcke M, van der Vleuten CPM. Scaffolding reflective learning in clinical practice: a comparison of two types of reflective activities. Medical Teacher 2014,36(7):602-607.

Embo M, Driessen E, Valcke M, van der Vleuten CPM. A Framework To Facilitate SelfDirected Learning and Supervision In Midwifery Practice: A Qualitative Study of Supervisors' Perceptions. Nurse Education in Practice 2014;14(4):441-446.

Embo M. De vroedvrouw staat voor kwaliteit en veilige zorgverlening! [The midwife is responsible to provide high quality and safe care!]. Tijdschrift voor vroedvrouwen 2011;17(3):151-155. (Publication in Dutch) 
Embo MP, Driessen EW, Valcke M, Van der Vleuten CPM. Assessment and feedback to facilitate self-directed learning in clinical practice of Midwifery students. Medical Teacher 2010;32(7):e263-269.

Embo M. Bijzonder Kwaliteitskenmerk Bachelor in de vroedkunde: de competentiemozaïek van de vroedvrouw als sturende motor van het onderwijsleerproces. [Special Quality label Bachelor in Midwifery: the competency mosaic of the Midwife as the driving motor of the learning process]. Magazine Kwaliteitszorg in het Hoger onderwijs (Q\&A). 2010. Via website NVAO http://www.qazine.eu/article-detail/bijzonderkwaliteitskenmerk-bachelor-in-de-vroedkunde/12. (Publication in Dutch)

Embo M. De competentiemozaïek van een vroedvrouw. Symbool van het competentiegericht modulair curriculum van de opleiding vroedkunde van de Arteveldehogeschool te Gent. [The competency mosaic of the midwife. Symbol of the competency-based modular curriculum of the University College Arteveldehogeschool Ghent.]. Tijdschrift voor vroedvrouwen 2005;11(2):79-91. (Publication in Dutch)

Embo M, Lauwers L, Van den Hove T, Vyt A. Wanneer is een vroedvrouw competent voor het werkveld? [When is a midwife fit for practice?]. Tijdschrift voor vroedvrouwen 2004;10(3). (Publication in Dutch)

Embo, M. Curriculumontwikkeling in de opleiding vroedkunde. Vroedkunde op modulaire vernieuwingsweg. [Curriculum development: the Midwifery department renews the traditional curriculum into a modular and competency-based curriculum]. Tijdschrift voor vroedvrouwen 2002;8(5):270-271. (Publication in Dutch)

Embo, M. Vroedkunde op modulaire vernieuwingsweg. [A new curriculum for the Midwifery department.] Arteveldemagazine 2002;1(3):25-26. (Publication in Dutch)

\section{Conference papers}

2015

Embo M, Driessen E, Valcke M, van der Vleuten CPM. Embo's Workplace Learning Model: an integrated approach to support self-directed and continuous learning in Midwifery practice. Paper that will be presented at the Midwifery Education conference: 'Innovation in Midwifery Education: what works?' Bournemouth University, United Kingdom, July $3^{\text {th }}$. 
Embo M, Driessen E, Valcke M, van der Vleuten CPM. Integrating workplace learning, assessment and supervision in midwifery education. Paper that will be presented at the Reproductive Health Conference: 'Education and practice for midwifery students'. Umea, Sweden, May $8^{\text {th }}$.

\section{4}

Embo M, Driessen E, Valcke $M$, van der Vleuten CPM. Embo's Workplace Learning Model: an integrated approach to support self-directed and continuous learning in practice. Paper presented at the annual European Association for Practitioner Research on Improving Learning (EAPRIL) conference. Nicosia, Cyprus, November $25-28^{\text {th }}$.

Embo M, Driessen E, Valcke M, van der Vleuten CPM. On the relationship between reflection ability and clinical performance: a cross-sectional and retrospectivelongitudinal correlational cohort study in midwifery. Paper presented at the annual Association for Medical Education (AMEE) conference. Milan, Italy, September $1-3^{\text {th }}$.

Embo M, Driessen E, Valcke M, van der Vleuten CPM. A framework to facilitate selfdirected learning and supervision in midwifery practice: a qualitative study of supervisors' perceptions. Paper presented at the triennial International Confederation of Midwives (ICM) conference. Prague, Tsjechoslowakije, June $1-4^{\text {th }}$.

Bharj K, Embo M, Stiefel A, Simon S, Bekker E. Education in clinical practice. Workshop ICM Educational Standing Committee and presentation of Embo's Workplace Learning model (the Integrated Learning, Assessment and Supervision Competency Framework) at the triannual International Confederation of Midwives (ICM) conference. Prague, Tsjechoslowakije, June $1-4^{\text {th }}$.

2013

Embo M, Driessen E, Valcke M, van der Vleuten CPM. Immediate reflection on clinical performance is more valued than delayed reflection on competency development. Paper presented at the European Midwifery Association (EMA) conference. Maastricht, the Netherlands, September $1-3^{\text {th }}$. November $29-30^{\text {th }}$.

Embo M, Driessen E, Valcke M, van der Vleuten CPM. Onmiddellijke reflectie op het klinisch handelen wordt meer gewaardeerd dan uitgestelde reflectie op competentieontwikkeling. [Immediate reflection on clinical performance is more valued than delayed reflection on competency development]. Paper presented at the annual 
Nederlandse Vereniging voor Medisch Onderwijs (NVMO) conference. Egmond aan Zee, the Netherlands, November $7-8^{\text {th }}$. (Presentation in Dutch)

Embo M, Driessen E, Valcke M, van der Vleuten CPM. Immediate reflection on clinical performance is more valued than delayed reflection on competency development. Paper presented at the annual Association for Medical Education (AMEE) conference. Prague, Tsjechoslowakije, August 25-28 ${ }^{\text {th }}$.

2012

Embo M, Driessen E, Valcke M, van der Vleuten CPM. Kan een geïntegreerd begeleidings- en beoordelingsraamwerk de begeleiding van het zelfsturend leren op de werkplek bevorderen? [Does an integrated learning and assessment instrument facilitate supervision at the workplace?]. Poster presented at the annual Nederlandse Vereniging voor Medisch Onderwijs (NVMO) conference. Egmond aan Zee, the Netherlands, November $15-16^{\text {th }}$. (Presentation in Dutch)

Embo M, Driessen E, Valcke M, van der Vleuten CPM. A framework to facilitate selfregulated learning and it supervision in clinical practice: a qualitative study of supervisor perceptions. Paper presented at the annual Association for Medical Education (AMEE) conference. Lyon, France, August 27-29 ${ }^{\text {th }}$.

2011

Embo M, Driessen E, Valcke M, van der Vleuten CPM. Een geïntegreerd feedback- en beoordelingsinstrument om het zelfsturend leren op de werkplek te bevorderen. [An integrated learning and assessment instrument to support self-directed workplace learning]. Paper presented at the annual Nederlandse Vereniging voor Medisch Onderwijs (NVMO) conference. Egmond aan Zee, the Netherlands, November $17^{\text {th }}$. (Presentation in Dutch)

Embo M. Competentiegericht beoordelen van de bachelorproef [Competency-based assessment of the bachelor thesis]. Workshop at the educational conference for teachers higher education. Erasmushogeschool, Brussels, Belgium, October $22^{\text {th }}$. (Presentation in Dutch)

Embo M. Klaar voor Hoger Onderwijs? De kracht van reflectie. [Are students prepared to start higher education? The power of reflection]. Workshop at the conference for teachers secondary education. University College Arteveldehogeschool Ghent, Belgium, May $24^{\text {th }}$. (Presentation in Dutch) 
Embo M. Waar kan de afgestudeerde vroedvrouw terecht en is zij voldoende opgeleid voor haar opdracht. [What are the job possibilities for midwives? Are they fit for practice at the moment of graduation?]. Panel discussion at the conference for head midwives of the Flemish Organisation of Midwives (VLOV). Ghent, Belgium, November $19^{\text {th }}$. (Presentation in Dutch)

Embo M, Driessen E, Valcke M, van der Vleuten CPM. An instrument to integrate feedback and assessment to support self-directed learning in clinical practice. Paper presented at the annual Association for Medical Education (AMEE) conference. Glasgow, Scotland, September $4-8^{\text {th }}$.

Embo M. Be-zorg-d om het competentiedenken: stemmen uit de gezondheidzorg. [Concerned about the concept of competence: voices from health care]. Panel discussion at the conference for teachers of het Vlaams Verbond Katholieke Hogescholen (VVKHO) en het Vlaams Secretariaat van het Katholiek Onderwijs (VSKO). Leuven, Belgium, April 22 $2^{\text {th }}$. (Presentation in Dutch)

Embo M. Kwaliteit + cultuur = kwaliteitscultuur? Een praktijkvoorbeeld van de opleiding Bachelor in de vroedkunde. [Quality + Culture = Quality culture? A practical example from the Midwifery department]. Presentation at the annual educational conference of the University College Arteveldehogeschool. Ghent, Belgium, March $19^{\text {th }}$. (Presentation in Dutch)

Embo M. Begeleiden en beoordelen van competenties van studenten op stage. [Supervision and assessment of competencies in clinical practice]. Presentation at the biennial conference Internationale Leerstoel Francine Gooris [International Chair Francine Gooris]. University College Arteveldehogeschool, Ghent, Belgium, February $25^{\text {th }}$. (Presentation in Dutch)

2008

Embo M. Midwifery education: three or four years to be fit for practice? Paper presented at the triennial International Confederation of Midwives (ICM). Glasgow, Scotland, June $3^{\text {th }}$.

Embo M. Is het zinvol om stagetoegang te bewaken via een instapcriterium en remedieringstraject? [Is it useful to monitor access to clinical placements via entry requirements and remediation programmes?]. Presentation at the annual educational confer- 
ence of the University College Arteveldehogeschool. Ghent, Belgium, April $4^{\text {th }}$. (Presentation in Dutch)

2006

Embo M, Lauwers L. The discerning power of competency based tests when assessing obstetric competencies in midwifery. Presentation at the Ottawa conference. New York, USA, May $22^{\text {th }}$.

\section{Education}

2015

Embo M. Competency-Based Education (CBE) Trainer of Trainers (TOT) Workshop. International Confederation of Midwives (ICM). Den Hague (the Netherlands), February $1-6^{\text {th }}$

2014

Embo M. Integrating Learning, Assessment and Supervision in a Competency Framework for Clinical Workplace Education. Workshop for teachers and clinical supervisors. Metropol - Midwifery Department, Copenhagen (Denmark), October 7-9 ${ }^{\text {th }}$. 

Dankwoord

H 



\section{BIRTH - Dit proefschrift draag ik op aan alle vroedvrouwen die wereldwijd medische zorg verlenen.}

Mijn passie voor het verloskundig onderwijs bracht mij tot de realisatie van dit proefschrift. Met de interesse in de academische wereld als aanzet wou ik graag de praktijk van de opleiding in de wetenschap brengen om op die manier bij te dragen aan de toekomst van het onderwijs in de gezondheidszorg. De realisatie van dit proefschrift heeft geleid tot een conceptueel model dat verwijst naar een 'Lifelong Learning Competency Journey'. Een belangrijk deel van deze reis heb ik in de afgelopen jaren afgelegd, een uitdagende reis met veel boeiende ervaringen en leerrijke ontmoetingen. Dit proefschrift heeft mijn grenzen verlegd!

Mijn eerste woord van dank gaat uit naar mijn promotoren. Zij waren belangrijke en inspirerende gidsen op mijn reis. Mijn grote dank gaat uit naar Cees van de Vleuten voor het geloof in mijn gezonde ambitie. Cees gaf mij de kans om dit proefschrift te schrijven vanuit mijn eigen praktijk omwille van zijn wereldwijde interesse in de onderwijspraktijk, en dus ook in deze van Gent. Cees verbond mijn reis aan de portfolio-expertise van Erik Driessen. Portfolio was het startpunt, een geïntegreerd werkplekmodel het einde van dit proefschrift. Erik kwam naar Gent en leerde ons dat onderwijsdocumenten bij studenten moeten blijven. Erik leerde mij zoeken naar eenvoud in denken en wetenschappelijk schrijven. Een derde woord van dank richt ik tot Martin Valcke die voor het belangrijk Nederlands-Vlaams evenwicht zorgde. De feedbackgesprekken in Gent waren inspirerende combinaties van schrijfsessies, dataverwerking en conceptuele schetsen. Indien nodig werd het verloop van mijn proefschriftreis in perspectief geplaatst. Cees, Erik en Martin, ik dank jullie voor het vertrouwen in de finish. Het was voor mij een grote levenservaring en een uniek voorrecht om begeleid te worden door een team van drie grote internationale onderwijs-experten.

Aansluitend wil ik een woord van dank richten aan alle medewerkers van de Universiteit Maastricht die voor of achter de schermen een bijdrage leverden aan de realisatie van dit proefschrift. In het bijzonder wil ik Lilian Swaen danken om gedurende het hele traject alle afspraken en praktische zaken perfect te regelen. Ook een dankjewel aan Angelique van den Heuvel om zich zo snel in te werken in de screening van de laatste teksten, het was aangenaam samenwerken.

Vervolgens wil ik een groot dankwoord richten aan alle studenten en begeleiders die meegewerkt hebben aan één van mijn onderzoeken. Dankzij jullie enthousiaste bijdrage was het mogelijk om dit proefschrift te realiseren. Toen ik op stap ging naar congressen of thuis aan de schrijftafel zat heb ik jullie steeds in gedachten meegenomen. Meer dan 
ooit besef ik hoe belangrijk, maar ook hoe complex, stage is. Daarom, aan elke begeleider op stage, dank voor jullie inzet voor de competentiegroei van onze toekomstige vroedvrouwen. Aan alle studenten wens ik een mooie carrière als vroedvrouw toe!

Een speciaal woord van dank richt ik tot mijn collega's van nu en voorgaande jaren, alsook tot al mijn leermeesters en betrokken medewerkers van de Arteveldehogeschool. Enkele jaren geleden kreeg ik de goedkeuring van Johan Veeckman, Algemeen Directeur, om een proefschrift te realiseren aan de Universiteit Maastricht. Ik heb de afgelopen jaren geprobeerd om jullie werk in de wetenschap te brengen. De onderzoekslijn 'evidence-based education' was voor mij een onbekende wereld. Ik heb af en toe voor gesloten deuren gestaan maar ik heb ook veel interessante mensen ontmoet. Ik heb opnieuw ervaren wat het betekent om een echte student te zijn en hoe belangrijk begeleiders zijn. Ik wil elke collega van de opleiding maar ook de betrokken collega's van andere opleidingen en Arteveldediensten danken voor de interesse, het meedenken en het bemoedigend woord. Ik ben dankbaar dat ik dit uniek persoonlijk en professioneel ontwikkelingstraject kon doorlopen en hoop via dit proefschrift deuren te kunnen openen om in de toekomst samen aan deze onderzoekslijn verder te kunnen werken.

Aangezien ik dit proefschrift gerealiseerd heb buiten mijn job-time kan ik niet ontkennen dat de vrije tijd voor vrienden en familie iets beperkter was de laatste jaren. Lieve vrienden en familie, jullie waren steeds in mijn gedachten aanwezig. Ik ben dankbaar voor alle trouwe vriendschap. Jullie zorgden regelmatig voor de noodzakelijke ontspanning of een telefoontje om lief en leed te delen. Een speciaal woord van dank richt ik tot mijn ouders en schoonouders. Zij zijn voor mij een voorbeeld om grenzen te verleggen in werk, kunst en cultuur. Lieve (schoon-)zussen, (schoon-)broer(s), neefjes en nichtjes van België, Nederland en Engeland. Het is een zegen omringd te zijn door een grote familie. Duizendmaal dank voor alle steun de afgelopen jaren! Een heel speciale merci voor zus Tracy die mij regelmatig taalkundig bijstond op mijn reis, alsook voor Frederique en voor Willem om mijn paranimfen te willen zijn.

Tot slot, het allergrootste woord van dank aan mijn lieve man en prachtige kinderen. Duizendmaal dank voor alle kansen die jullie mij gaven. Ik besef heel goed dat de vele uren bureauwerk niet altijd gezellig waren voor jullie maar toch had het ook een zekere charme en misschien zijn jullie dit nu al voor het grootste deel vergeten. Lieve Willem, Michiel, Heleen en Judith, samen met papa ben ik ongelooflijk trots op jullie. Pluk de dag en geniet van alle kansen op de weg om jullie talenten samen met vriend en vriendin verder te ontplooien. Die kansen heb ik ook gekregen. Schat, dank voor alle steun en toeverlaat. Weinigen doen het je na. Geduldig en trots afwachten tot het 
proefschrift af is, één en al vertrouwen in de goede afloop, congressen en hotels boeken, boodschappen doen en klussen in huis regelen, en nog zoveel ontelbare dingen meer. Ik hou van jou, dankjewel!

\section{In memoriam}

Graag wil ik een dankwoord schrijven voor de familie van Mereke Gorsira. Mereke heeft veel betekend in de realisatie van dit proefschrift. Zij was de laatste schakel in het traject naar een tijdschrift. In de handen van Mereke veranderde tekst in goud. Mereke corrigeerde 3 studies. Zij overleed na een korte periode van ziekte op 17/12/2013. Ik had Mereke graag op de verdediging van mijn proefschrift bedankt voor deze gouden bijdrage. Dat kan nu niet meer, vandaar deze woorden in memoriam. 

Curriculum vitae 

Mieke Embo was born in Ghent, Belgium, on $30^{\text {th }}$ July 1965. She studied Nursing and Midwifery at the Higher Institute of Paramedical Professions, Ghent (Belgium) where she received her Bachelor's degrees in 1986 and 1987 respectively. She started her midwifery career in Kinshasa (Democratic Republic of Congo) and continued to practice midwifery at the maternity hospital of Sint-Vincentius Hospital in Ghent (Belgium) until 1991. While still in practice, she also studied for a Masters in Health Management and obtained her Master's Degree from the University of Brussels (Belgium) in 1991.

In the same year she moved to Leuven, where she worked in the pediatrics ward of the Holy Heart Hospital, and the neonatal unit of the University Hospital. Subsequently, she spent a short stint as a representative in the pharmaceutical industry after which she served as a preventative health advisor to primary schools in Brussels.

In 1999 she and her family moved back to her native Ghent where she began her teaching career in Midwifery at the very same college where she studied. In the meantime, Midwifery had evolved into an autonomous Bachelor programme with direct entry after secondary education. In 2000 she was promoted to Head of the Midwifery programme. The college has since merged with the University College Arteveldehogeschool, Ghent, and continues to grow to date. Her first achievement in education was to transform the traditional curriculum to a competency-based modular curriculum. In 2008 the programme received a special quality label of the Dutch Flemish Accreditation Organisation: 'The competence mosaic of the midwife as a driving engine of the learning process'. In the same year, she started her PhD thesis at the University of Maastricht (Netherlands) to further develop this concept according to international and evidence-based standards. She combined this study with her full-time management role because she strongly believes in the cross-fertilization between research and practice. As head of the Midwifery programme she has led and been involved in numerous projects in the fields of education, services and research at home and abroad. Her special interests include quality management, change management, competency-based education and workplace learning. She was also instrumental in initiatives to improve the stature of the Midwifery profession and strengthen Midwifery education in Belgium.

Mieke is married to Frank, a Dutch intervention radiologist, and they combine work and life between the two countries. They have four children, Willem, Michiel, Heleen and Judith. Outside work, she enjoys opera, culture, sports, cooking and socializing with friends, and a large extended family. 
